\title{
ORNL/TM-2001/116
}

\section{TRUCK ROLL STABILITY DATA COLLECTION AND ANALYSIS}

\author{
S. S. Stevens, Principal Investigator \\ S. M. Chin \\ K. A. Hake \\ H. L. Hwang \\ J. P. Rollow \\ L. F. Truett
}

July 2001

\author{
Prepared for the \\ Federal Highway Administration Intelligent Vehicle Initiative \\ U.S. DEPARTMENT OF TRANSPORTATION \\ Washington, D.C. 20590 \\ Prepared by the \\ Center for Transportation Analysis \\ OAK RIDGE NATIONAL LABORATORY \\ Oak Ridge, Tennessee 37831 \\ managed by \\ UT-BATTELLE, LLC \\ for the \\ U.S. DEPARTMENT OF ENERGY \\ under Contract No. DE-AC05-00OR22725
}





\section{CONTENTS}

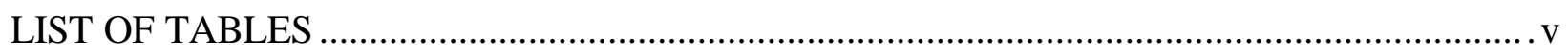

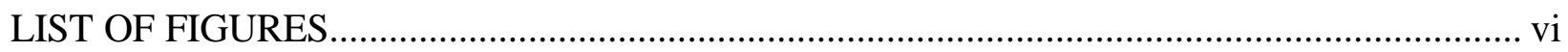

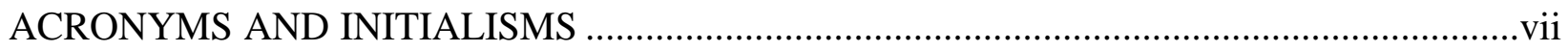

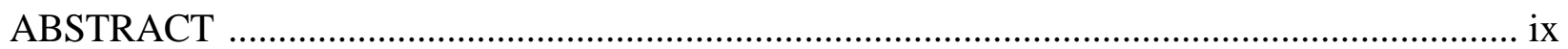

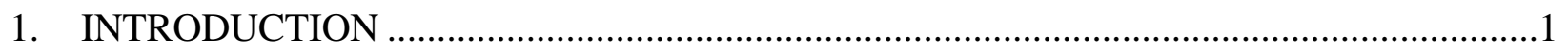

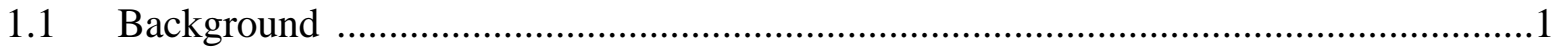

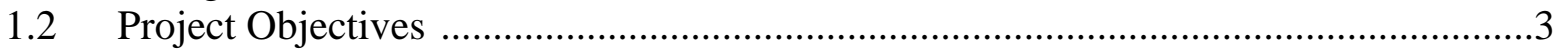

1.3 Project Partners and the Experimental Situation ......................................................

2. CHARACTERISTICS OF THE ON-BOARD COMPONENTS .............................................

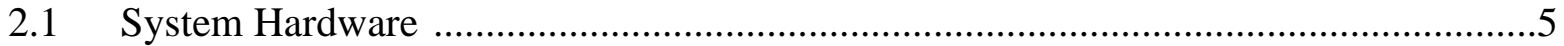

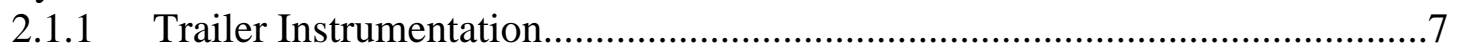

2.1.2 Tractor Instrumentation ....................................................................

2.1.3 On-board Data Communication....................................................................

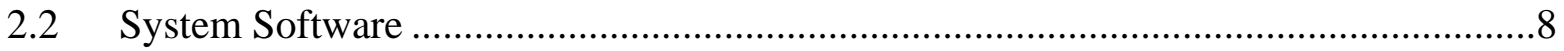

2.2.1 Data Collection and Transmission................................................................

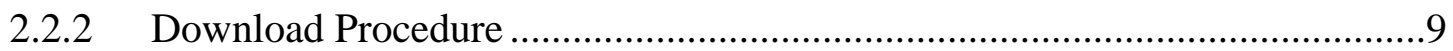

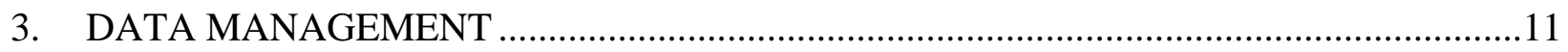

3.1 Data Transfer to ORNL...................................................................................11

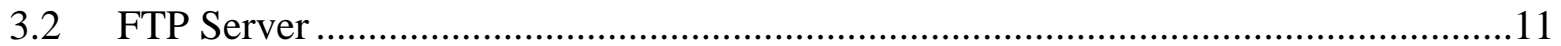

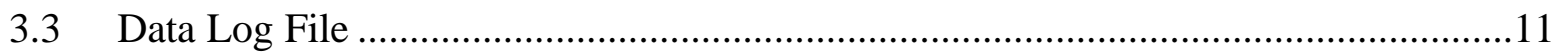

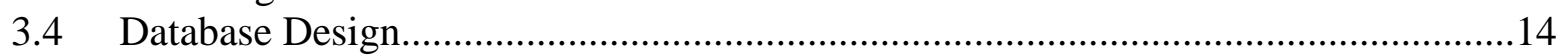

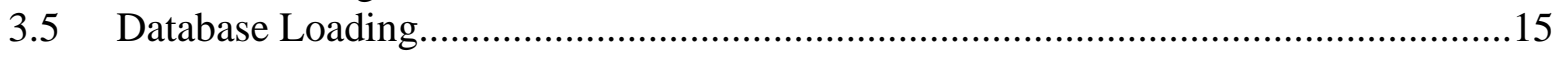

3.6 Data Validation ..................................................................................................

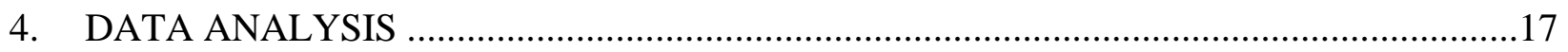

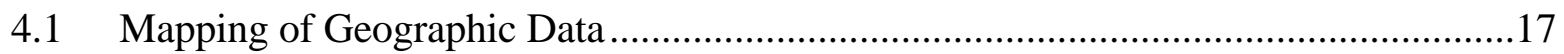

4.2 Comparison of U.S. Xpress and Praxair Data Analyses ...............................................18

4.3 Identification of Individual U.S. Xpress Truck Trips ..................................................18

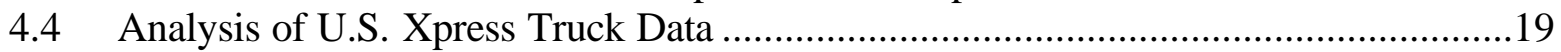

4.4.1 Measurements over time.........................................................................19

Lateral acceleration ................................................................................. 19

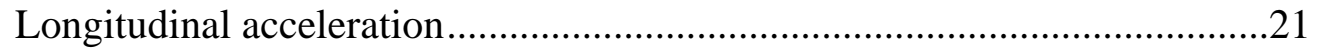

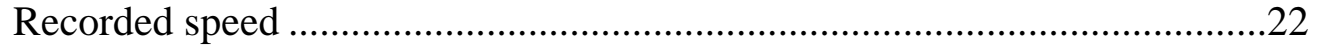

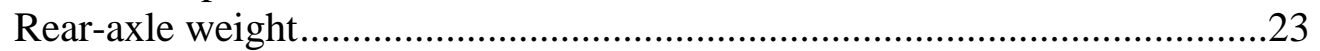

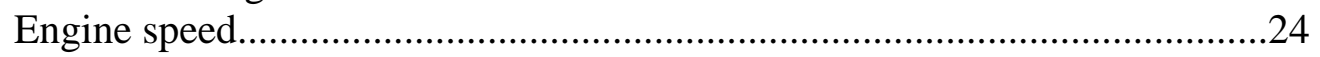

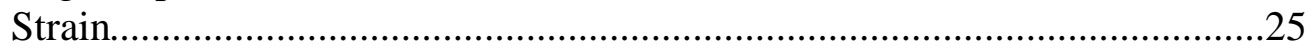

4.4.2 Adjustments to correct instrument bias .......................................................26

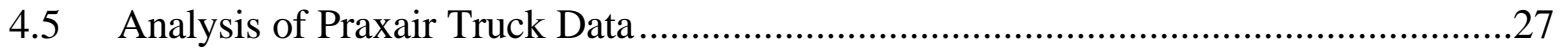




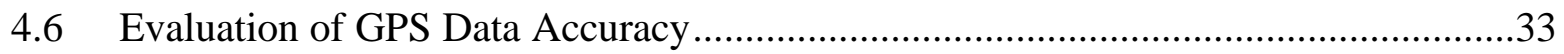

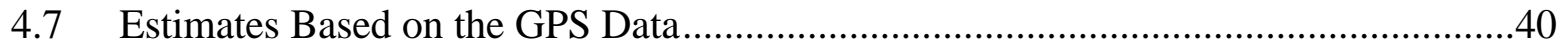

4.7.1 Mathematical method to calculate turning angle...................................... 41

4.7.2 Estimate of speed..........................................................................4

4.7.3 Calculation of lateral and longitudinal accelerations ................................42

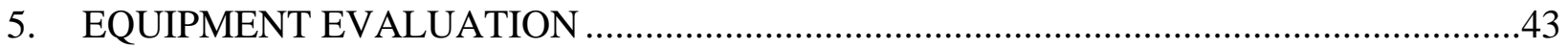

6. EVALUATION OF THE ACCURACY AND TIMELINESS OF THE DATA ..................45

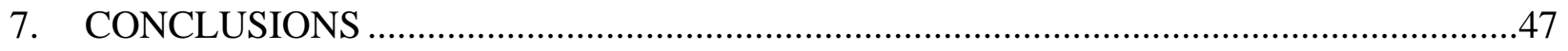

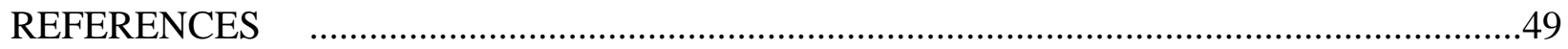

APPENDIX A AD HOC DATA COLLECTION PROGRAM ......................................... A-1

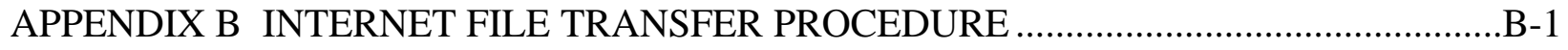

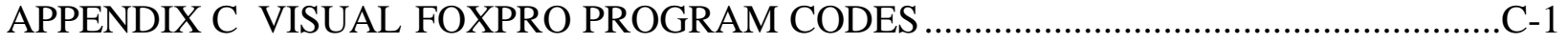

APPENDIX D STRAIN GAGE VERIFICATION TEST ................................................. D-1

APPENDIX E CASE STUDIES ….................................................................................. 


\section{LIST OF TABLES}

1.1 Vehicles involved in fatal crashes by vehicle type and rollover occurrence, 1998 ...............2

1.2 Occupant fatalities for 1999, by rollover occurrence, for large trucks and all other vehicles....

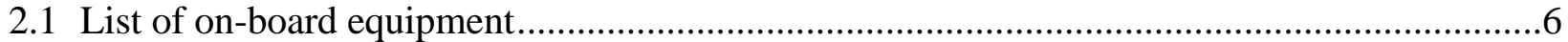

3.1 Codes indicating the type of data for lines in the $\log$ file ...............................................13

3.2 Data files received from the participating truck companies ............................................14

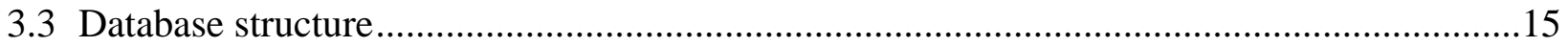




\section{LIST OF FIGURES}

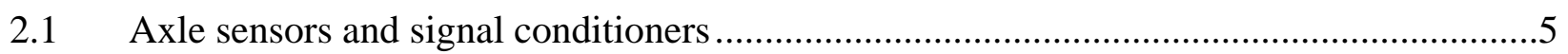

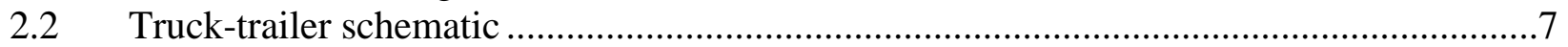

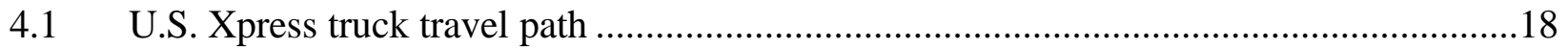

4.2 Lateral acceleration measured during the selected 2-hour period......................................20

4.3 Truck trajectory on curve at junction of I-24/I-75 near

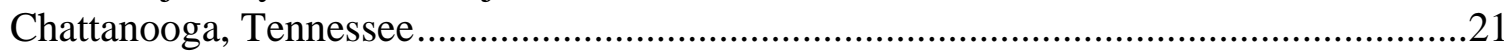

4.4 Longitudinal acceleration measured during the selected 2-hour time

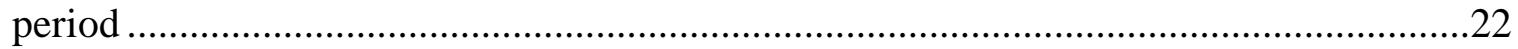

4.5 Speed (MPH) recorded by the on-board instrument for the selected

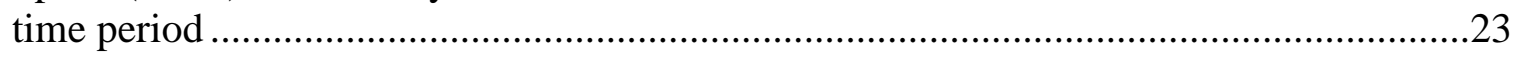

4.6 Rear axle weight measured during the selected 2-hour time period ...................................24

4.7 RPM measurements for the selected 2-hour time period...................................................25

4.8 Measurements of strain for the selected 2-hour time period..............................................26

4.9 Adjusted lateral acceleration measurements of strain for the selected

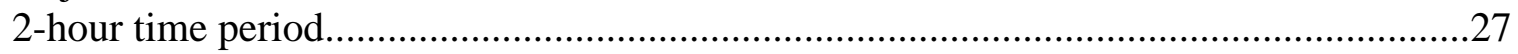

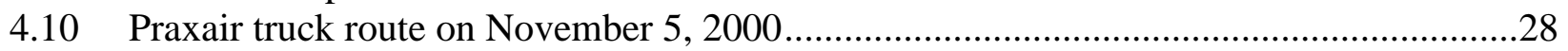

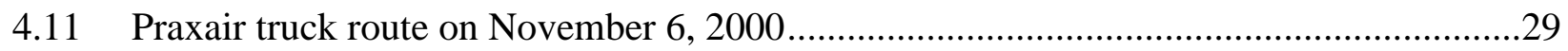

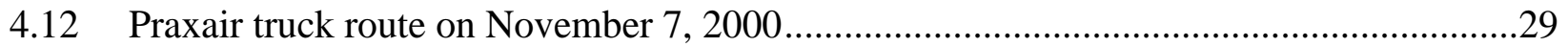

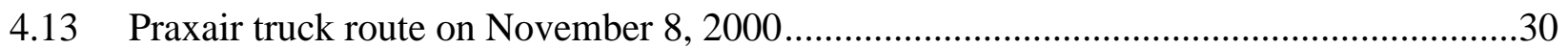

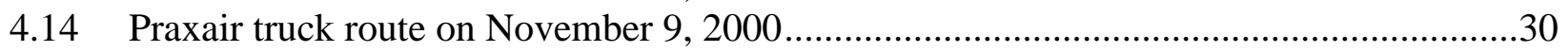

4.15 Speed measured on November 5, 2000, for a Praxair truck................................................ 31

4.16 Weight measured on November 5, 2000, for a Praxair truck................................................

4.17 Lateral acceleration measured on November 5, 2000, for a Praxair truck..........................32

4.18 East-bound, I-75, pre-May 1, 2001, truck trajectories, measured near

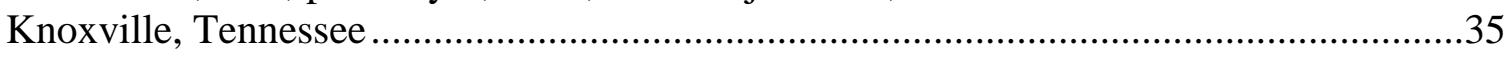

4.19 West-bound, I-75, pre-May 1, 2001, truck trajectories, measured near Knoxville, Tennessee .............................................................................................

4.20 North-bound and south-bound, I-275, pre-May 1, 2001, truck trajectories, measured near Cincinnati, Ohio

4.21 North-bound and south-bound, I-75, post May 1, 2001, truck trajectories, measured near Knoxville, Tennessee.

4.22 North-bound and south-bound, post May 1, 2001, truck trajectories, measured north of Stockertown, Pennsylvania.

4.23 North-bound and south-bound, post May 1, 2001, truck trajectories, measured south of Stockertown, Pennsylvania. 


\section{ACRONYMS AND INITIALISMS}

$\begin{array}{ll}\text { CD } & \text { Compact Disk } \\ \text { FARS } & \text { Fatality Analysis Reporting System } \\ \text { FHWA } & \text { Federal Highway Administration } \\ \text { FTP } & \text { File Transfer Protocol } \\ \text { GI } & \text { Geographic Information System } \\ \text { GPS } & \text { Global Positioning Systems } \\ \text { LAN } & \text { Local Area Network } \\ \text { MPH } & \text { Miles per Hour } \\ \text { NHTSA } & \text { National Highway Traffic Safety Administration } \\ \text { ORNL } & \text { Oak Ridge National Laboratory } \\ \text { RFI } & \text { Radio Frequency Interference } \\ \text { RPM } & \text { Revolutions per Minute } \\ \text { SA } & \text { Selective Availability } \\ \text { SDL } & \text { Stability Data Logger } \\ \text { TDOT } & \text { Tennessee Department of Transportation } \\ \text { TTI } & \text { Texas Transportation Institute } \\ \text { UMTRI } & \text { University of Michigan Transportation Research Institute } \\ \text { USGS } & \text { U.S. Geological Survey } \\ \text { UTC } & \text { Coordinated Universal Time } \\ \text { UT } & \text { The University of Tennessee } \\ \text { VMT } & \text { Vehicle Miles Traveled }\end{array}$





\begin{abstract}
The principal objective of this project was to collect and analyze vehicle and highway data that are relevant to the problem of truck rollover crashes, and in particular to the subset of rollover crashes that are caused by the driver error of entering a curve at a speed too great to allow safe completion of the turn. The data are of two sorts - vehicle dynamic performance data, and highway geometry data as revealed by vehicle behavior in normal driving. Vehicle dynamic performance data are relevant because the roll stability of a tractor trailer depends both on inherent physical characteristics of the vehicle and on the weight and distribution of the particular cargo that is being carried. Highway geometric data are relevant because the set of crashes of primary interest to this study are caused by lateral acceleration demand in a curve that exceeds the instantaneous roll stability of the vehicle.
\end{abstract}

An analysis of data quality requires an evaluation of the equipment used to collect the data because the reliability and accuracy of both the equipment and the data could profoundly affect the safety of the driver and other highway users. Therefore, a concomitant objective was an evaluation of the performance of the set of data-collection equipment on the truck and trailer.

The objective concerning evaluation of the equipment was accomplished, but the results were not entirely positive. Significant engineering apparently remains to be done before a reliable system can be fielded. Problems were identified with the trailer to tractor fiber optic connector used for this test. In an over-the-road environment, the communication between the trailer instrumentation and the tractor must be dependable. In addition, the computer in the truck must be able to withstand the rigors of the road.

The major objective - data collection and analysis - was also accomplished. Using data collected by instruments on the truck, a "bad-curve' database can be generated. Using this database, instrumented vehicles would not need roadside beacons. The speed, acceleration, and roll stability of the vehicle could be determined prior to entering a curve, and a warning issued, if appropriate, for curves that have been characterized in the database. Thus, the analysis indicates that the data can be effectively used to provide a timely warning of rollover risk. 


\section{INTRODUCTION}

The trucking industry is a crucial part of the economic well-being of the United States. Since 1993, large trucks, defined as single-unit trucks and truck tractors with a gross vehicle weight rating of more than 10,000 pounds, have accounted for about $3 \%$ of all registered vehicles and about $7 \%$ of all vehicle miles traveled (VMT). ${ }^{1}$

In 1998, large trucks were involved in $8.7 \%$ of all fatal crashes, $2.4 \%$ of all injury crashes, and $4.2 \%$ of all property-damage-only crashes. Most of the heavy truck fatal crashes $(72 \%)$ involved a truck tractor body type. In general, when a crash involves a large truck and another vehicle, about $80 \%$ of the fatalities are occupants of the other vehicle.

\subsection{BACKGROUND}

Rollover crashes are of particular concern to safety analysts because they result in fatalities at a greater frequency than other types of crashes. In fact, $18.9 \%$ of all vehicles involved in fatal crashes were rollovers in 1998. This percentage is almost five times as high as the proportion of rollovers in injury crashes $(4.1 \%)$ and almost 16 times as high as property-damage-only crashes.

Table 1.1 compares the numbers and percentages of vehicles involved in rollover crashes in 1998 for various crash categories.

${ }^{1}$ National Highway Traffic Safety Administration. Various years. "Traffic Safety Facts,"

http://www.nhtsa.dot.gov/people/ncsa/factshet.html and

http://www.nhtsa.dot.gov/people/ncsa/factprev.html\#1996 . 
Table 1.1. Vehicles involved in fatal crashes by vehicle type and rollover occurrence, 1998

\begin{tabular}{|c|c|c|c|}
\hline Vehicle type & Rollovers & Non-rollovers & Percent rollover \\
\hline \multicolumn{4}{|c|}{ Fatal crashes } \\
\hline Large truck & 683 & 4,252 & $13.8 \%$ \\
\hline All other vehicles & 9,597 & 40,009 & $19.3 \%$ \\
\hline Total & 10,280 & 44,261 & $18.9 \%$ \\
\hline \multicolumn{4}{|c|}{ Injury crashes } \\
\hline Large truck & 10,000 & 79,000 & $11.4 \%$ \\
\hline All other vehicles & 143,000 & $3,480,000$ & $4.0 \%$ \\
\hline Total & 153,000 & $3,559,000$ & $4.1 \%$ \\
\hline \multicolumn{4}{|c|}{ Property-damage only crashes } \\
\hline Large truck & 8,000 & 310,000 & $2.4 \%$ \\
\hline All other vehicles & 83,000 & $7,178,000$ & $1.1 \%$ \\
\hline Total & 90,000 & $7,488,000$ & $1.2 \%$ \\
\hline
\end{tabular}

Source: National Highway Traffic Safety Administration. October 1999.

Traffic Safety Facts 1998: A Compilation of Motor Vehicle Crash Data from the Fatality Analysis Reporting System and the General Estimates System, http://www.nhtsa.dot.gov/people/ncsa/tsf-1998.pdf .

While Table 1.1 lists numbers of vehicles in fatal crashes, Table 1.2 shows numbers of fatalities in rollover accidents. The fatalities listed in this table are occupants of the vehicle type listed in the left column. Although trucks account for about 8-9\% of all vehicles involved in fatal crashes, the truck occupants are fatalities only about $2 \%$ of the time. However, as noted in Table 1.2, $53.1 \%$ of all large-truck occupant fatalities occur when the truck is involved in a rollover crash.

Table 1.2. Occupant fatalities for 1999 , by rollover occurrence, for large trucks and all other vehicles

\begin{tabular}{|l|c|c|c|}
\hline \multicolumn{1}{|c|}{ Vehicle type } & $\begin{array}{c}\text { Total } \\
\text { fatalities }\end{array}$ & $\begin{array}{c}\text { Rollover } \\
\text { fatalities }\end{array}$ & $\begin{array}{c}\text { Percent } \\
\text { rollovers }\end{array}$ \\
\hline Large trucks & 763 & 405 & $53.1 \%$ \\
\hline All other vehicles & 35,043 & 10,289 & $29.4 \%$ \\
\hline All types & 35,806 & 10,694 & $29.9 \%$ \\
\hline
\end{tabular}

Source: National Highway Traffic Safety Administration. FARS (Fatality Analysis Reporting System) on-line query system, http://www-fars.nhtsa.dot.gov/www/query.html . 
With these statistics in mind, it is easy to see why a study of truck roll stability is important. In August 2000, Cate documented research in the prioritization of sites in Tennessee that appear to be potential rollover hazards. ${ }^{2}$ Cate's thesis examined the relationship between rollover crashes and geometric highway design with the purpose of developing a set of guidelines that highway officials could use to determine the placing of truck rollover warning systems.

This report examines data that can be produced by equipment installed on the vehicle itself.

\subsection{PROJECT OBJECTIVES}

The objective of this project was to test the concept that a combination of on-board equipment and cooperative infrastructure could provide the information needed to give a commercial vehicle driver warning of rollover risk in time for the driver to take corrective action. For timely warning, knowledge is required about the vehicle's roll stability as loaded, its location relative to an upcoming "bad curve," its projected speed as it enters and traverses the curve, and the lateral acceleration demand of the curve. On-board equipment was used to collect data about the weight of the loaded trailer and weight transfer when the vehicle was subjected to lateral acceleration in a curve. Satellite signals from the Global Positioning System (GPS) were used to determine vehicle location. Speed information was collected from the vehicle's internal data bus. In the original concept, the GPS location data about the vehicle and potential bad curves were to be supplemented by positional information and curve data derived from broadcasts from roadside beacons. The vehicle and curve data were to be analyzed in real time to determine a truck's approach to a curve at a speed that could result in rollover. Likely rollover would have invoked a computer-generated warning signal a few seconds in advance of the curve.

Significant changes in this approach occurred during the project. First, the data from roadside beacons were never available. Second, the frequent introduction of deliberate error in signals from GPS satellites, so-called Selective Availability, was discontinued, making GPS-derived location data an order of magnitude more accurate. More accurate GPS data make it potentially feasible to generate and/or use a database of locations and characteristics of bad curves, thus making roadside beacons less necessary.

The fundamental problem addressed by this project remained the same: determination of safe speed in a curve, which depends on information that a driver cannot easily obtain. Characteristics of the curve can in theory be known in advance, but this information is not normally published. In addition, knowledge is also required about the instantaneous roll stability of the vehicle, and that information can be obtained only from measurements on the loaded vehicle.

${ }^{2}$ Cate, Matthew Alan. August 2000. "Development of a System to Prioritize Sites for the Installation of Automated Truck Rollover Warning Systems in Tennessee," a thesis prepared for the University of Tennessee, Knoxville, Tennessee. 
Thus, the objective of the Federally-funded portion of this project, as stated above, is to determine if the prototype system under test could obtain the information required to give drivers timely and credible warning of rollover risk. This objective was accomplished through

- An evaluation of the suite of test equipment to determine its reliability, and

- An analysis of the data to determine its accuracy and timeliness as a predictor.

\subsection{PROJECT PARTNERS AND THE EXPERIMENTAL SITUATION}

Contributing partners in the project originally included U.S. Xpress Enterprises, a major 48-state truckload hauler with headquarters in Chattanooga, Tennessee; Volvo Trucks North America; Wabash National Corporation, a major manufacturer of trailers; Control by Light Inc. (formerly a division of Raytheon Corporation); and the Operations Division of the Tennessee Department of Transportation (TDOT). Praxair, a hauler of cryogenic fluids, asked to join the project in midcourse. Significant subcontractors originally included the Texas Transportation Institute (TTI) and the University of Michigan Transportation Research Institute (UMTRI). The University of Tennessee (UT) Transportation Center, in a concurrent collaboration with TDOT, was to assist in the procurement of roadside equipment and will be responsible for some analysis of the data produced by our test-and-evaluation efforts.

The trucking firms, U.S. Xpress and Praxair, collected the data using trucks in revenue service and provided the data to ORNL for analysis. U.S. Xpress had three instrumented tractors and six instrumented trailers traveling primarily on Interstate-75 on a long-distance route between Atlanta, Georgia, and Wilmington, Ohio. Praxair, a company specializing in industrial gases, delivers cryogenics liquids to a number of customers in Pennsylvania, New Jersey, New York, and Connecticut. One instrumented tanker was used to collect Praxair data for this project. 


\section{Characteristics of the On-Board Components}

\subsection{SYSTEM HARDWARE}

Onboard instrumentation includes components on both the tractor and the trailer. Of particular interest is the trailer instrumentation, since in almost all cases it is the roll stability of the trailer that determines the stability of the entire rig. The instrumentation includes a strain gauge, a twoaxis accelerometer, a pressure gauge, and a temperature sensor (Figure 2.1). The trailer instruments operate under the control of a programmable trailer-mounted module (embedded computer) that provides excitation for the strain gauges, analog-to-digital conversion, and protocol generation for digital transmission of the data to the tractor cab. Manufacturers of the data acquisition equipment and the model numbers are given in Table 2.1. A schematic of tractor-trailer equipment is shown in Figure 2.2.

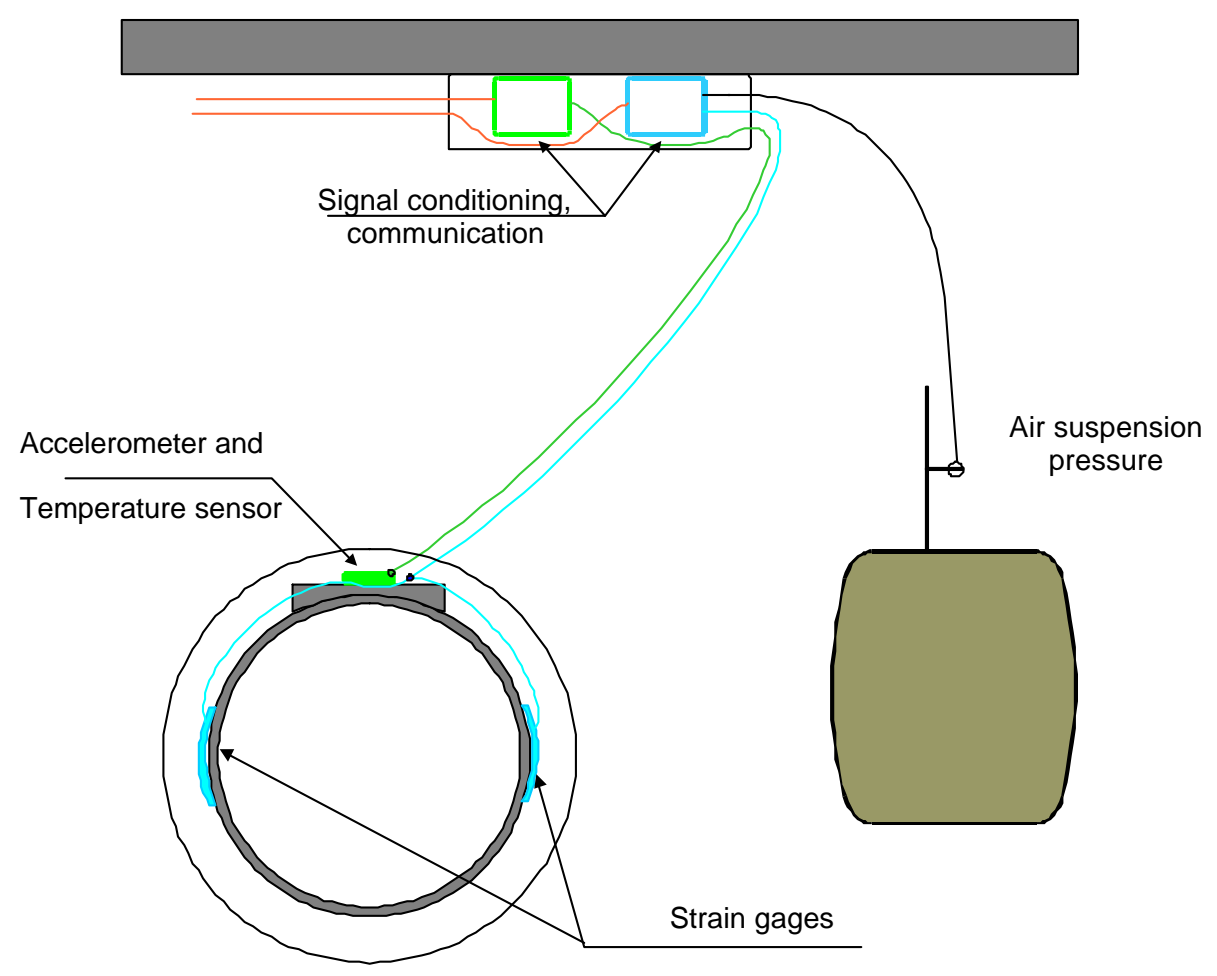

Figure 2.1. Axle sensors and signal conditioners. 
Table 2.1. List of on-board equipment

\begin{tabular}{|c|c|c|c|c|}
\hline $\mathrm{F} / \mathrm{N}$ & QTY & Part No./ID & Spec or Vendor Name & Title \\
\hline \multicolumn{5}{|c|}{ Tractor Segment } \\
\hline 0 & REF & G712977 & CBL Systems Corp* & Truck Rollover Warning System - Tractor Segment \\
\hline 1 & 1 & PT-6500 & DSE & Cab Mount, Rugged PC with Touch Display \\
\hline 2 & 1 & C-1075 & BICC Brand Rex & Cab Mounted Fiber Cable Assembly \\
\hline 3 & 1 & C-1077 & BICC Brand Rex & Cab To Trailer Umbilical Fiber Cable Assembly \\
\hline 4 & 1 & 73200 & Echelon & Network Interface Card (PCC-10) \\
\hline 5 & 1 & $75005-1$ & CBL Systems Corp & Fiber Optic Pod for PCC-10 Interface \\
\hline \multicolumn{5}{|c|}{ Trailer Segment } \\
\hline 0 & REF & G712978 & CBL Systems Corp & Truck Rollover Warning System - Trailer Segment \\
\hline 1 & 1 & G712979 & CBL Systems Corp & D4SIO Enclosure \\
\hline 2 & 1 & G733469-1 & CBL Systems Corp & D4SIO \\
\hline 3 & 1 & G712981 & CBL Systems Corp & Wire Harness \\
\hline 4 & 1 & C-1076 & BICC Brand Rex & Trailer Mounted Fiber Cable Assembly \\
\hline 5 & 1 & $23203 \mathrm{~A}$ & Summit Instruments & Two-Axis Accelerometer \\
\hline 6 & 4 & $\begin{array}{c}\text { CEA-06-187UV- } \\
350\end{array}$ & $\begin{array}{l}\text { Measurements Group, } \\
\text { Inc. }\end{array}$ & Strain Gage \\
\hline 7 & 1 & PK 80042 & Honeywell & Pressure Sensor \\
\hline
\end{tabular}

*Control by Light (CBL) is one of the project partners, as noted in Section 1.3.

A schematic of the original design showing locations of proposed components is given in Figure 2.2. 


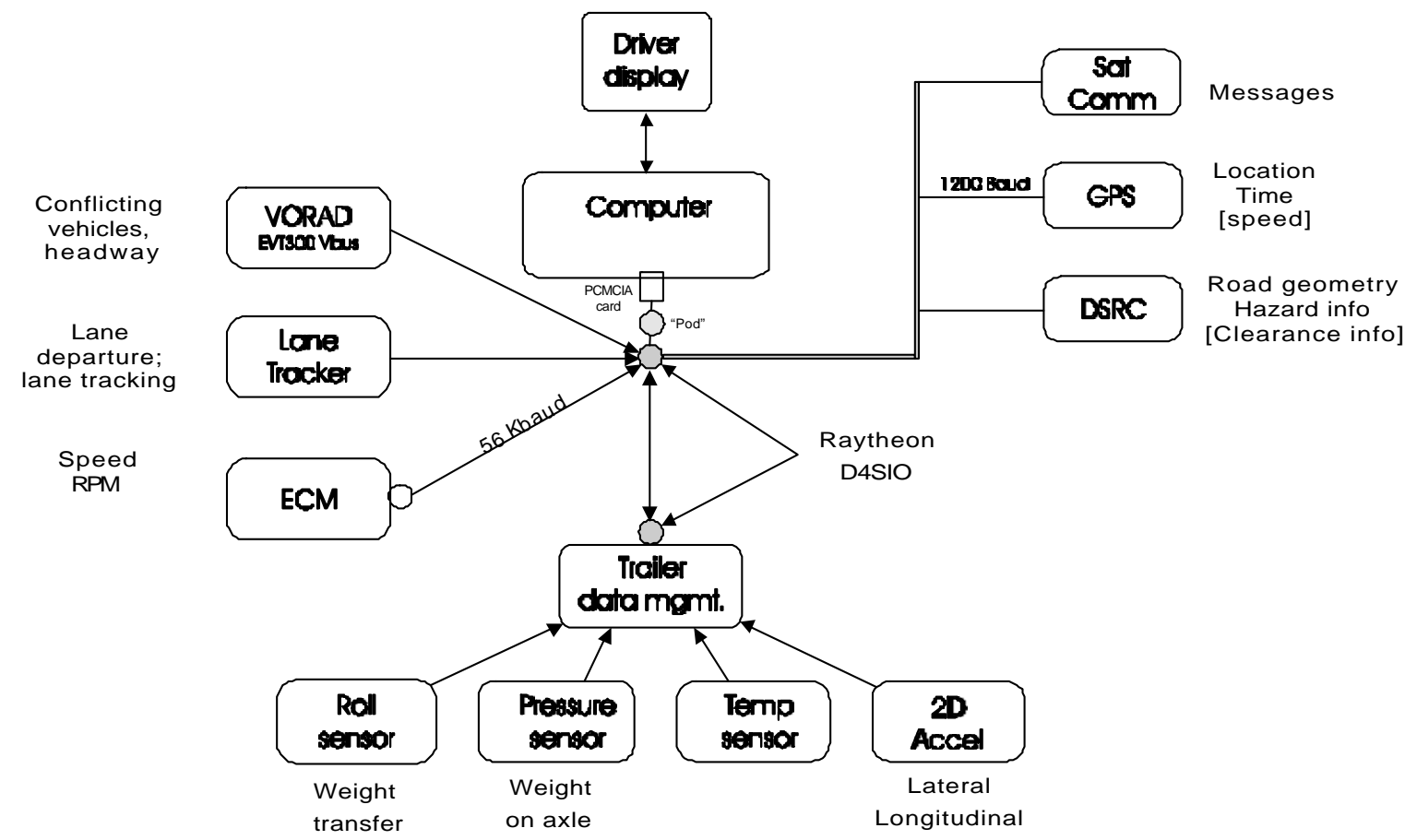

Figure 2.2. Truck-trailer schematic.

\subsubsection{Trailer instrumentation}

Trailers used in the project have air suspensions; such suspensions typically have leading or trailing arms on each side with air bags that support the load but provide little roll stiffness. The trailing arms are connected by torque tubes that provide the primary roll stiffness of the suspension. The assembly resists roll moment in a manner similar to that of an anti-sway bar in an automobile suspension. (For an excellent and more extensive discussion, see Winkler, et al. ${ }^{3}$ Our trailer instrumentation closely follows the example provided by the successful UMTRI project.)

${ }^{3}$ Winkler, C. B., P. Fancher, R. Ervin. 1999. "Intelligent Systems for Aiding the Truck Driver in Vehicle Control." University of Michigan, Transportation Research Institute, Ann Arbor, Michigan. IV Vehicle Navigation Systems and Advanced Controls (SAE-SP-1428). Warrendale, SAE, 1999, pp. 165178. Report No. SAE 1999-01-1301. 
Sensing of the strain in the torque tube as the trailer sways from side to side provides a signal proportional to the side-to-side weight transfer. Similarly, measurement of the air pressure in the suspension's air bags provides an output proportional to the total load of trailer and cargo. In addition, a two-axis accelerometer on the axle is mounted so that it measures lateral and longitudinal acceleration as the vehicle travels on the highway. A temperature sensor is included in the instrumentation to allow compensation for the temperature dependencies of the measurements provided by the rest of the sensors.

\subsubsection{Tractor instrumentation}

Instrumentation in the tractor includes a rugged computer with a VGA-capable liquid crystal touch screen display, a receiver for signals from GPS satellites, an interface to the vehicle's internal (J1708) data bus, and other features that could be used to assist the driver.

\subsubsection{On-board data communication}

The embedded data acquisition computer on the trailer and the main computer in the tractor are connected by a dedicated fiber optic cable. At the time that hardware was being specified for this project, there were competing systems for multiplexing data onto the trailer power leads, and hardware was not readily available for either multiplexing system. A fiber optic cable was proposed, and its superior bandwidth and immunity to radio frequency interference (RFI) were cited as advantages. With some expressed misgivings about the survivability of such components in the over-the-road environment, we selected the fiberoptic system.

\subsection{SYSTEM SOFTWARE}

\subsubsection{Data collection and transmission}

Software installed on the trailer's embedded computer manages the collection of data from the trailer's sensors. In normal operation, air pressure, torque tube strain, and acceleration data are collected ten times a second; the embedded computer can be programmed to change that rate if a situation warrants a different collection rate. The software for the embedded computer was furnished by Control by Light, one of the corporate partners in the project.

The main on-board computer, mounted in the cab, accepts messages from all of the installed equipment and stores the data in a log file according to specific conditions. Data management programs in Visual Basic 6.0 for the main computer were written by John Bate of Volvo and furnished by Volvo Trucks North America. Documentation for the data collection programs is included as Appendix A. ${ }^{4}$ The programs were originally intended to serve only as an interim

\footnotetext{
${ }^{4}$ Bate, John. May 8, 2000. SDL: Stability Data Logger, Version 1.1.20.
} 
capability, until "final" programs were written by a contractor; they have served far beyond the original intent.

Additional information about the data logs is provided in Section 3.3.

\subsubsection{Download procedure}

In keeping with the spirit of the ad hoc data collection program, Bate's "data download" procedure, though not complicated, still is more suitable for computer-knowledgeable persons than for the computer-illiterate. This procedure copies the data from the tractor's on-board computer to removable media. The download procedure involves removing a cover that protects the in-dash computer, inserting a memory card, and performing a manual file transfer operation. After the data transfer, the log file is reset, and data collection is re-enabled. For the complete set of instructions, see Appendix A. 


\section{Data MANAgement}

\subsection{DATA TRANSFER TO ORNL}

After downloading data from their trucks, U.S. Xpress and Praxair staff sent the data to Oak Ridge National Laboratory (ORNL) electronically. Transfer over the Internet using File Transfer Protocol (FTP) was the method selected for transferring information. The procedures that were developed allow users to schedule their uploads at their convenience and will work with virtually any size file. In addition, they do not require disks or memory cards to be exchanged with ORNL and work from within current versions of Netscape Communicator and Internet Explorer browsers. Instructions for use of the transfer procedure are included as Appendix B.

\subsection{FTP SERVER}

A Windows NT Server machine at ORNL was selected to host the FTP service. Three separate directories were set up underneath the primary FTP directory - one for PraxAir, one for U.S. Xpress, and the third for ORNL project use. Praxair and U.S. Xpress user accounts were established on the NT Server operating system; these users were given limited privileges and allowed logon access only to their own areas. External users were not allowed to delete or rename files once they were uploaded as a security precaution in case the password was compromised.

Files transferred to the FTP server from the trucking companies were maintained in duplicate. A copy of each file was placed into a separate directory on the FTP server accessible only by the project team via a shared directory on the ORNL local area network (LAN). Internet access to any ORNL LAN shared directories is blocked by a proxy server making this a secure means of project file access.

Data files were copied by the team members as the need arose. The files on the FTP server were considered originals, were not edited or replaced, and were archived onto writeable compact disks (CDs).

\subsection{DATA LOG FILE}

As noted in Section 2.2.1, data captured from the truck on-board system were written to a $\log$ file in a pre-defined format by the Stability Data Logger (SDL) programs (see Appendix A).

Trucks for U.S. Xpress and Praxair were equipped with several on-board instrument sources including a GPS receiver, a DPA II J1708 adapter manufactured by Dearborn Group, and trailer instrumentation as discussed above and tabulated in Table 2.1. The GPS data included information such as time (as measured by Coordinated Universal Time - UTC, which is the same as Greenwich Meridian Time), and geographic locations of the trucks (longitude and latitude). The J1708 adapter provided speed, revolutions per minute (RPM), and odometer readings, while 
the gauges attached to the trailer recorded measurements on lateral and longitudinal accelerations, torque tube strain, temperature, and weight on the rear axles.

It is important to note that the frequency of readings varied by instrument and data type. Generally, GPS readings were recorded once per second, while lateral and longitudinal accelerations were captured up to ten times per second. Because these data were written to a text file, certain conventions were used to identify data types. They are described as follows.

C All GPS readings were identified by a line that began with the letter " $G$ "or characters "\$G" followed by a UTC code that included time and, in some cases, date, latitude and longitude of the truck's location, and an indication of GPS data quality. Each data item was separated by commas. For example, a line representing readings from the GPS might read

$$
\mathrm{G}, 142326,3604.788390, \mathrm{~N}, 07958.179359, \mathrm{~W}, 1
$$

In this example, $G$ identifies the line as containing GPS data, 142326 is the UTC (14 hours, 23 minutes, and 26 seconds), 3604.788390 is latitude in degrees, $\mathrm{N}$ is the latitudinal compass direction (i.e., North), 07958.179359 is longitude in degrees, $\mathrm{W}$ is longitudinal compass direction (i.e., West), and 1 is GPS quality code (i.e., by definition, $0=$ invalid; $1=$ GPS fix; and $2=$ Diff. GPS fix).

It should be noted that various message formats can be output from GPS receivers, and the U.S. Xpress and Praxair receivers were not set to provide exactly the same messages. Variations in GPS readings between data captured by U.S. Xpress and Praxair trucks are discussed in Section 3.4.

C Every other data item was identified by a line that began with a letter followed by a comma and then a single reading. For example, lines for the log file might read

$\mathrm{S}, 33$ which indicates a speed of $33 \mathrm{MPH}$, or $\mathrm{R}, 1583$ which indicates $1583 \mathrm{RPM}$.

Table 3.1 shows the letter codes used to a identify a particular data element, as well as the typical frequency of recording and their instrument source. 
Table 3.1. Codes indicating the type of data for lines in the log file

\begin{tabular}{|c|l|l|l|}
\hline $\begin{array}{c}\text { Identification } \\
\text { Letter }\end{array}$ & \multicolumn{1}{|c|}{ Data Type } & \multicolumn{1}{c|}{ Frequency } & \multicolumn{1}{c|}{ Instrument } \\
\hline G or \$G & GPS Data & 1 per second & GPS \\
\hline S & Speed & 1 per second & J1708 \\
\hline R & RPM & 1 per second & J1708 \\
\hline O & Odometer & 10 per second & J1708 \\
\hline X & Lateral Acceleration & 10 per second & Trailer Gauges \\
\hline Y & Longitudinal Acceleration & 10 per second & Trailer Gauges \\
\hline Q & Strain & 10 per second & Trailer Gauges \\
\hline C & Ambient Air Temperature & 1 per second & Trailer Gauges \\
\hline W & Weight at Rear Axle & 10 per second & Trailer Gauges \\
\hline
\end{tabular}

To reduce the amount of storage space needed for the output data file, the SDL program applied certain rules for writing data to the log file. No data captured from the J1708 adaptor was written to the log file unless a GPS data point was recorded. Unless a problem occurred, such as inadequate reception of transmissions from satellites, GPS data was always to be written to the log file whenever data logging was enabled (see Appendix A for additional explanation about the user interface) and the minimum speed limit was greater than or equal to the minimum logging speed entered in the user interface (usually 5 to $10 \mathrm{MPH}$ ). To minimize the size of the log file, additional constraints were applied to the speed and RPM records. Speed was logged only if the current reading was 2 MPH different from the last reading; RPM was logged when the current reading was 50 RPM different from the last reading.

Between June 2000 and late January 2001 (to date), ORNL received four data files from U.S. Xpress and five data files from Praxair. Table 3.2 shows the files ORNL received from each company. 
Table 3.2. Data files received from the participating truck companies

\begin{tabular}{|l|l|l|r|r|r|c|}
\hline $\begin{array}{l}\text { Date up- } \\
\text { loaded }\end{array}$ & Company & \multicolumn{1}{|c|}{ File name } & \multicolumn{1}{|c|}{$\begin{array}{c}\text { File size } \\
\text { (in KB) }\end{array}$} & $\begin{array}{c}\text { Number of } \\
\text { records } \\
\text { (i.e., lines) }\end{array}$ & $\begin{array}{c}\text { Number of } \\
\text { GPS readings }\end{array}$ & $\begin{array}{c}\text { With } \\
\text { acceleration } \\
\text { measurements }\end{array}$ \\
\hline $6 / 6 / 00$ & U.S. Xpress & log.txt & 160,407 & $6,753,703$ & $2,783,350$ & Yes \\
\hline $6 / 6 / 00$ & Praxair & ornl_june.txt & 5,161 & 338,844 & 33,040 & Yes \\
\hline $7 / 24 / 00$ & Praxair & ornljuly.txt & 1,378 & 117,788 & 4,047 & Yes \\
\hline $8 / 22 / 00$ & U.S. Xpress & 2000_05_27.txt & 760 & 19,799 & 16,592 & No \\
\hline $8 / 29 / 00$ & Praxair & augdata.txt & 5,857 & 482,801 & 20,114 & Yes \\
\hline $8 / 30 / 00$ & U.S. Xpress & 2000_aug_29.txt & 52,070 & $1,843,715$ & $1,004,730$ & Yes (very few) \\
\hline 9/25/00 & U.S. Xpress & 2000_sept_24.txt & 2,032 & 53,316 & 44,333 & No \\
\hline $10 / 11 / 00$ & Praxair & prax10_09.txt & 499 & 34,085 & 2,682 & Yes \\
\hline $11 / 16 / 00$ & Praxair & orn1_nov.txt & 37,228 & $3,324,634$ & 92,121 & Yes \\
\hline $1 / 25 / 01$ & Praxair & jan-o1-a.txt & 71,666 & $6,232,861$ & 206,094 & Yes \\
\hline
\end{tabular}

As ORNL began to receive log files from both U.S. Xpress and Praxair, it became apparent that there were differences between sets of GPS data from the two companies. The major differences in the GPS data were that (1) the Praxair file contained UTC date as well as time, while the U.S. Xpress file contained time only, and (2) the GPS data line was identified by the literal expression \$GPRMC in Praxair files and G in U.S. Xpress files. In addition, more data items were recorded in Praxair's GPS data line. Because of these differences, two slightly different database structures and programs were designed.

\subsection{DATABASE DESIGN}

During the summer of 2000, ORNL's effort on this project was refocused on data collection and analysis. To that end, an initial quick database design was implemented to allow immediate analysis of the data. The initial design of the database was very simple and constructed quickly so that data from the log files could be quickly put into tables in preparation for data analysis. Visual FoxPro 6.0 was chosen as the database to be used for two reasons: (1) project team members had the software readily available and (2) the programs to load the database could be written without investing time and effort in building an unnecessary event-driven user interface (required by Visual Basic 6.0).

A decision was made to extract, for analysis purposes, only the last reading for data elements that were captured more often than once every second. Because of the differences in the log file line containing GPS data, two slightly different tables were constructed, one for the U.S. Xpress data and one for Praxair data. The Praxair table contained one additional column to account for the date, which was not contained in the U.S. Xpress files. Table 3.3 shows the database structure for the database tables. 
Table 3.3 Database structure

\begin{tabular}{|l|l|l|l|l|}
\hline \multicolumn{1}{|c|}{ Data Name } & \multicolumn{1}{|c|}{ Type } & \multicolumn{1}{c|}{ Width } & \multicolumn{1}{c|}{$\begin{array}{c}\text { Decimal } \\
\text { Places }\end{array}$} & \multicolumn{1}{c|}{ Description } \\
\hline Time & Numeric & 6 & & Time signal from GPS \\
\hline Date $^{\text {a }}$ & Numeric & 6 & & Date signal from GPS \\
\hline Longitude & Float & 15 & 6 & GPS position reading \\
\hline Latitude & Float & 15 & 6 & GPS position reading \\
\hline Speed & Float & 5 & 1 & MPH from J1708 \\
\hline RPM & Integer & 4 & & RPM from J1708 \\
\hline Lateralacc & Float & 10 & 6 & Trailer lateral acceleration \\
\hline Longitacc & Float & 10 & 6 & Trailer longitudinal acceleration \\
\hline Strain & Float & 10 & 6 & Strain in trailer suspension torque tube \\
\hline Temp & Float & 6 & 2 & $\begin{array}{l}\text { Trailer accelerometer temperature sensor } \\
\text { reading }\end{array}$ \\
\hline Weight & Float & 10 & & Weight measured from pressure in air bag \\
\hline
\end{tabular}

${ }^{\text {a}}$ The Date field only existed in the table receiving Praxair data.

\subsection{DATABASE LOADING}

A utility program was written in Visual FoxPro to parse the text log files and load data items into the appropriate U.S. Xpress or Praxair tables. If a data element was not captured for a particular GPS reading, then the program inserted a null value (indicating missing data) into this field. A program listing is included in Appendix C.

Two versions of the program were written to accommodate the differences in the log file for the GPS line for U.S. Xpress and Praxair (see Section 3.3). The following shows how the GPS line was written for U.S. Xpress and Praxair, with the differences highlighted in bold.

U.S. Xpress: G,020331,3448.4154,N,08500.9751,W,1

Praxair: \$ \$GPRMC,195003,,4112.1325,N,07956,W,110500,„A*67

where $\mathbf{G}$ and \$GPRMC identified lines of GPS readings, the $\mathbf{1 1 0 5 0 0}$ in the Praxair line indicated the UTC date (no date available for the U.S. Xpress data), and the $\mathbf{1}$ and $\mathbf{A} * \mathbf{6 7}$ indicated the GPS quality or checksum, respectively. 


\subsection{DATA VALIDATION}

Validation procedures were applied to scan and to check the validity of the data after they were loaded into the appropriate tables. Some data problems were identified.

1. Run-delimiting data elements were not present. The input fields on the user interface screen that could be helpful in identifying a run - driver ID, vehicle ID, trailer ID, and load ID - were optional fields that the driver usually did not enter. Furthermore, U.S. Xpress data files did not contain a date element in their GPS data line, though Praxair files did. It was decided to attempt to separate Praxair runs by using the date field for analysis purposes, while U.S. Xpress runs were separated by using latitude/longitude location information and time-stamps recorded by the GPS.

2. Trailer data was missing from the majority of the U.S. Xpress files. Early in the project, U. S. Xpress dispatchers were seldom able to assure that the instrumented trailers were available to connect to the instrumented tractors. In addition, one fiber-optic cable had incorrect connectors installed and soon failed. As the project progressed and the tractor-trailer pairs were more often mated properly, the remaining fiber-optic connectors began to wear and fail. The net result was that most runs for U.S. Xpress had only tractor data (primarily GPS locations).

3. Early Praxair data was fragmented. Praxair data that were collected at the beginning of their participation in the project showed brief segments of reasonable data separated by significant time gaps within a day. There were only occasional episodes of contiguous data that could be analyzed.

The following data validation checks were run on data from both Praxair and U.S. Xpress. In general, all the data that were available looked valid.

$\begin{array}{lll}\text { 1. } & \text { Longitude } & \mathrm{NA}^{5} \\ \text { 2. } & \text { Latitude } & \mathrm{NA} \\ \text { 3. } & \text { Speed } & 0.0 \text { to } 100.0 \\ \text { 4. } & \text { RPM } & 0 \text { to } 3500 \\ \text { 5. } & \text { Temperature } & -20.0 \text { to }+120.0 \\ \text { 6. } & \text { Weight } & 0.0 \text { to } 30000 \\ \text { 7. } & \text { Lateral acceleration } & -1.0 \text { to }+1.0 \\ \text { 8. } & \text { Longitudinal acceleration } & -1.0 \text { to }+1.0 \\ \text { 9. } & \text { Strain } & -1.0 \text { to }+1.0\end{array}$

${ }^{5}$ Plotted using a Geographic Information System (GIS) tool and checked against U.S. Geological Survey data. 


\section{Data Analysis}

The following sections describe the processes of analyzing the data to determine its accuracy and usability as a predictor of rollover potential.

\subsection{MAPPING OF GEOGRAPHIC DATA}

The on-board GPS receiver collected geographic location data (i.e., longitude and latitude) of the truck approximately once every second. Such geographic reference information enabled ORNL to track truck routes with a GIS tool. GIS is a computer system capable of assembling, storing, manipulating, and displaying geographically referenced information.

The Maptitude ${ }^{\circledR}$ Geographic Information System for Windows, a computer software system developed by the Caliper Corporation, was used to evaluate and display the data. Maptitude, a personal-computer-based mapping tool, allowed the project team members to perform geographic mapping and to conduct spatial data analyses.

As described previously, the on-board GPS provided geographic reference information, in terms of longitude and latitude, for a truck's current position. This geographic referencing information is point-based data. To track a truck route, these point-based data were converted to polylinebased data. For this study, ORNL developed a simple algorithm to interpolate a polyline between two GPS data points. This algorithm is briefly explained here.

For any three consecutive geographic data points, $\mathrm{P}_{\mathrm{n}-1}, \mathrm{P}_{\mathrm{n}}$, and $\mathrm{P}_{\mathrm{n}+1}$ collected by the GPS unit, the interpolated polyline for $\mathrm{P}_{n}$ (including two line segments, one on each side of $\mathrm{P}_{n}$ ) is defined by the following three new data points:

$$
\begin{aligned}
& \mathrm{Q}_{\mathrm{n}-1}=\left(\mathrm{P}_{\mathrm{n}-1}+\mathrm{P}_{\mathrm{n}}\right) / 2 \text {, which is the mid-point between } \mathrm{P}_{\mathrm{n}-1} \text { and } \mathrm{P}_{\mathrm{n}} \\
& \mathrm{Q}_{\mathrm{n}}=\mathrm{P}_{\mathrm{n}} \text {, and } \\
& \mathrm{Q}_{\mathrm{n}+1}=\left(\mathrm{P}_{\mathrm{n}}+\mathrm{P}_{\mathrm{n}+1}\right) / 2 \text {, which is the mid-point between } \mathrm{P}_{\mathrm{n}} \text { and } \mathrm{P}_{\mathrm{n}+1} \text {. }
\end{aligned}
$$

In other words, discrete data points (e.g., $\mathrm{P}_{\mathrm{n}-1}, \mathrm{P}_{\mathrm{n}}$, and $\mathrm{P}_{\mathrm{n}+1}$ ) are replaced with a polyline consisting of two line segments (e.g., one line segment connecting $Q_{n-1} Q_{n}$ and the other connecting $\mathrm{Q}_{\mathrm{n}} \mathrm{Q}_{\mathrm{n}+1}$ ). It should be noted that available maps of interstate highways are based on geographic location information collected - in some cases, many years ago - by the U.S. Geological Survey (USGS). It is common for geographic information collected by different agencies, at different times, using different equipment, to result in minor discrepancies in displays, especially when viewed at high spatial resolution. 


\subsection{COMPARISON OF U.S. XPRESS AND PRAXAIR DATA ANALYSES}

Most of the data analysis efforts performed under this study were conducted using U.S. Xpress data sets. The early data sets received from Praxair contained fragmented data, and the problem causing the fragmentation was difficult to diagnose. Although the Praxair data sets contained a date field, which eliminated the problem inherent in the U.S. Xpress data sets of determining the beginning and ending of a "trip" (see Section 4.3), the fragmentation problem caused most of the Praxair data sets to be unusable for our purposes. Sections 4.3-4.4 provide information and analyses on U.S. Xpress truck trips, and Section 4.5 discusses Praxair data.

\subsection{IDENTIFICATION OF INDIVIDUAL U.S. XPRESS TRUCK TRIPS}

With the exception of a few locally oriented short trips, the U.S. Xpress trucks participating in this study traveled a long-distance route between Atlanta, Georgia, and Wilmington, Ohio (see Figure 4.1). These long-distance truck trips were almost entirely on I-75. Since U.S. Xpress data did not typically contain information on travel date nor truck/trailer identification, data transmitted from the trucks were received as a long continuous stream of records. Additional effort was, therefore, required to separate these data into meaningful northbound or southbound truck-trips.

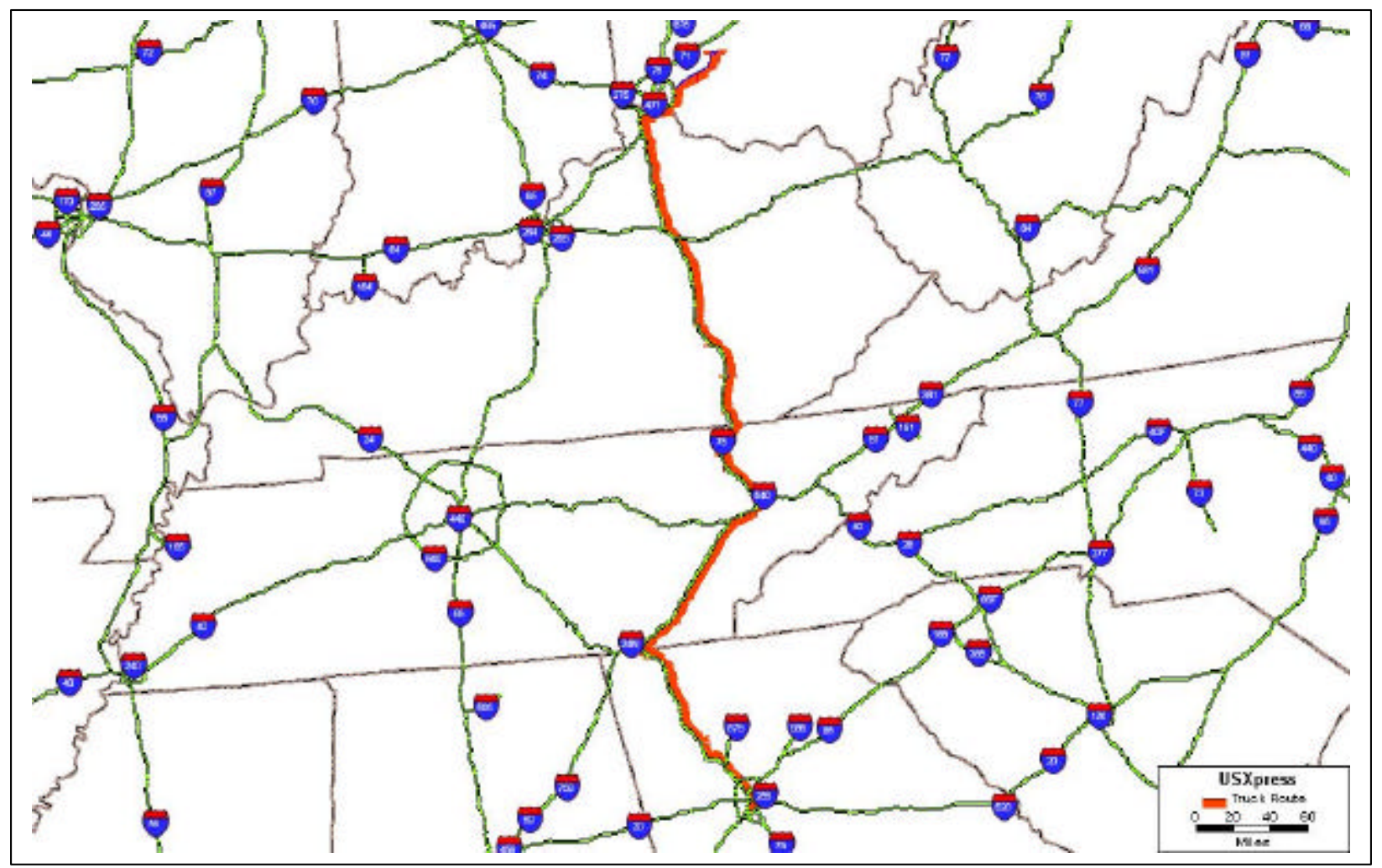

Figure 4.1. U.S. Xpress truck travel path. 
To identify and separate individual truck trips, the project team developed a fairly simple algorithm that takes into consideration both spacial and temporal data gaps in the data stream. The algorithm allows one to set criteria to define the beginning of a truck trip. These criteria include (1) setting a temporal gap limitation (e.g., 30 minutes) or a spacial gap limitation (e.g., 2 miles); (2) setting a temporal gap limitation and a spacial gap limitation; (3) setting a temporal gap limitation or a fixed distance from a fixed point; and (4) setting a temporal gap limitation and a fixed distance from a fixed point. It should be noted that this algorithm would not necessarily generate "perfect" results. Some manual modification of the preliminary results might be needed.

Data from Praxair trucks did not require this trip-identification process because the Praxair data contained date information.

\subsection{ANALYSIS OF U.S. XPRESS TRUCK DATA}

The largest U.S. Xpress data file received (i.e., log.txt, June 2000) was processed using the method described above. Over 80 long-distance one-way truck trips were identified from this process. These trucks traveled, either northbound or southbound, between Atlanta, Georgia, and Wilmington, Ohio, and, generally, made a stop at a location near Corbin, Kentucky, to switch drivers. Only three of over 80 truck trips contained a significant amount of trailer data (i.e., measurements on lateral and longitudinal accelerations). These three routes are referred to as the "complete" trips in this report. Detailed analyses were conducted using data from these "complete" runs to evaluate the characteristics of, and relationships among, measurements collected from the on-board instruments. The following presents a summary of these results.

The U.S. Xpress truck trip data set described in this section contained a northbound trip, which began at Atlanta, Georgia, and ended at Wilmington, Ohio (Figure 4.1). Time series plots for several on-board-system-recorded data items were generated to evaluate possible changes in driving behavior or patterns along the travel path. Spatial displays of these measurements were reviewed using the GIS tool as described previously. This type of analysis is especially useful in visualizing measurement variations due to changes in roadway curves or types (e.g., urban streets or rural interstates).

\subsubsection{Measurements over time}

\section{$\underline{\text { Lateral acceleration }}$}

Lateral acceleration is an important measurement in studying the relationship between truck-roll stability and the roadway design of a location. Generally, lateral acceleration is a positive or negative value between $-1.0 \mathrm{~g}$ and $+1.0 \mathrm{~g}$. The unit " $\mathrm{g}$ " represents the acceleration of one unit of the earth gravity which is $9.8 \mathrm{~meter} / \mathrm{sec}^{2}$, or equivalently $32 \mathrm{feet} / \mathrm{sec}^{2}$. The sign of this value 
depends on the direction of a turn that the truck makes at a roadway curve. When traveling on a straight and level roadway, the average lateral acceleration is expected to be zero.

A set of lateral acceleration measurements recorded by the trailer-mounted instrument, for a selected period of approximately two hours, is presented in Figure 4.2. This specific time period was chosen because it included data collected from the location where I-24 and I-75 merge. This I-24/I-75 junction, located near Chattanooga, Tennessee, has a relatively sharp turning curve (see Figure 4.3). It was expected that measurements of lateral acceleration at this location would be higher then those measured at other straighter stretch of the I-75.

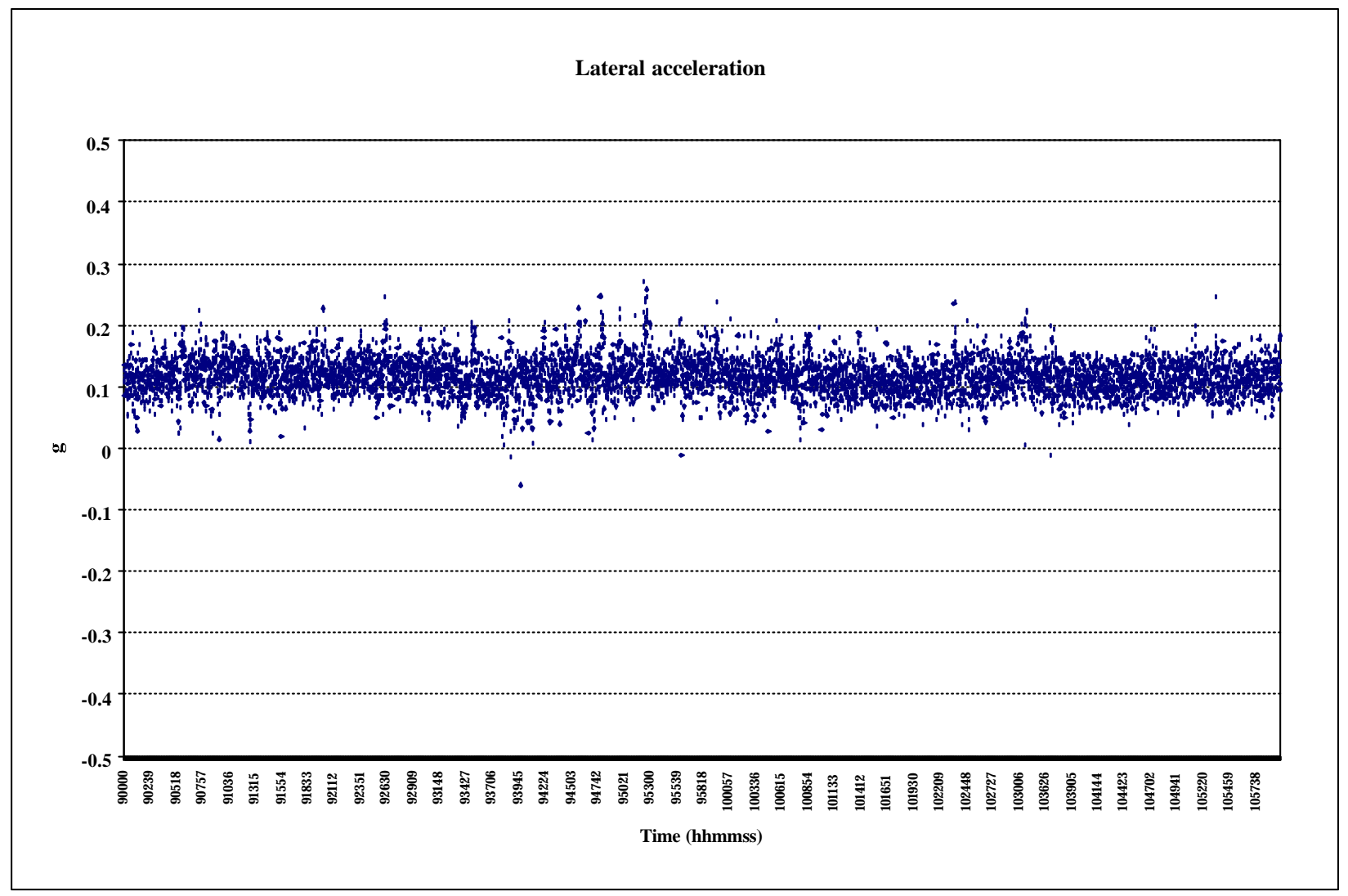

Figure 4.2. Lateral acceleration measured during the selected 2-hour period. 


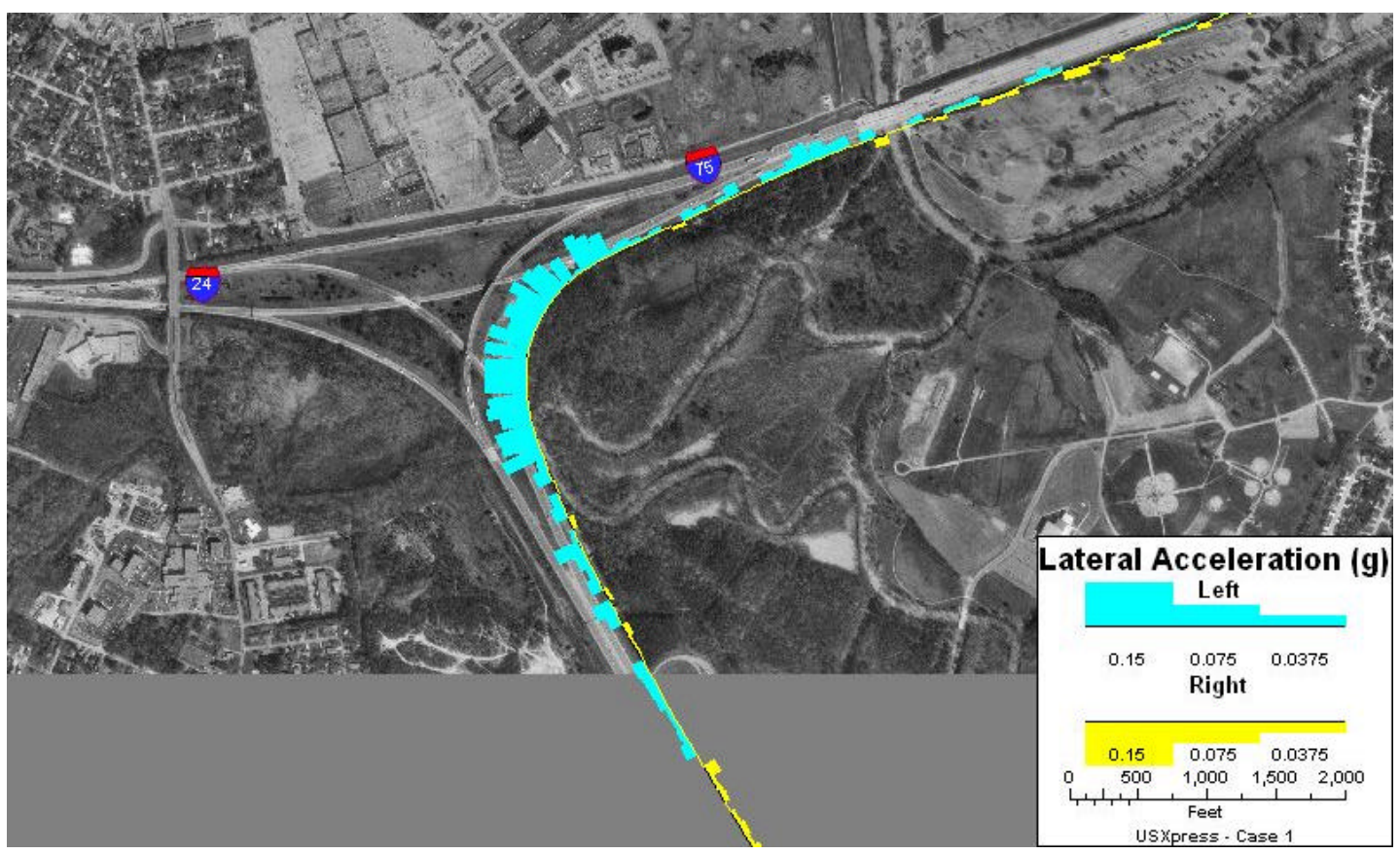

Figure 4.3. Truck trajectory on curve at junction of I-24/I-75 near Chattanooga, Tennessee.

From Figure 4.2, it appears that the average lateral acceleration is located approximately at $+0.12 \mathrm{~g}$. Further review of lateral accelerations collected for the entire travel path revealed that similar positive values were measured from all locations. Review of another data set from a different U.S. Xpress truck-trip confirmed the existence of this positive bias. The sensors on the trailer have known temperature coefficients, and some instrument drift probably occurred. Refined analysis of the data should allow separation of these two causes of biased readings, but a simple adjustment as discussed later in this report was used by the project team for this analysis. A simple calibration check (described in Appendix D) would resolve any ambiguities and assure valid data.

\section{$\underline{\text { Longitudinal acceleration }}$}

Longitudinal acceleration measurements for the same data set are presented in Figure 4.4. Longitudinal acceleration measurements represent either actual forward acceleration, braking, or the effect on a vehicle traveling either downhill or uphill at a location. When traveling at constant speed on a "flat" roadway with a properly calibrated instrument, readings from this measurement should be on or near zero. It can be easily seen from Figure 4.4 that an unusual change of pattern occurred at approximately 10:30 Universal Time. Further examination of associated geographic location information with the Maptitude GIS tool pointed to a four-lane, 
steep uphill stretch on northbound I-75 near the town of Ooltewah at the north of Chattanooga in Tennessee, followed by a three-lane downhill section. Trucks were required to travel on the two right-most lanes while ascending the hill.

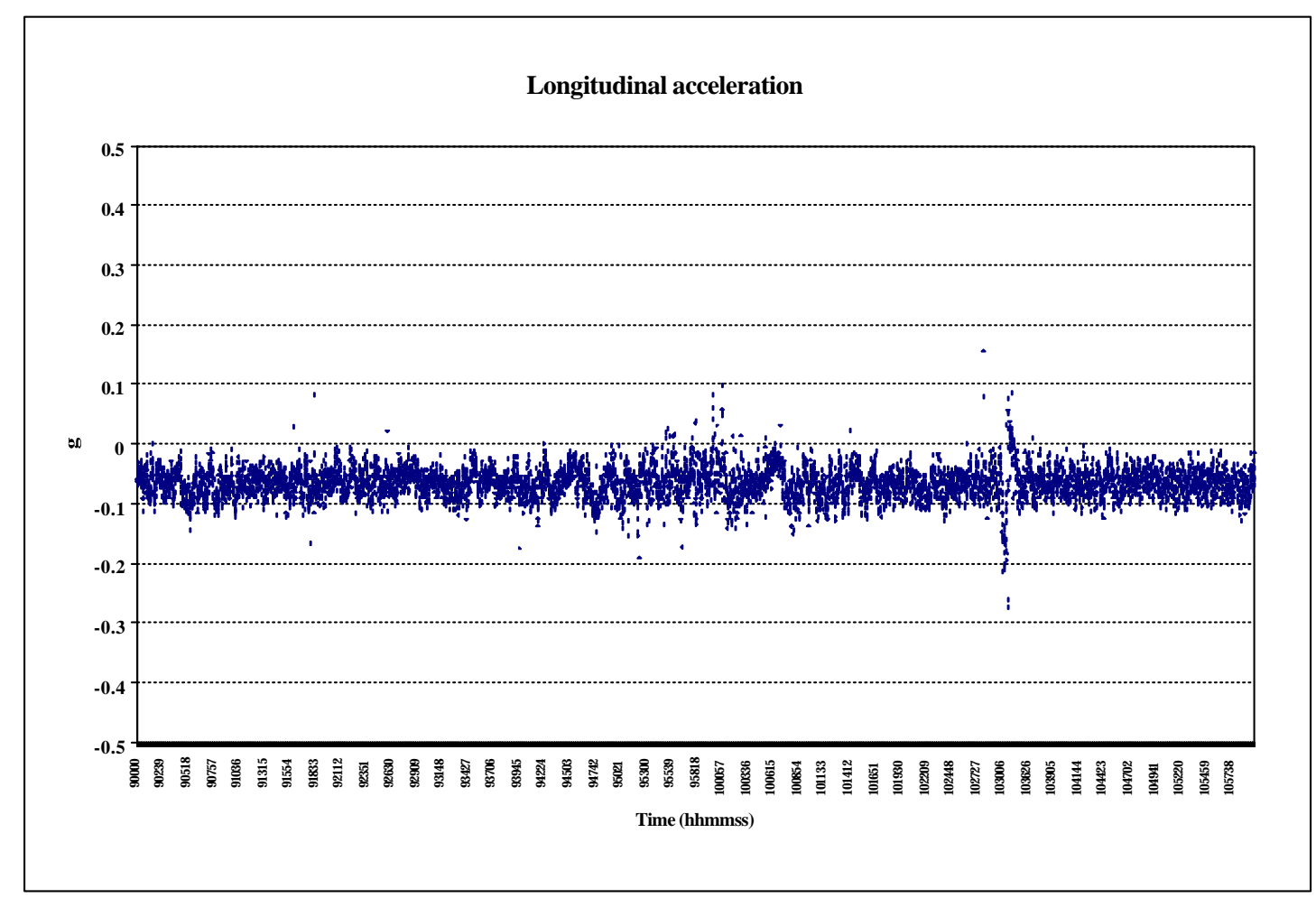

Figure 4.4. Longitudinal acceleration measured during the selected 2-hour time period.

\section{$\underline{\text { Recorded speed }}$}

Figure 4.5 is a time-series plot of the truck speed as recorded by the on-board instrument for the same data set. The data capturing utility program (see Appendix A) was designed to log vehicle speeds only when the speed changed by 2 MPH and the GPS data was logged. A minimum speed of $10 \mathrm{MPH}$ was set for the data logger on U.S. Xpress trucks. The GPS data were logged only when this minimum speed was met. Data for recorded speeds, as shown in Figure 4.5, were rather spotty, which indicated that the truck traveled mostly around steady speeds. Speed was recorded more frequently at the area of the I-24/I-75 junction. Moreover, a rapid decline of speed followed by a rapid gain of speed can also be clearly seen at the location where the steep hill is located. 


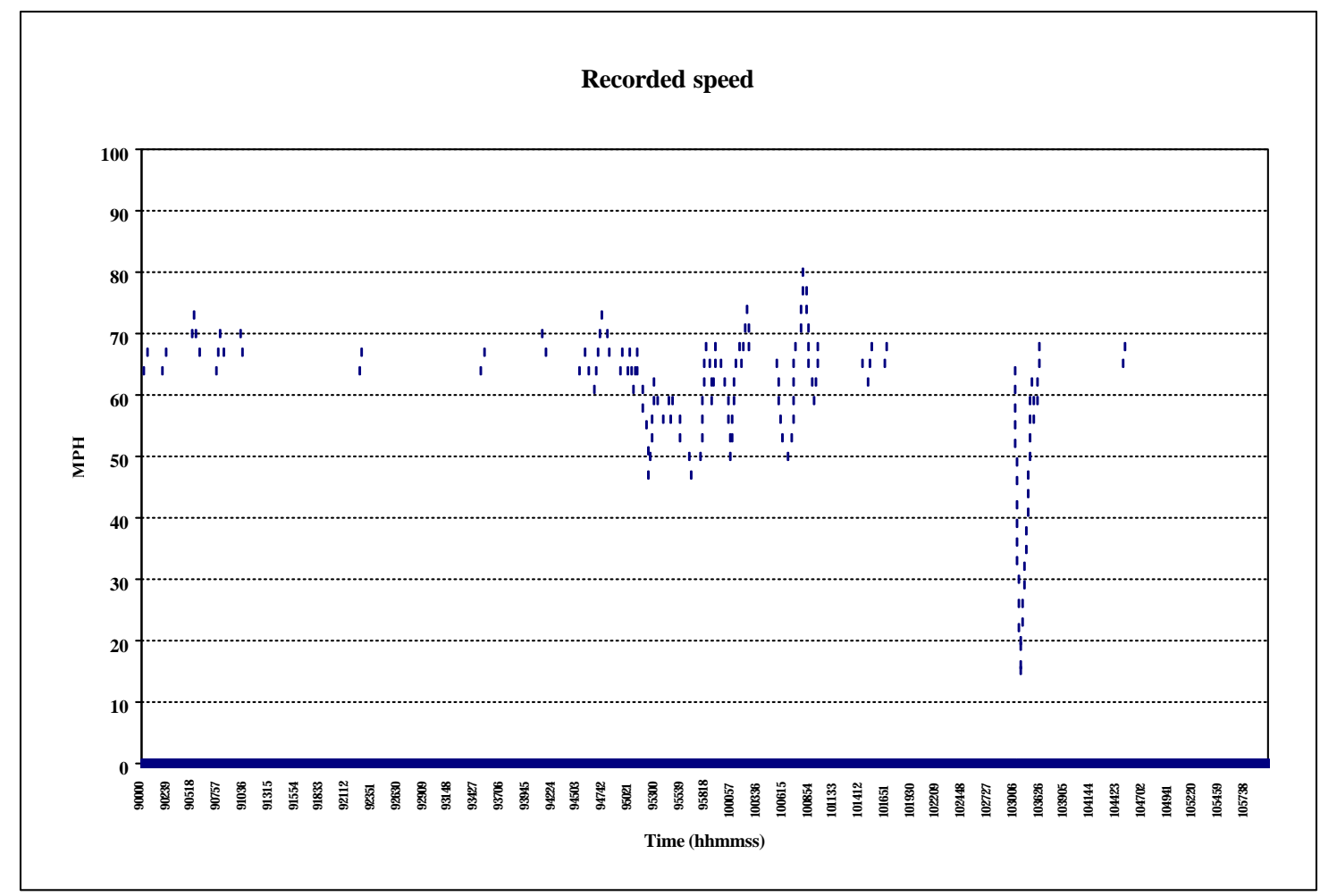

Figure 4.5. Speed (MPH) recorded by the on-board instrument for the selected time period.

$\underline{\text { Rear-axle weight }}$

The instrument mounted on the trailer also records the weight of truck and load (in pounds) at its back axle. Measurement of load from the same data set (as used in previous figures) is displayed in Figure 4.6. When traveling on a "flat" and straight roadway, the rear-axle weight of a truck should stay at a relatively constant level. Geographic impacts to the weights measured around the two specific locations (i.e., I-24/I-75 curve and the steep hill) can be seen from the graph shown in Figure 4.6. 


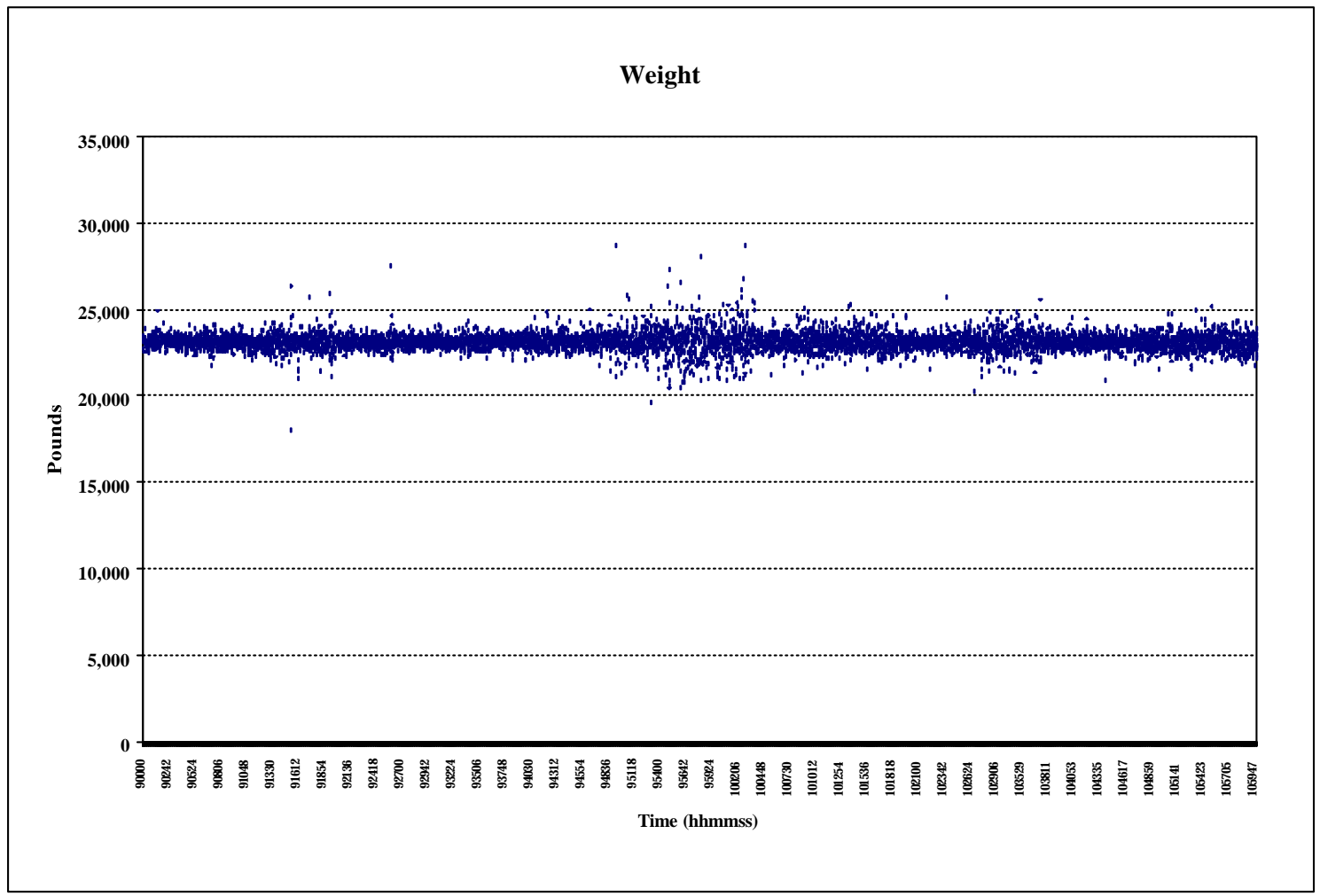

Figure 4.6. Rear axle weight measured during the selected 2-hour time period.

\section{Engine speed}

Vehicle engine rotational speed, i.e., RPM, was also logged by the on-board computers on these trucks. To minimize the data storage requirement of the output file, the data logger recorded the RPM measurement only if it changed by 50 RPM. It was anticipated that these RPM measurements could provide insight into driver behavior as well as the driving situation at a given location. Figure 4.7 shows values of RPM from the same data set as those used in earlier discussions. Changes in RPM measurements can be seen at I-24/I-75 junction as well as at the location of the steep hill. 


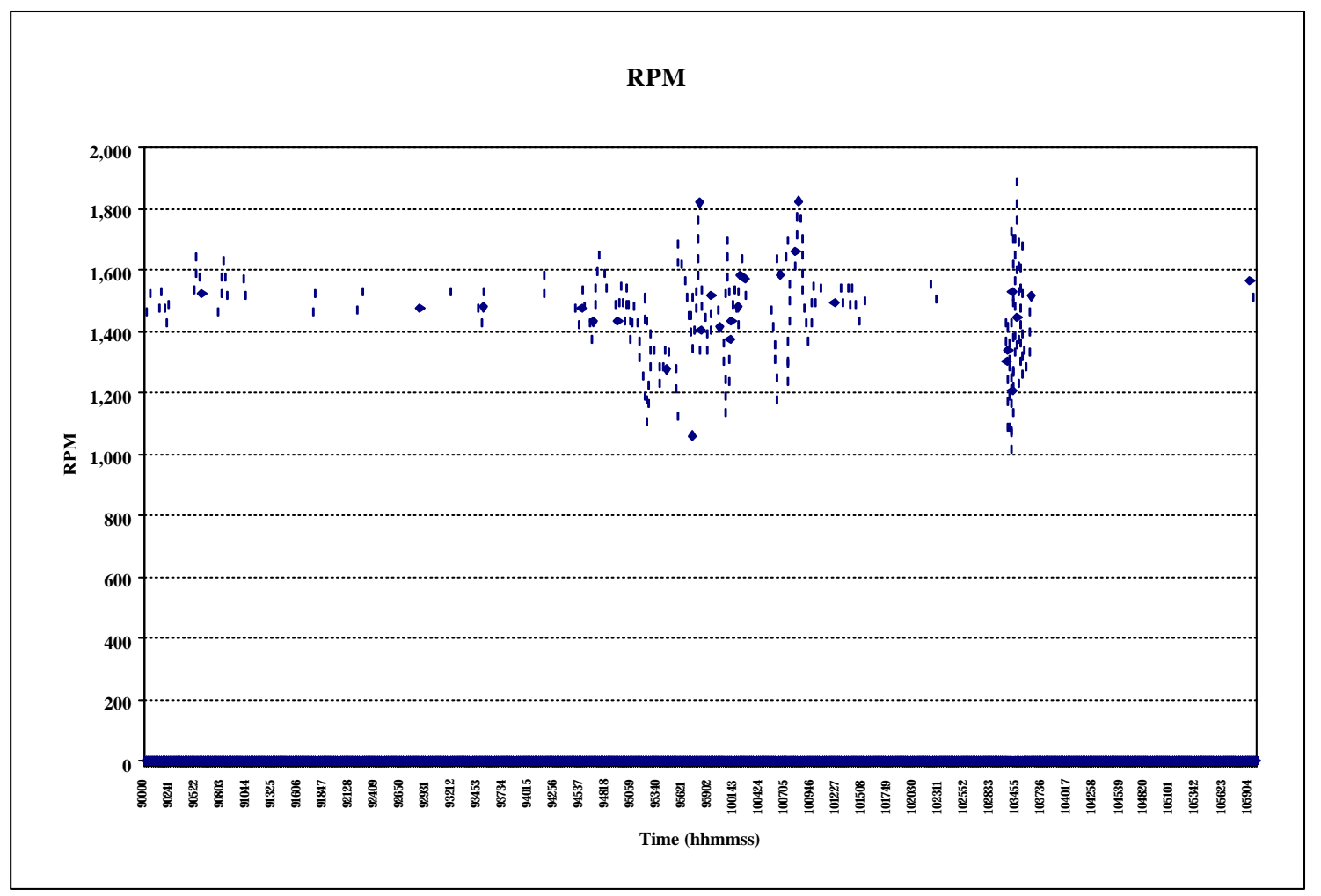

Figure 4.7. RPM measurements for the selected 2-hour time period.

\section{$\underline{\text { Strain }}$}

Another measurement collected from the on-board system was the vehicle torque-tube strain. These data were used to determine truck roll response to lateral acceleration. Figure 4.8 displays the strain measured for the same trip as those used in earlier figures. 


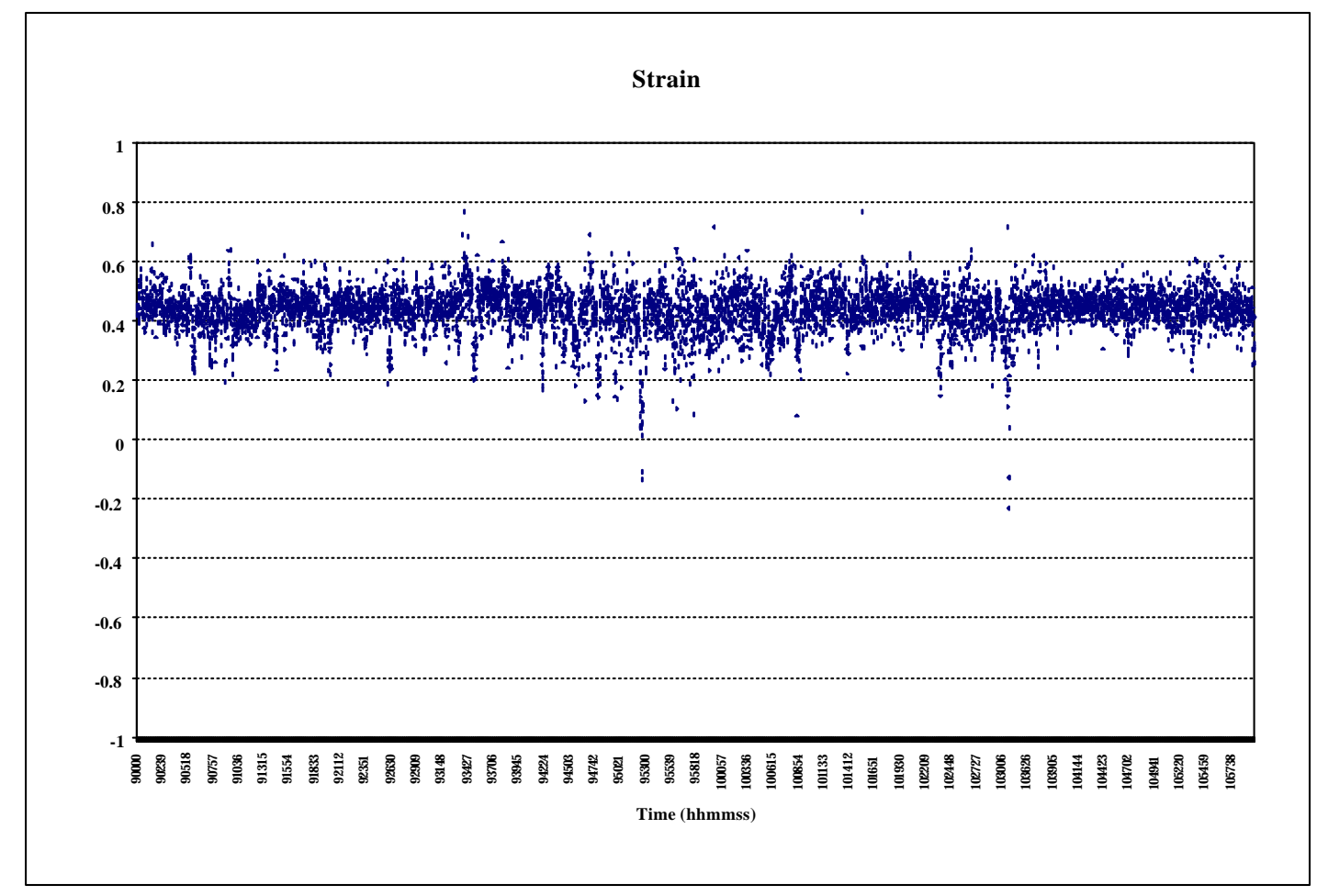

Figure 4.8. Measurements of strain for the selected 2-hour time period.

\subsubsection{Adjustment to correct instrument bias}

As discussed before, lateral acceleration measured at a straight stretch of roadway should be approximately zero. Review of lateral accelerations collected from U.S. Xpress trucks revealed a positive value "band" at about $+0.12 \mathrm{~g}$ for the entire travel path. A simple adjustment was used to correct this positive bias. Values of lateral acceleration were adjusted downward by subtracting the average value calculated from measurements collected from all locations on the travel route. These adjusted lateral acceleration measurements are presented in Figure 4.9. 


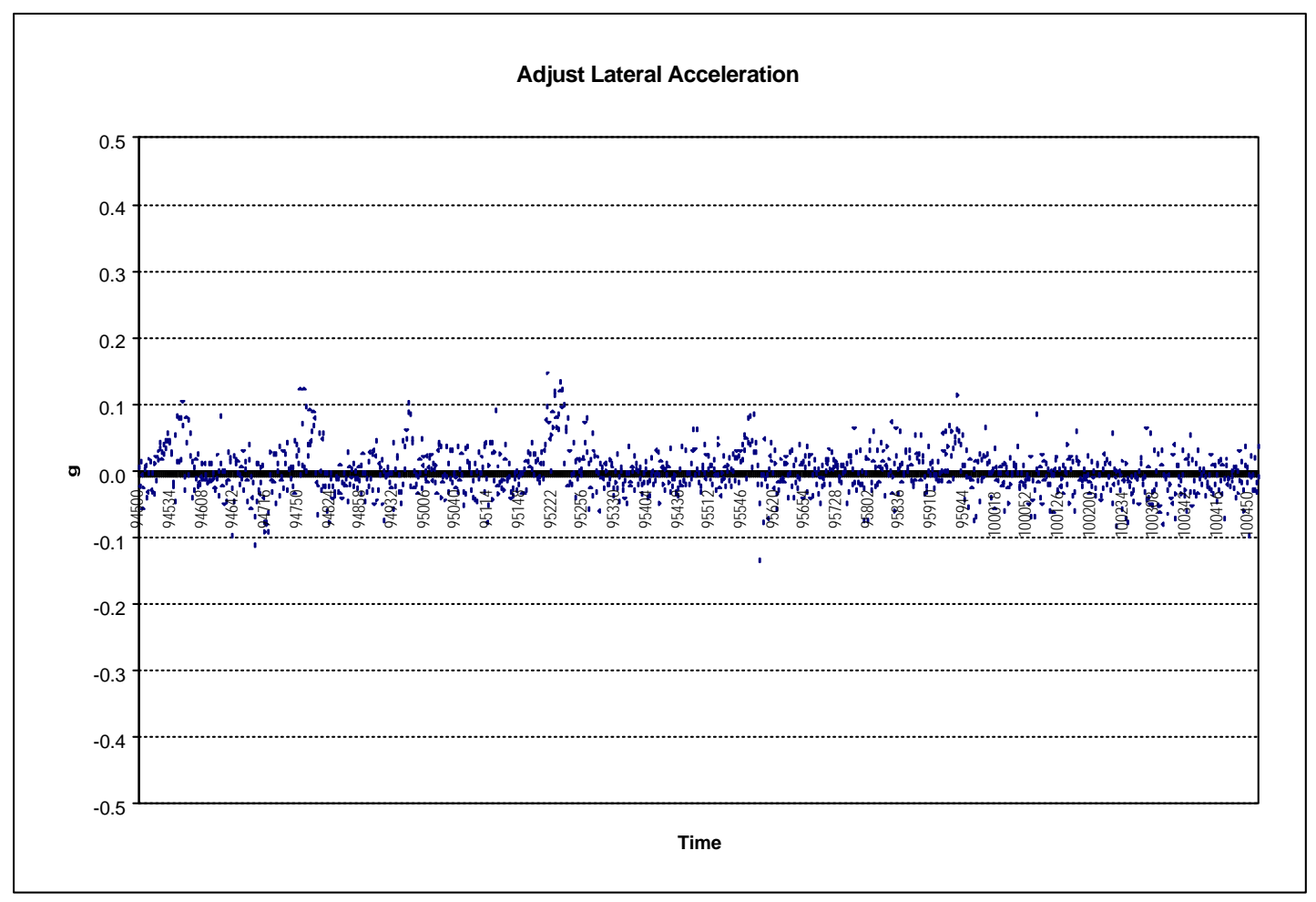

Figure 4.9. Adjusted lateral acceleration measurements for the selected 2-hour time period.

\subsection{ANALYSIS OF PRAXAIR TRUCK DATA}

Unlike U.S. Xpress trucks which travel along the same north-south route between Ohio and Georgia, Praxair trucks travel to different locations in Pennsylvania, New Jersey, New York, and Connecticut. The routes use a combination of local streets and limited-access highways. It should be noted that of the five data sets received from Praxair between June and November, most of them contained very fragmented data. Based on the largest and most complete data sets received (November 2000 and January 2001) from Praxair, ORNL was able to complete some limited analysis. This set of data shows that Praxair trucks make frequent stops along the travel routes. Figures 4.10-4.14 show routes for the Praxair instrumented trucks for November 5-9, 2000. 


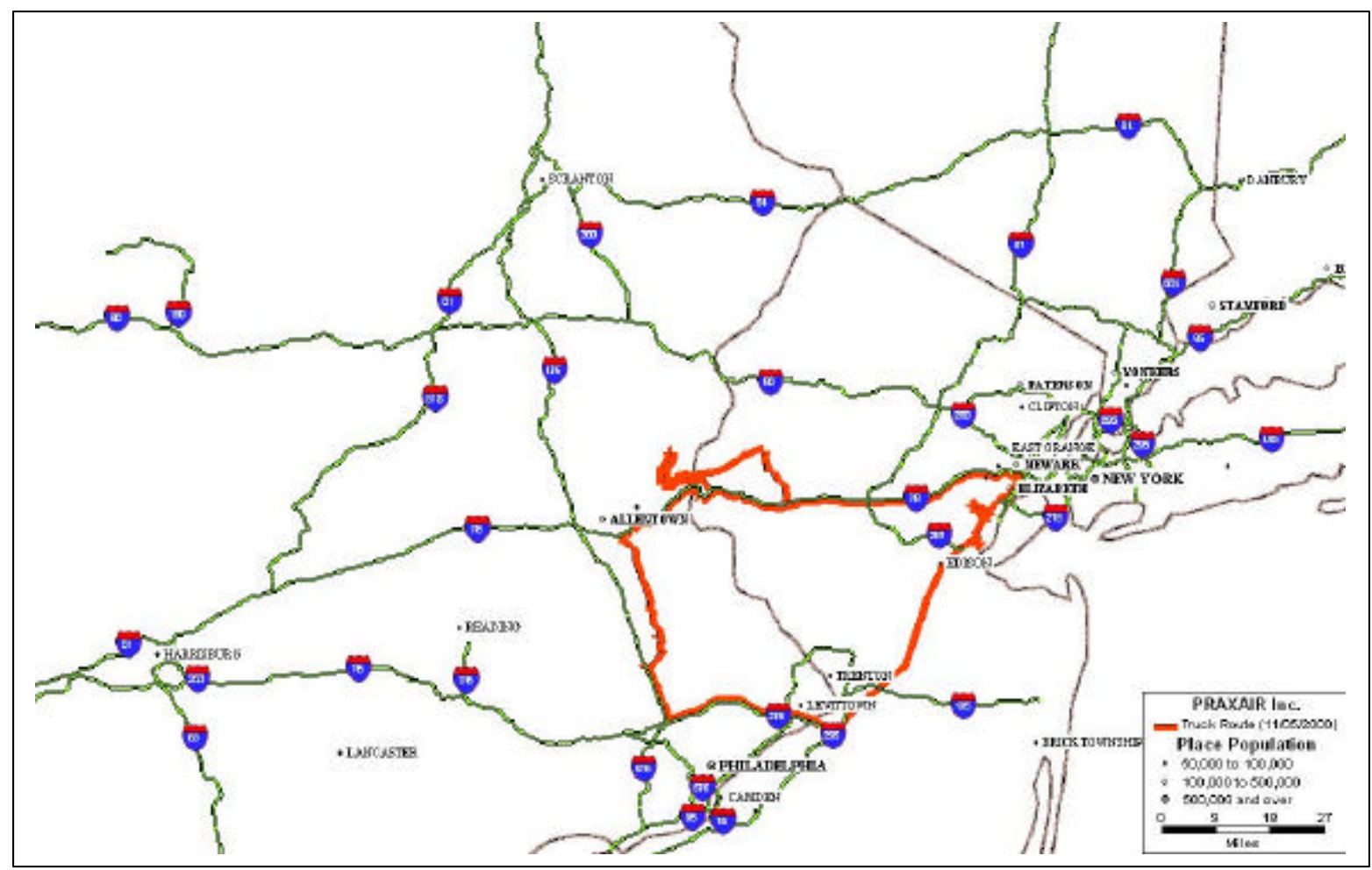

Figure 4.10. Praxair truck route on November 5, 2000.

Data collected during these five days indicated that all Praxair trucks left from Stockertown, Pennsylvania, to begin their trips. In four of the five days, these trucks returned to the same location at the end of their routes. The only exception was on November $7^{\text {th }}$. On this trip (Figure 4.12), the truck left Stockertown, traveled through Danbury, Connecticut, where the Praxair Headquarters is located, traveled back to Stockertown via a different route, and continued on to New York.

Data collection operation, from the truck-mounted equipment, appeared to be incomplete for November $8^{\text {th }}$ (see Figure 4.13). Because of the frequent stops, the speed measured from Praxair trucks showed a very different pattern from that of U.S. Xpress trucks. Figure 4.15 shows the speed changes for a Praxair truck on November 5. Recall that speed was only recorded when there was a difference of at least $2 \mathrm{MPH}$ in the measured speed. In many cases, at the locations of the truck stops, the load also changed; Figure 4.16 shows weight changes for the November 5 route. 


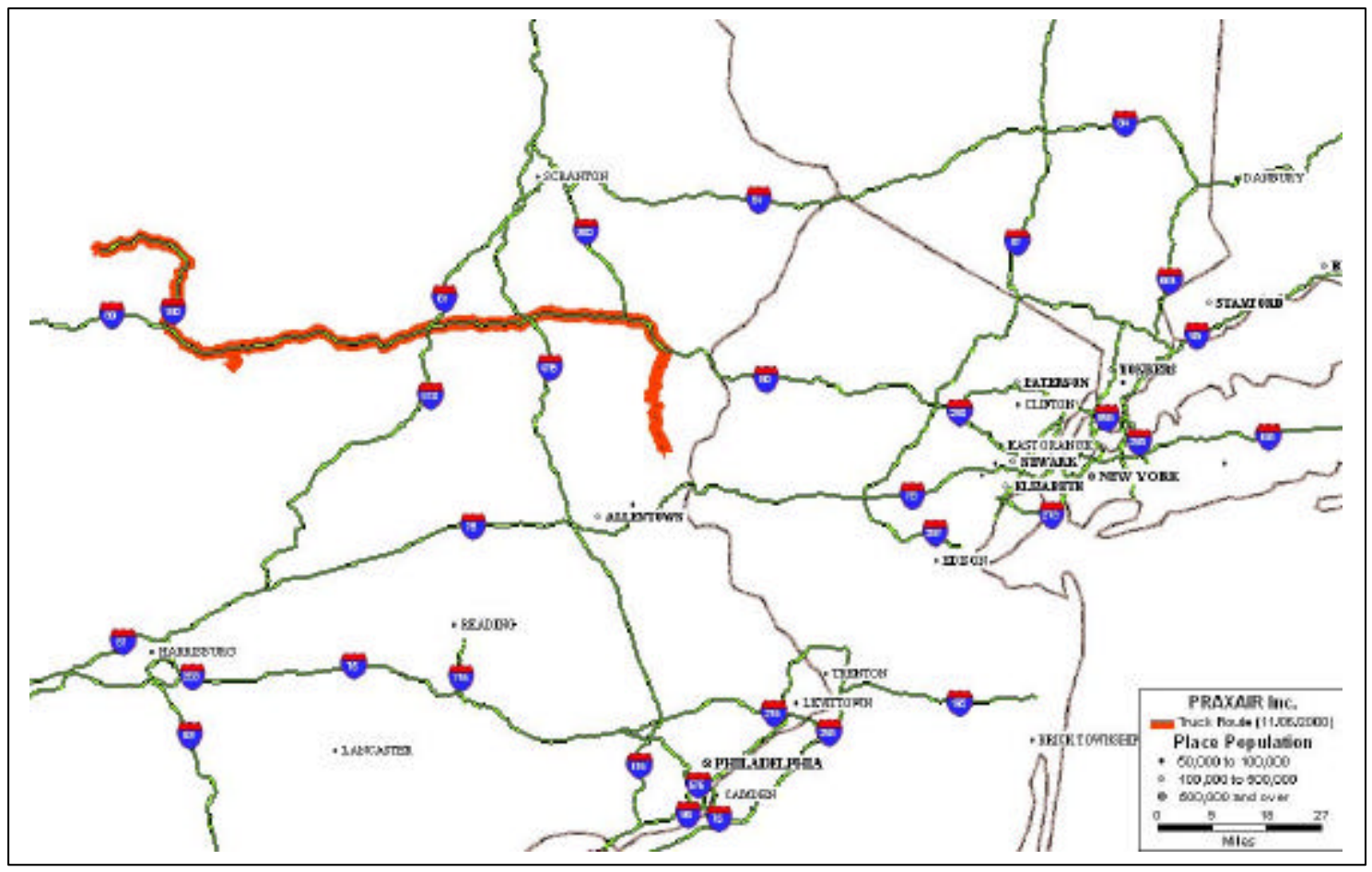

Figure 4.11. Praxair truck route on November 6, 2000.

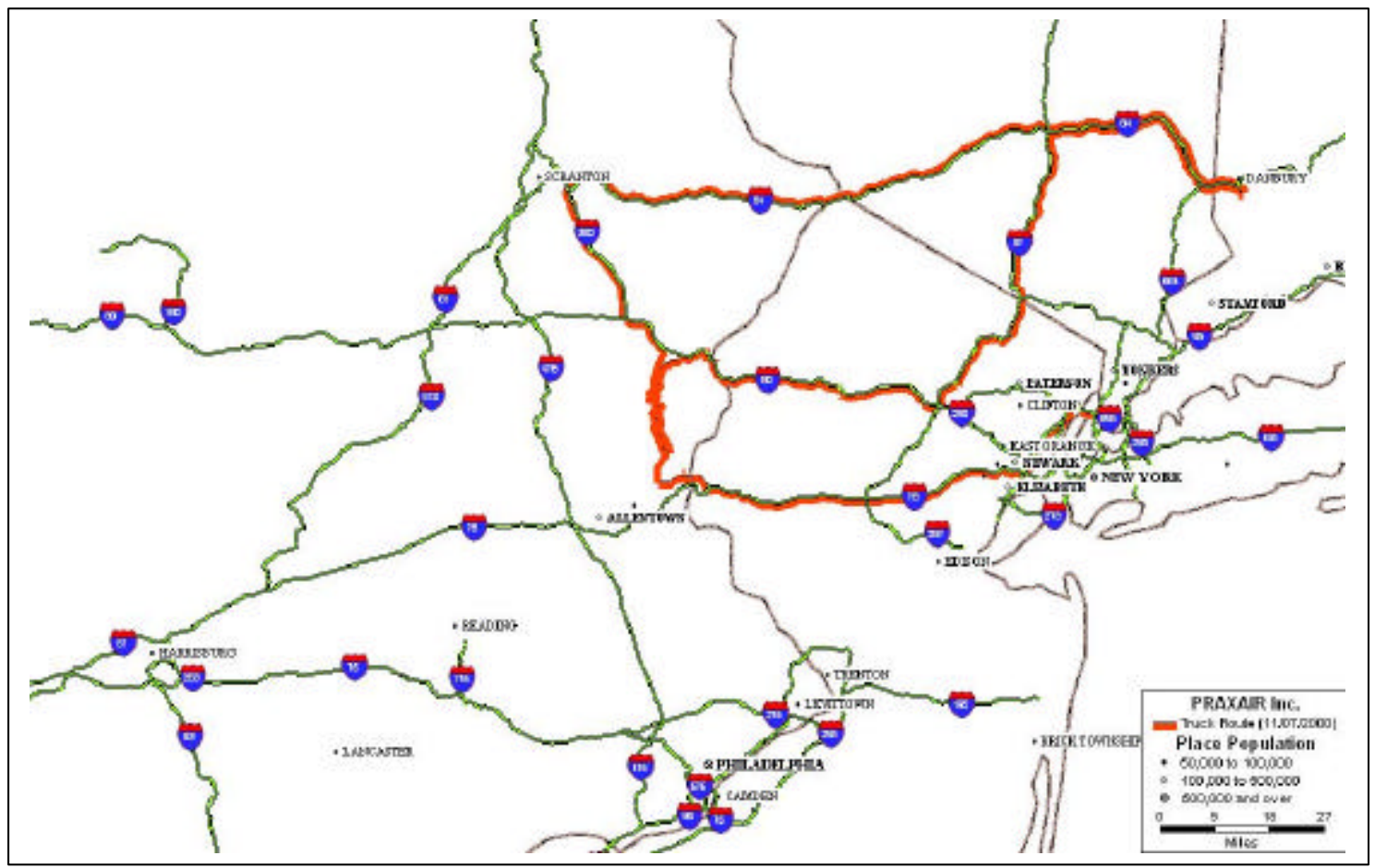

Figure 4.12. Praxair truck route on November 7, 2000. 


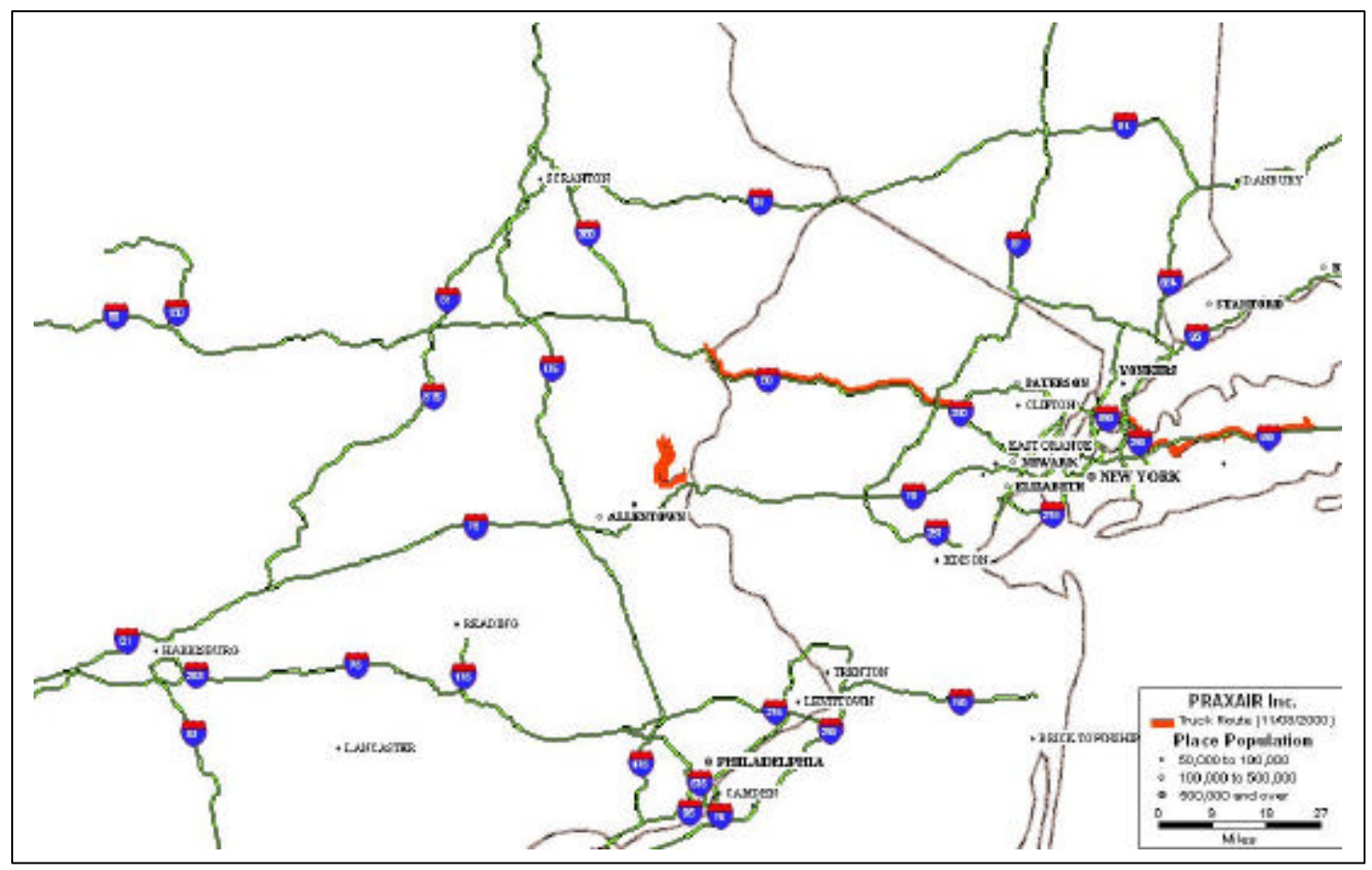

Figure 4.13. Praxair truck route on November 8, 2000.

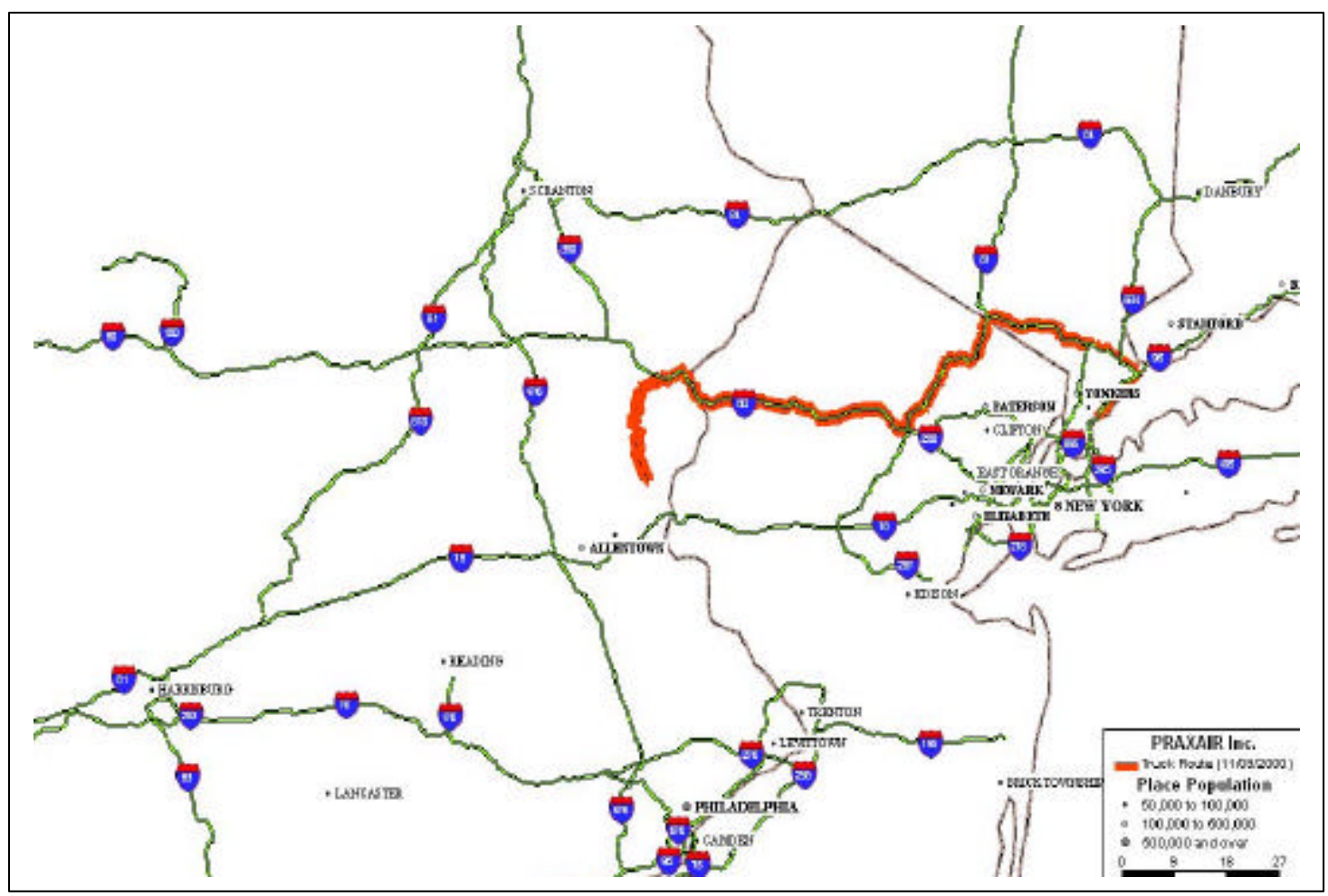

Figure 4.14. Praxair truck route on November 9, 2000. 


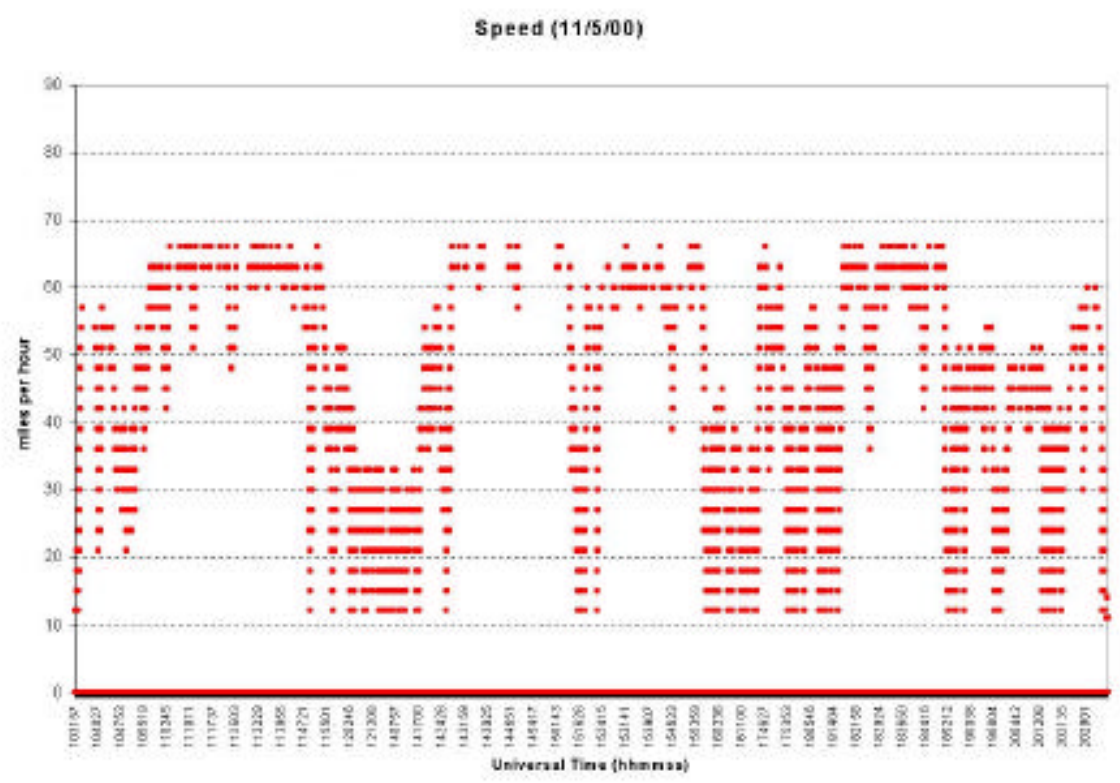

Figure 4.15. Speed measured on November 5, 2000, for a Praxair truck.

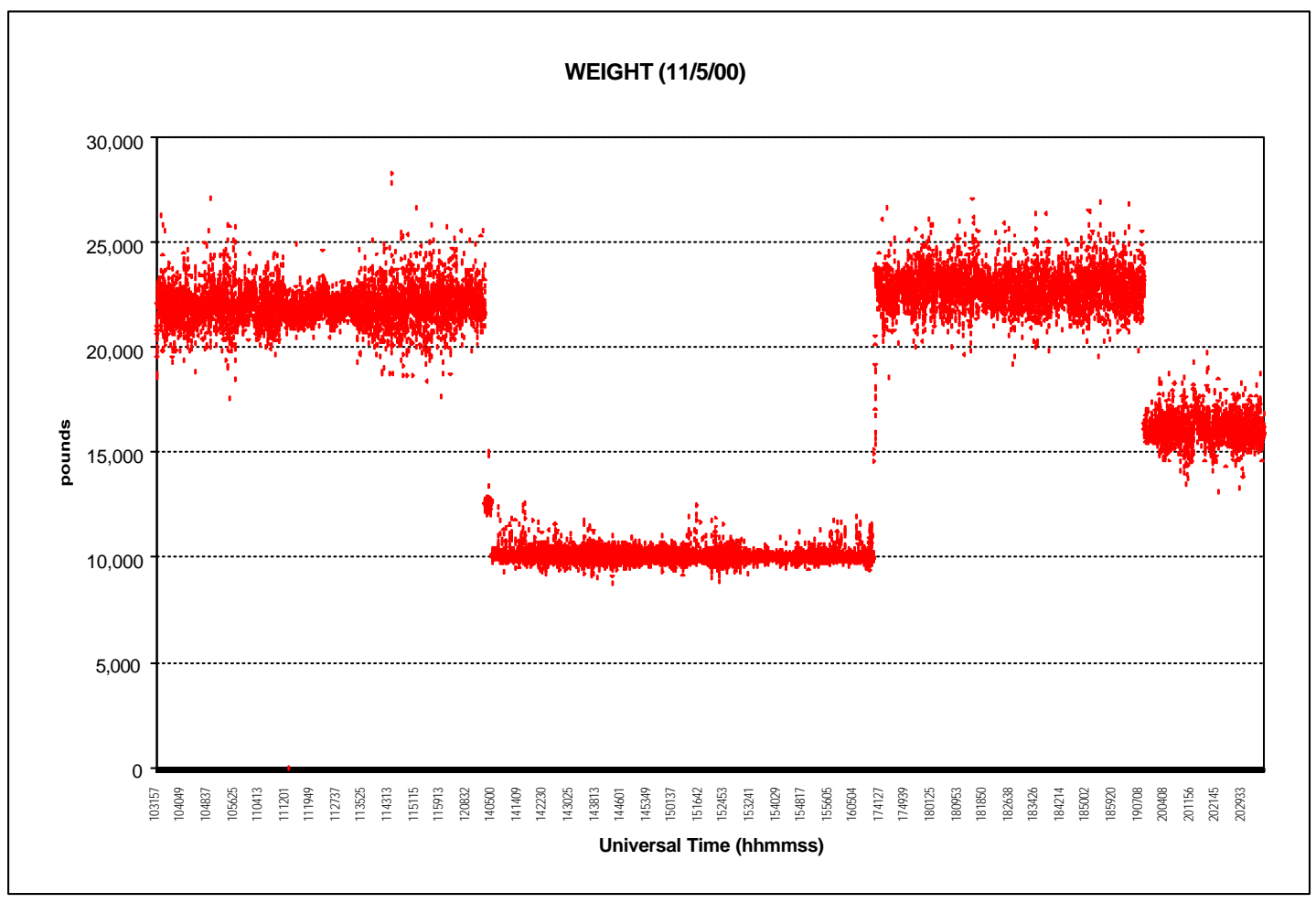

Figure 4.16. Weight measured on November 5, 2000, for a Praxair truck. 
Analysis of the Praxair lateral acceleration data produced results similar to those collected from the U.S. Xpress trucks. Figure 4.17 shows lateral acceleration for a Praxair truck on November 5. Unlike the U.S. Xpress data, the Praxair lateral acceleration measurements did not indicate any instrument shifting. In other words, no systematic bias was observed from the Praxair data. The relatively frequent stops and truck-weight changes are mainly due to the characteristics of Praxair's operation.

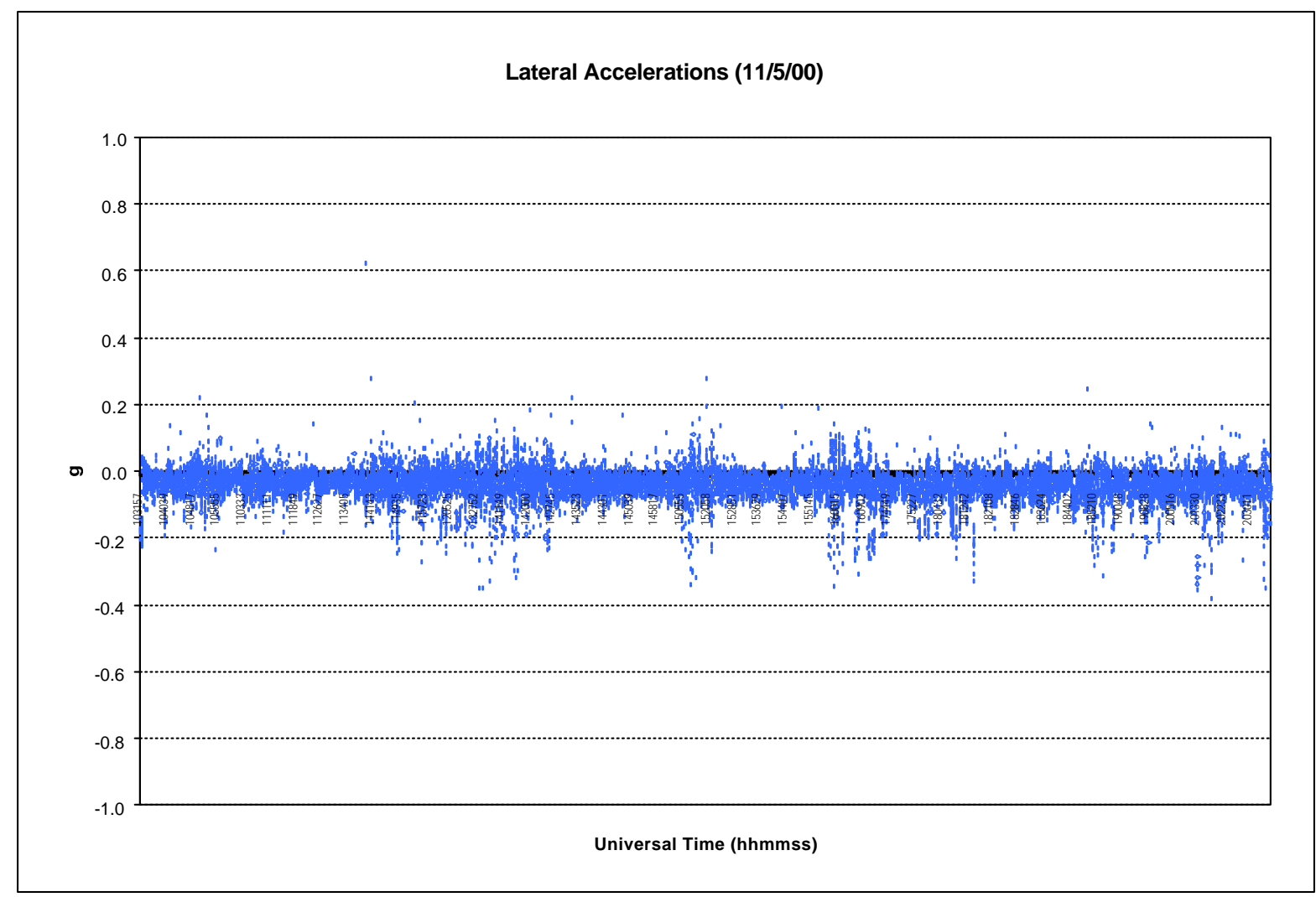

Figure 4.17. Lateral acceleration measured on November 5, 2000, for a Praxair truck.

A review of Praxair data from the January data set revealed similar patterns in the driving behavior to that of the November data. Most routes began from Stockertown, Pennsylvania, made the runs in similar regions, and then returned to Stockertown. 


\subsection{EVALUATION OF GPS DATA ACCURACY}

Originally developed by the Department of Defense (DOD) as a military system, GPS has become a global utility. It benefits users around the world in many different applications, including air, road, marine, and rail navigation, telecommunications, emergency response, oil exploration, mining, and others. In an effort to protect the security interests of the United States and its allies, a feature called Selective Availability (SA) was implemented on March 25, 1990, on all GPS Block II satellites. SA was a technique to reduce the accuracy of un-augmented, single-receiver GPS measurements. This purpose was accomplished by altering the GPS satellite clock signals, and by modifying orbital elements of the broadcast navigation message. These alterations were done in a coded fashion and could be removed by authorized users. This alteration caused horizontal positional errors on the order of 100 meters (95\%) and varied in a manner that prevented rapid averaging of positional data. ${ }^{6}$

SA was discontinued during Operation Desert Storm in September 1990 and was returned to standard level on July 1, 1991. On May 1, 2000, President Clinton announced that the United States would stop the intentional degradation of GPS signals available to the public. Therefore, beginning at midnight on May 1, 2000, the discontinuation of SA meant that civilian users of GPS were able to pinpoint locations with much more accuracy, although the total improvement might be expected to vary depending upon the particular receiver and the level of solar disturbance of the ionosphere. Effort was made by the ORNL project team to evaluate the accuracy of GPS data collected by the GPS receiver mounted on tractors participating in this project, during periods before and after May 1, 2000.

Two locations along the U.S. Xpress truck route were selected for the initial assessment. The first location was on a straight segment of I-75 around Farragut, Tennessee, and the second location was on a straight segment of I-275 at the eastern suburb of Cincinnati, Ohio. The first location had east-west traffic with three lanes in each direction and no dividing grass mall area. The second location had north-south traffic with two lanes in each direction and a 70- to 80-footwide median grass mall.

Data received from U.S. Xpress in June 2000 was selected for this preliminary investigation because it was a fairly large file which contained more "runs" along this route. As mentioned previously, U.S. Xpress GPS data do not contain information on date of data collection. A few system initialization records from the on-board system in these U.S. Xpress trucks contained date data, however, and these dates were used to approximate the GPS data collection dates. Although the data set used was received in June 2000, data on dates reflected that the data were collected prior to May 1, 2000.

\footnotetext{
${ }^{6}$ Federal Geographic Data Committee. http://www.ngs.noaa.gov/FGCS/info/sans_SA .
} 
Using a GIS tool and overlaying these GPS data with satellite images of these roadways, it appeared that GPS data collected along the first location had significantly large variations. GPS data collected at the second location, however, showed much smaller variations. To further examine the precision of the GPS system used during this study, ORNL developed an analytical methodology to quantitatively measure the degree of variations (i.e., accuracy) in these GPS data. This method is described as the following.

First, at each selected location, a line perpendicular to the highway alignment was determined. Line segments connecting two successive GPS data pairs in each truck "run," intersecting this perpendicular line, were then marked. Ten GPS data points were extracted from each of the "runs" passing the selected locations. Five were immediately prior to, and the other five were immediately after, the intersection point. Because of the time series nature of data collected from the GPS receiver, direction of travel could be easily identified and "runs" could be distinguished. There are over forty data sets, each representing a "run" passing the study site, in each travel direction at these two locations.

Next, another line parallel to the highway alignment was determined as a reference line. Distances in feet for the above-described 10 points in each data set to this reference line were calculated. The standard deviations of these distances for each data set were also calculated. These standard deviations were used to quantify variations of the truck trajectories or the "width" of the truck trajectories "band."

Based on preliminary observation, the GPS receiver used in this study did generate good "relative" longitude and latitude data series. In other words, geographic information generated by the GPS receiver produced smooth trajectories. However, significant discrepancies were visible when the truck trajectories were overlaid on the aerial photograph.

At the first location, the calculated standard deviations were 193.13 and 83.38 feet for eastbound (Figure 4.18) and west-bound (Figure 4.19), respectively, truck trajectories. On the other hand, the standard deviations were 6.85 and 9.74 feet for north- and south- bound traffic, respectively, at the second location (Figure 4.20). Assuming that truck trajectories follow the normal distribution, $95 \%$ of the truck trajectories fell within a band of two standard deviations on each side of the mean (i.e., average). This results in a width of $193.13 \mathrm{H} 4=772.52$ feet for the east-bound traffic at the first location. This band is quite wide. On the contrary, $95 \%$ of the truck trajectories for the north-bound traffic at the second location were within a band less than 28 feet wide.

To see the GPS accuracy improvement after the discontinuation of SA, data collected from U.S. Xpress trucks after May 2000 were reviewed. Due to equipment failure in U.S. Xpress trucks, unfortunately, GPS data for this time period were very limited. ORNL could only identify data for three truck "runs" from a data set received in August 2000. Nevertheless, when overlaid on a satellite image of roadways, these GPS data appeared to be right on the highway lanes (Figure 4.21). Interestingly, one can clearly see the drifting of GPS signals when they were blocked by the I-40 overpass. 


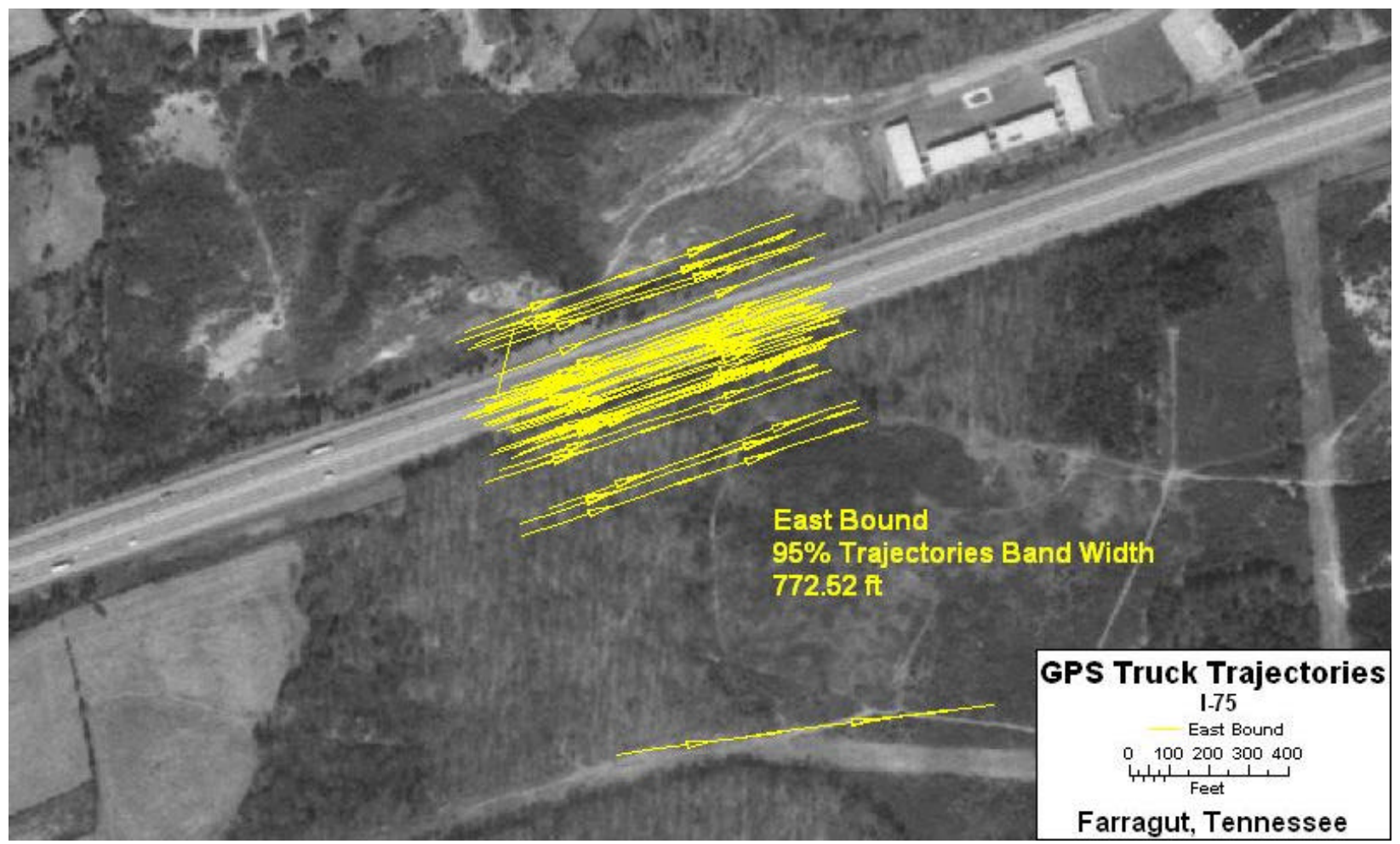

Figure 4.18. East-bound, I-75, pre-May 1, 2001, truck trajectories, measured near Knoxville, Tennessee. Note: band width $=773$ feet. 


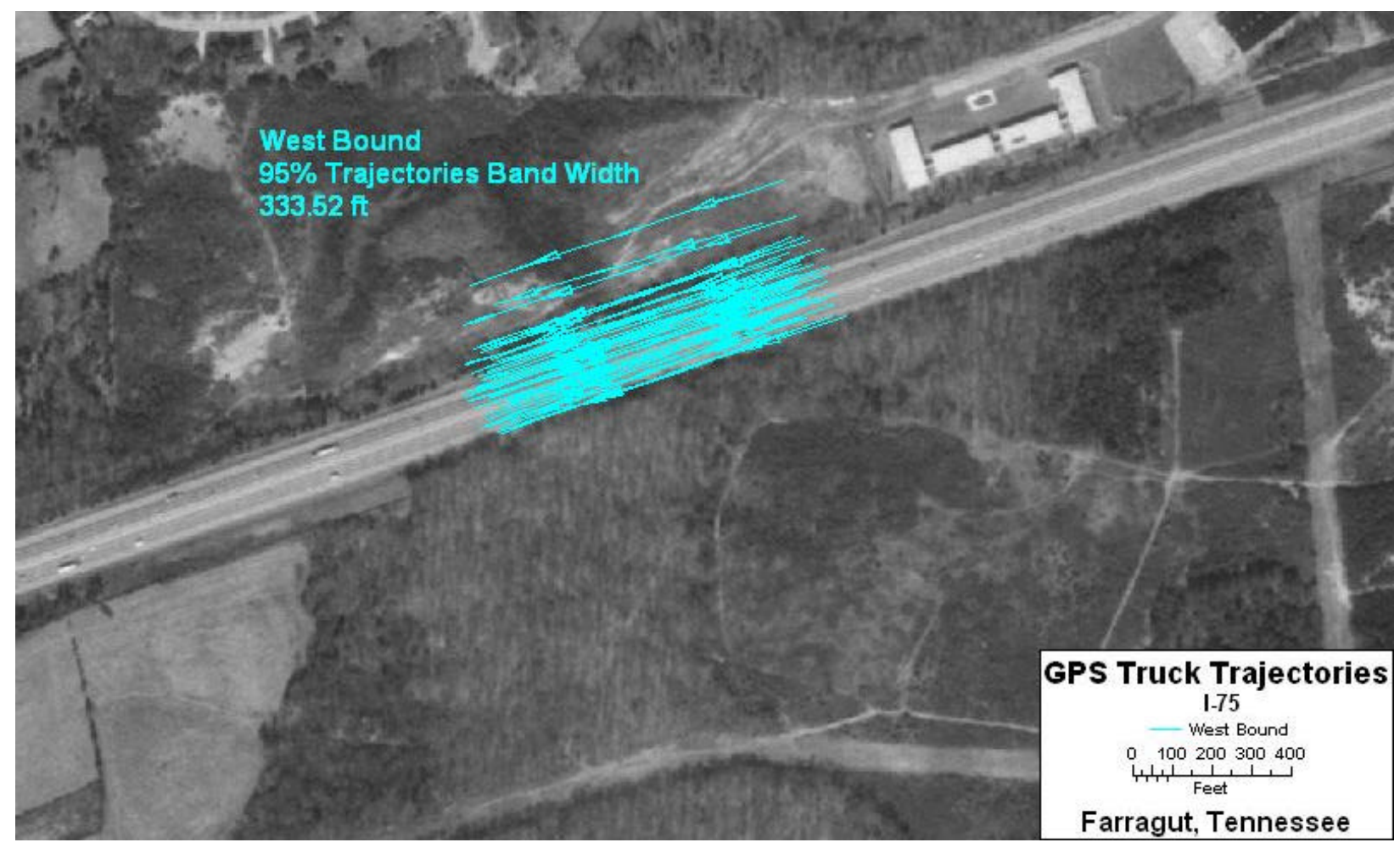

Figure 4.19. West-bound, I-75, pre-May 1, 2001, truck trajectories, measured near Knoxville, Tennessee. Note: band width $=334$ feet. 


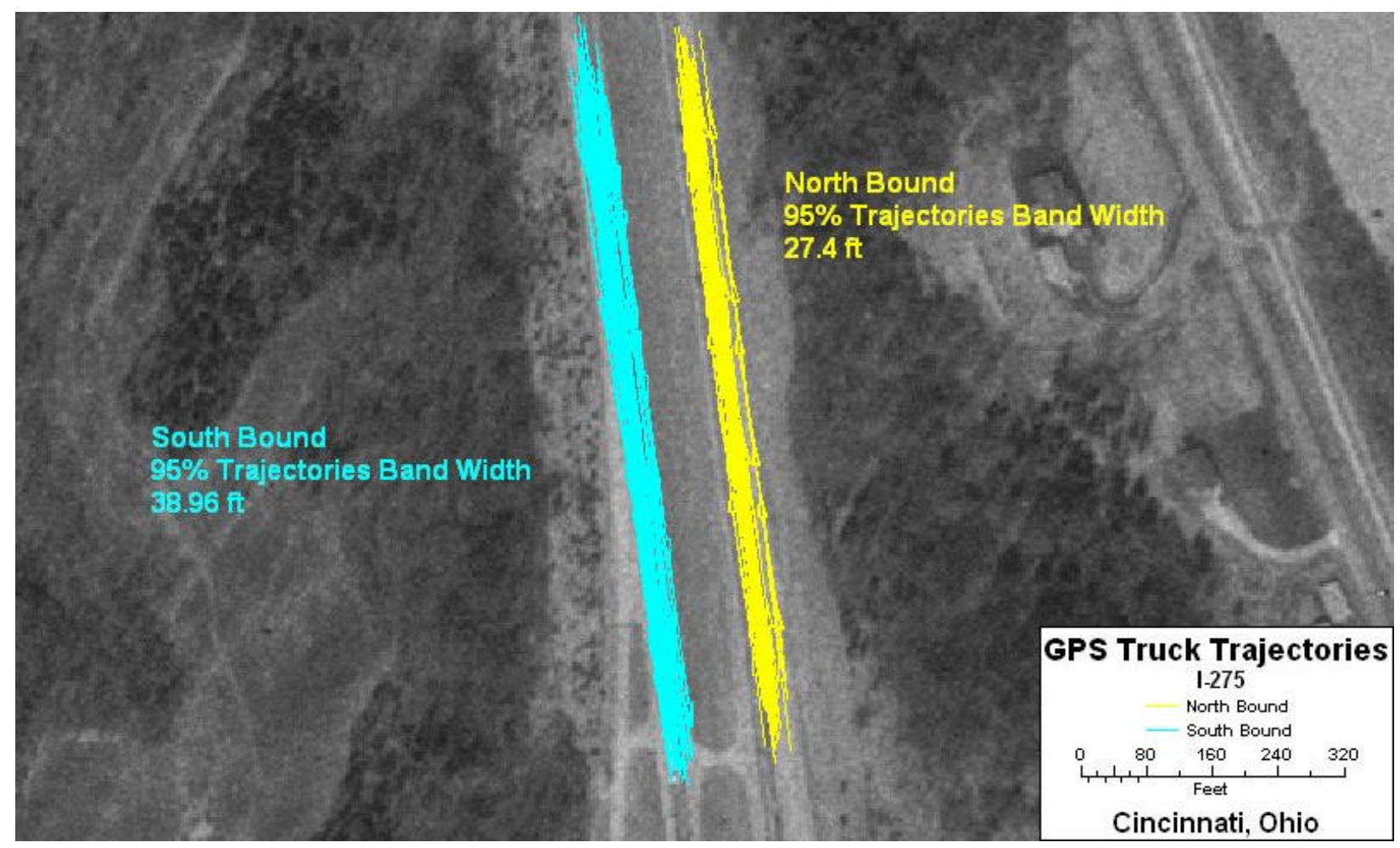

Figure 4.20. North-bound and south-bound, I-275, pre-May 1, 2001, truck trajectories measured near Cincinnati, Ohio. Note: band widths $=27$ feet (north-bound) and 39 feet (south-bound). 


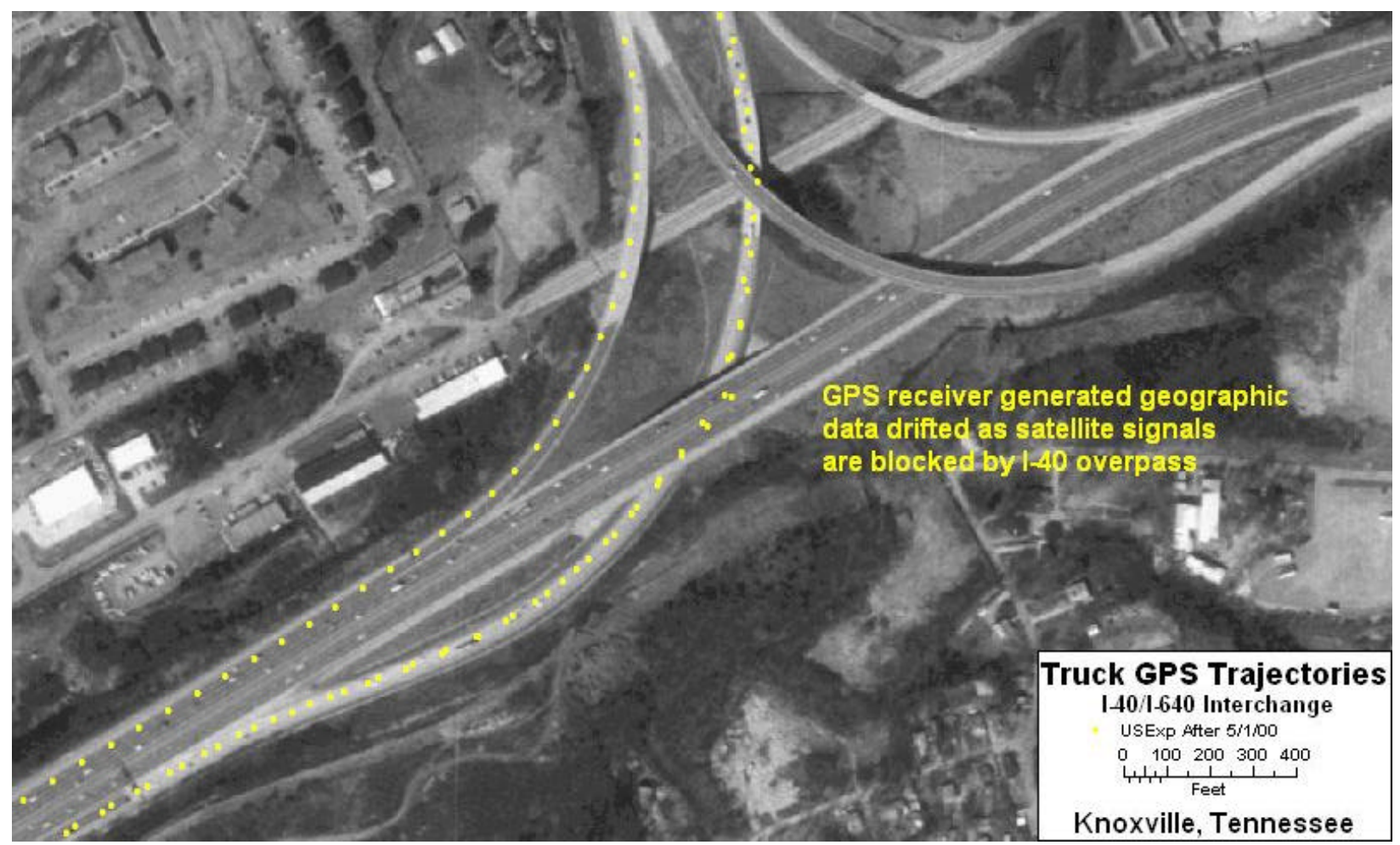

Figure 4.21. North-bound and south-bound, post May 1, 2001, truck trajectories, measured near Knoxville, Tennessee. Note the drift when signals were blocked by the overpass. 
Since there is no large set of data available from the U.S. Xpress trucks after May 2000, data from Praxair files were used to illustrate the change in GPS data accuracy. Due to the nature of Praxair's business, their trucks did not travel on a single fixed route as did the U.S. Xpress trucks. Praxair routes, generally, started from a distribution facility located near Stockertown, Pennsylvania, and returned to the same location at the end of their "runs." Therefore, to maximize the number of truck trips passing through a segment of roadway, two locations on SR33 , one on the north and the other on the south of Stockertown, were selected for this evaluation.

Using a similar method as that described earlier, it was found that standard deviations for these two locations were extremely narrow. The standard deviations were approximately 4 feet for both north-bound and south-bound trucks at the location north of Stockertown (Figure 4.22). This yields a 16-foot band in which $95 \%$ of the trajectories of trucks that pass this location (either north- or south-bound) fall. Similarly, the standard deviations for the second location, which is south of Stockertown, were 5 feet for the north-bound trucks and 6 feet for the southbound trucks (Figure 4.23). In other words, about $95 \%$ of the truck trajectories will fall within a band that is less than 25 feet wide for both travel directions at this second location.

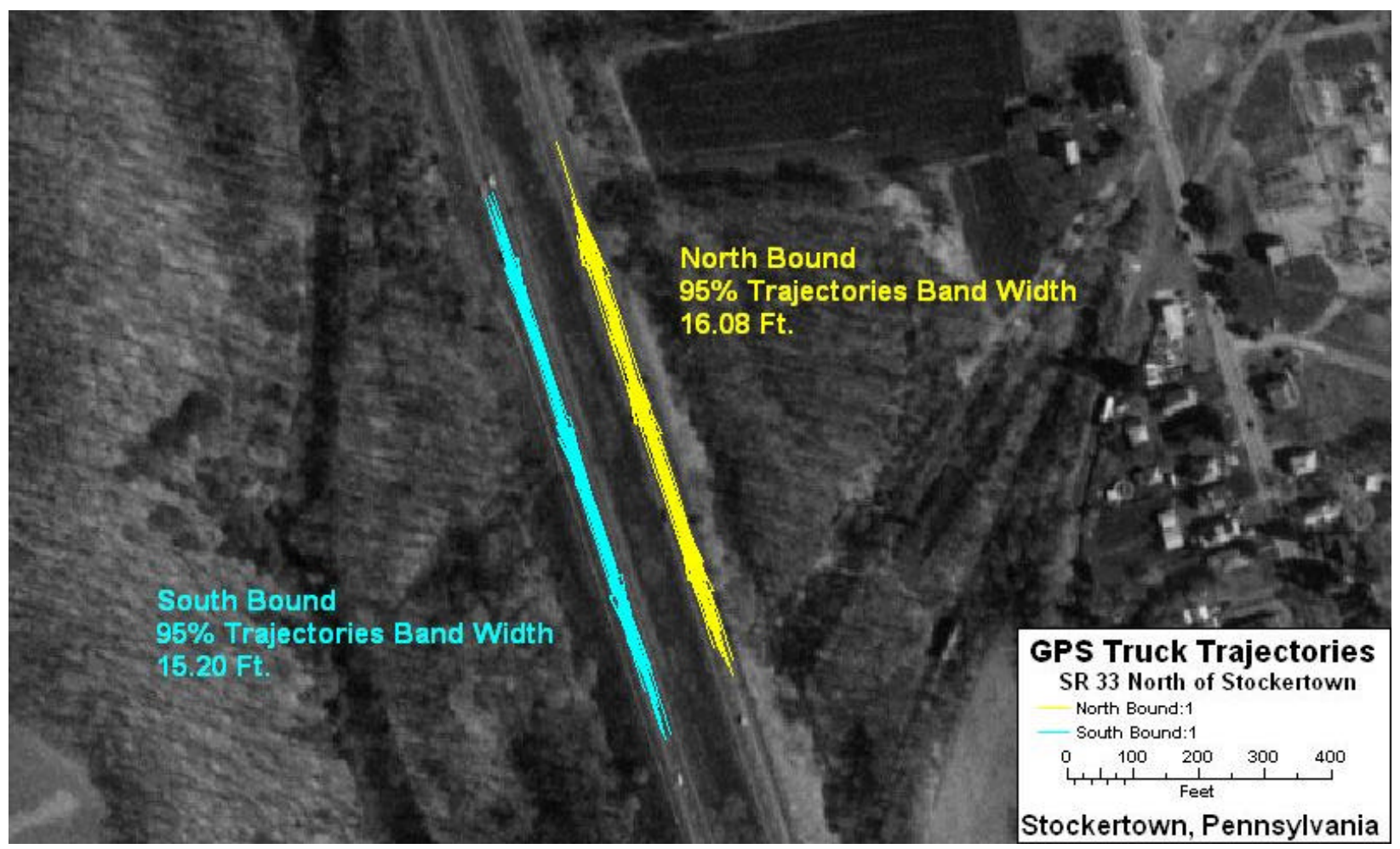

Figure 4.22. North-bound and south-bound, post May 1, 2001, truck trajectories, measured north of Stockertown, Pennsylvania. Note: band widths = 16 feet (north-bound) and 15 feet (south-bound). 


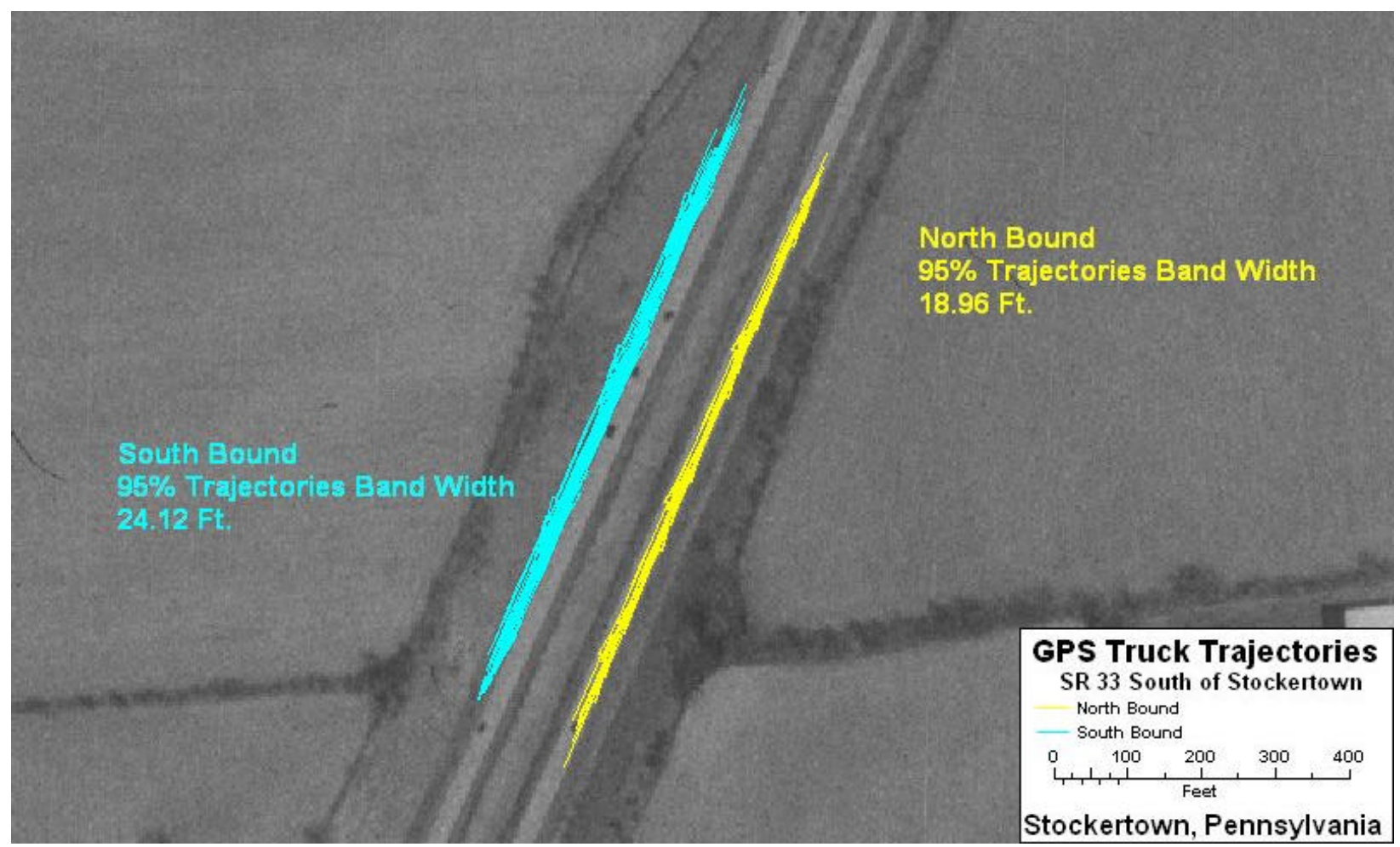

Figure 4.23. North-bound and south-bound, post May 1, 2001, truck trajectories, measured south of Stockertown, Pennsylvania. Note: band widths $=19$ feet (north-bound) and 24 feet (south-bound).

To put this in perspective, a typical highway lane has a width of 12 feet. Two lanes plus the shoulder would be about 26-28 feet. Furthermore, assuming an average travel speed of $55 \mathrm{MPH}$ on these roadways, the truck would be moving about 81 feet per second. Using these criteria as "benchmark" measurements, one can easily see that GPS data received from Praxair trucks participating in this study were quite accurate.

\subsection{ESTIMATES BASED ON THE GPS DATA}

GPS data (time and geographic location) are available from the 80+ runs logged by the U.S. Xpress vehicles. Using these data, one can mathematically estimate vehicle speed, vehicle traveling directional change (i.e., turning angle), as well as lateral and longitudinal accelerations at a given location. It is then possible to compare the estimated values with the actual recorded measurements. For simplicity, a "flat" roadway was assumed for the analysis in this section. Computer program codes written in Microsoft's Visual FoxPro to perform these calculations are included in Appendix $\mathrm{C}$ of this document. 


\subsubsection{Mathematical method to calculate turning angle}

The mathematics used to calculate the turning angles along the travel path is as follows: suppose a polyline is defined by three points $\mathrm{P}_{1}, \mathrm{P}_{2}$, and $\mathrm{P}_{3}$ in a two-dimension Euclidian plane. The objective is to find the angle, 2 , between lines $\mathrm{P}_{2} \mathrm{P}_{1}$ and $\mathrm{P}_{2} \mathrm{P}_{3}$. Assume the coordinates of these three points are $\left(\mathrm{x}_{1}, \mathrm{y}_{1}\right),\left(\mathrm{x}_{2}, \mathrm{y}_{2}\right)$, and $\left(\mathrm{x}_{3}, \mathrm{y}_{3}\right)$ for $\mathrm{P}_{1}, \mathrm{P}_{2}$, and $\mathrm{P}_{3}$, respectively.

Then, the angle 2 can be calculated as:

or

$$
2=2_{2}-2_{1} \text {, if } 2_{2} \$ 2_{1}
$$

$$
2=2_{2}-2_{1}+360^{\circ} \text {, otherwise, }
$$

where $2_{1}$ is the angle between line $\mathrm{P}_{2} \mathrm{P}_{1}$ and the line passed through $\mathrm{P}_{2}$ and parallel to the $\mathrm{X}$-axis, and $\mathrm{Z}_{2}$ is the angle between line $\mathrm{P}_{2} \mathrm{P}_{3}$ and the line passed through $\mathrm{P}_{3}$ and parallel to the $\mathrm{X}$-axis.

These two angles, $2_{1}$ and $2_{2}$, can be mathematically expressed as:

$$
\begin{aligned}
& \left.\mathrm{Z}_{1}=\operatorname{ArcCosine}\left[\left(\mathrm{x}_{2}-\mathrm{x}_{1}\right) /\left(\left(\mathrm{x}_{2}-\mathrm{x}_{1}\right)^{2}+\left(\mathrm{y}_{2}-\mathrm{y}_{1}\right)^{2}\right)\right)^{0.5}\right], \text { if } \mathrm{P}_{1} \text { is in the first or second quadrant, } \\
& \left.\mathrm{Z}_{1}=180^{\circ}-\operatorname{ArcSine}\left[\left(\mathrm{y}_{2}-\mathrm{y}_{1}\right) /\left(\left(\mathrm{x}_{2}-\mathrm{x}_{1}\right)^{2}+\left(\mathrm{y}_{2}-\mathrm{y}_{1}\right)^{2}\right)\right)^{0.5}\right], \text { if } \mathrm{P}_{1} \text { is in the third quadrant, } \\
& \left.\mathrm{Z}_{1}=360^{\circ}+\operatorname{ArcSine}\left[\left(\mathrm{y}_{2}-\mathrm{y}_{1}\right) /\left(\left(\mathrm{x}_{2}-\mathrm{x}_{1}\right)^{2}+\left(\mathrm{y}_{2}-\mathrm{y}_{1}\right)^{2}\right)\right)^{0.5}\right], \text { if } \mathrm{P}_{1} \text { is in the fourth quadrant; }
\end{aligned}
$$

and

$$
\begin{aligned}
& \left.\mathrm{Z}_{2}=\operatorname{ArcCosine}\left[\left(\mathrm{x}_{2}-\mathrm{x}_{3}\right) /\left(\left(\mathrm{x}_{2}-\mathrm{x}_{3}\right)^{2}+\left(\mathrm{y}_{2}-\mathrm{y}_{3}\right)^{2}\right)\right)^{0.5}\right], \text { if } \mathrm{P}_{3} \text { is in the first or second quadrant, } \\
& \left.\mathrm{Z}_{2}=180^{\circ}-\operatorname{ArcSine}\left[\left(\mathrm{y}_{2}-\mathrm{y}_{3}\right) /\left(\left(\mathrm{x}_{2}-\mathrm{x}_{3}\right)^{2}+\left(\mathrm{y}_{2}-\mathrm{y}_{3}\right)^{2}\right)\right)^{0.5}\right], \text { if } \mathrm{P}_{3} \text { is in the third quadrant, } \\
& \left.\mathrm{Z}_{2}=360^{\circ}+\operatorname{ArcSine}\left[\left(\mathrm{y}_{2}-\mathrm{y}_{3}\right) /\left(\left(\mathrm{x}_{2}-\mathrm{x}_{3}\right)^{2}+\left(\mathrm{y}_{2}-\mathrm{y}_{3}\right)^{2}\right)\right)^{0.5}\right], \text { if } \mathrm{P}_{3} \text { is in the fourth quadrant. }
\end{aligned}
$$

\subsubsection{Estimate of speed}

The on-board equipment also collects truck operating speed information. Truck speed is recorded only if it changes by $2 \mathrm{MPH}$ from the previously recorded speed. This preserves the general pattern of the truck travel speed but provides less detailed information on speed variations. The message recorded from the on-board GPS unit contains the geographic location of the truck, and of course, the precise time. Based on these data, ORNL was able to calculate truck operating speed for each GPS data point. The GPS receiver also performs such a calculation, but it is not included in the currently-programmed message.

Suppose $\mathrm{P}_{\mathrm{n}-1}$ and $\mathrm{P}_{\mathrm{n}}$ are two consecutive GPS data points with associated time stamps $\mathrm{T}_{\mathrm{n}-1}$ and $T_{n}$, respectively. The speed of a truck at location $P_{n}$ can be calculation as 
Speed at location $P_{n}=\left(\right.$ distance between $P_{n-1}$ and $\left.P_{n}\right) /\left(\right.$ travel time between $P_{n-1}$ and $\left.P_{n}\right)$.

Great circle distance between the two points was calculated based on their coordinates of latitude and longitude. Travel time was the difference between $T_{n-1}$ and $T_{n}$, or $T_{n}-T_{n-1}$ in seconds. The result was then converted to the unit of miles per hour.

\subsubsection{Calculation of lateral and longitudinal accelerations}

Using the methods described in Sections 4.7.1 and 4.7.2, travel speed and the related turning angle at each GPS data point location was calculated. Using these estimates, ORNL then mathematically computed the longitudinal and lateral accelerations in term of $g$ (i.e., acceleration of one earth gravity).

Let $\mathrm{P}_{\mathrm{n}-1}, \mathrm{P}_{\mathrm{n}}$ and $\mathrm{P}_{\mathrm{n}+1}$ be three consecutive GPS data points and angle 2 be the angle between lines $\mathrm{P}_{n} \mathrm{P}_{n-1}$ and $\mathrm{P}_{n} \mathrm{P}_{n+1}$. Suppose $\mathrm{S}_{\mathrm{n}}$ and $\mathrm{S}_{\mathrm{n}+1}$ are the speeds at $\mathrm{P}_{\mathrm{n}}$ and $\mathrm{P}_{\mathrm{n}+1}$, respectively. Then the longitudinal and lateral accelerations can be calculated as

Longitudinal Acceleration $=S_{n+1} H \sin \left(2_{n}\right)-S_{n}$, per unit time (i.e., $1 \mathrm{sec}$ ), and Lateral Acceleration $\quad=\mathrm{S}_{\mathrm{n}+1} \mathrm{H} \cos \left(2_{\mathrm{n}}\right)$, per unit time,

where $Z_{\mathrm{n}}=2-90 \mathrm{E}$ if $Z_{\mathrm{n}}<90 \mathrm{E}$, or $Z_{\mathrm{n}}=270 \mathrm{E}+2$, otherwise .

Comparisons of the estimated and recorded lateral acceleration measurements were evaluated for four specific cases selected from the U.S. Xpress travel route. All four cases include locations with relatively sharp roadway curves. Results from this effort are presented in Appendix E.

Note that the instrument on the truck does not record elevation information at this time. The accelerations calculated from the above-mentioned formulas represent the accelerations of the truck when traveling on a flat surface. By comparing these estimated accelerations to those actual measurements of accelerations from the on-board accelerometer, it is possible to estimate pavement features such as super-elevation and the grades of vertical incline and decline. Collection and analysis of this sort of data is a straightforward extension of the collection and analysis presented here. 


\section{Equipment Evaluation}

A guiding concept for this project has been to test and evaluate the system components under realistic conditions, on vehicles in revenue service. That concept implies that the primary purpose of the vehicles is to generate revenue - make money - for their operators, and that collection of data is only an important secondary purpose. One consequence of that priority has been that the vehicles are occasionally unavailable for data download or equipment inspection.

In addition, the conditions of U.S. Xpress revenue service often led to situations where instrumented tractors were not connected to instrumented trailers in spite of good intentions of dispatchers and schedulers. It was intended that the U. S. Xpress vehicles be dedicated to a particular customer who hauls freight between a terminal in Ohio and a terminal in Georgia on a regular basis. Under such circumstances, the six instrumented trailers could in principle be swapped among the three instrumented tractors and almost always be connected to allow trailer data collection. It took quite a while to persuade the yard operators that this connection of instrumented tractor and trailer mattered; therefore, in the early days of the project, the instrumented trailers were somewhere else most of the time. On the contrary, Praxair had no such problem. The Praxair tractor for this test was also a special vehicle, and the tractor and trailer stayed together except for brief maintenance periods.

Trailer-to-tractor communication remains a problem, though there is evidence that the industry is addressing it. One version of multiplexing data onto power leads for the trailer is receiving widespread testing, and dedicated short range radio frequency technology also has advocates. Fiber optics appears to have a number of significant advantages such as ample bandwidth and RFI immunity, but at least for this project, it had connector weaknesses that outweighed the advantages. For fleets that routinely use whatever tractor is available to pull whatever trailer is loaded and ready to go, connecting and disconnecting is a fact of life subject to all the rigors of the over-the-road environment. When the data communication problem is "solved," estimation of as-loaded roll stability will be an attractive value-added feature.

Because of the problems experienced with the tractor-trailer communications, there is some rationale for positioning instrumentation only in the tractor. The interesting possibility of sensing trailer stability from tractor-based instruments is intriguing, but remains a challenging researchand-development effort as far as we know. There were promising preliminary results at UMTRI, ${ }^{7}$ but there are no published reports of a subsequent study at this time.

The connector problems of fiber optics should be less severe for tractor-trailer combinations that stay coupled, as our Praxair vehicle did. However, another sort of connector problem plagued the Praxiar data collection efforts. Board connections internal to the on-board computer and/or port connections on attached devices appear to have been the cause(s) of the serious problem of intermittent data logging. Such connection problems are already being attacked by vendors; the

\footnotetext{
${ }^{7}$ Private communication from C. B. Winkler, 9 November 2000.
} 
simple expedient of integrating functions onto the main computer board can make computers sufficiently reliable. The ability to know a vehicle's location precisely is valuable for many reasons, and GPS receiver functions can certainly be integrated into vehicle computers as the marketplace develops.

One additional problem occurred with the U.S. Xpress trucks after several months of data collection. In November 2000, the on-board computer "crashed." Although a final diagnosis of the cause of the failure is not known at this time, it is possible that the operating system (Windows 98) was affected by the shut-down procedures. Because the computer on-off switch was connected to the ignition switch, the shut-down procedures were not "graceful."

In summary, although equipment problems occurred for both trucking partners, the problems are being addressed, and it appears that the issues can be resolved. 


\section{Evaluation OF THE ACCURACY AND TIMELINESS OF THE DATA}

GPS data can now provide real-time vehicle position and can be used to support driver warning, although this was not the case during the entire project. The detailed analysis given in Section 4.6 shows that the original GPS data from U. S. Xpress trucks, collected almost entirely before SA was turned off, were not always precise enough to support driver warning. Data collected near Knoxville, Tennessee, showed a standard deviation of hundreds of feet. A truck traveling at 81 feet per second travels slightly over 400 feet in 5 seconds. Five seconds of advance warning is a time interval of the order of magnitude that one might want to give a driver, in order to allow the driver to recognize the warning and take appropriate action. Failure to measure location/timeto-hazard with enough precision would make it difficult to avoid both false-negative and falsepositive errors.

However, even before SA was stopped, it was possible to collect "good" GPS data. GPS data collected near Cincinnati, Ohio, by U.S. Xpress trucks during the same period show a standard deviation of only a few feet. The U.S. Coast Guard broadcasts differential corrections that allow ships to correct GPS receptions for various errors, including SA. ${ }^{8}$ These Coast Guard corrections cover the U. S. Coasts and the Mississippi and Ohio River valleys. Cincinnati is within range of these broadcasts, and Knoxville is not.

Fortunately for prospective civilian users of GPS location equipment, the deliberate errors of SA have gone away. The available precision of the GPS is illustrated by recent data collected by Praxair, which show a standard deviation of less than five feet. Clearly, such precision can support determination of a vehicle's proximity to a sharp curve. Likewise, in combination with the trucks' on-board measurements of lateral acceleration, such measurements can determine with precision those highway locations where vehicles are routinely subjected to forces that could overturn them. Indeed, with that sort of precision, it becomes feasible to infer the lane of travel on a multilane highway, information that could be useful in estimating the likelihood that a vehicle will indeed take an approaching exit ramp.

This project originally included plans to use signals from beacons to provide precise reference distance to a critical portion of a hazardous curve. However, roadside beacon technology is relatively expensive and somewhat inconvenient to use and maintain. Now that GPS has sufficient precision to determine a vehicle's proximity to an upcoming sharp curve, it is no longer useful or necessary to employ any auxiliary information from, for instance, the timing of signals from roadside beacons. A map database can contain precise locations of sharp curves and their lateral acceleration demands, and an approaching vehicle can determine how far away the curve is. With knowledge of the vehicle's speed, acceleration, and roll stability, an on-board computer can project the speed in the turn and can warn the driver if action is required. Beacons perhaps are still useful for transient hazards like weather and traffic/work-zones, but fixed hazards such as sharp curves need not be identified by expensive roadside hardware.

${ }^{8}$ U.S. Coast Guard, http://www.uscg.mil/hq/g_cp/comrel/factfile/Factcards/DGPS.html . 
As discussed above, the instrumentation can generate the required "bad-curve" database. Based on the limited data analyzed so far, it appears that measured lateral acceleration and weight transfer are reasonable and correlated, and that they can be related to road speed and location.

That combination of data could be stored in a database for use by other drivers. As an alternative to collection of a great deal of truck data, the required data (with required precision and accuracy) could easily be collected by special vehicles with accurate speed sensors. If no mapping industry leader steps forward, the data collection could be accomplished by trucking companies themselves following the procedures of this project.

Trailer data also appear to be useful for rollover risk estimation. Instrument drift and temperature dependence apparently can be estimated and compensated, but a periodic calibration check would give more confidence. Significant engineering remains before such systems are robust enough for the rigors of over-the-road trucking, but we have demonstrated that such a system could give drivers advance warning of potential rollover. 


\section{CONCLUSions}

Using data collected by U.S. Xpress and Praxair from trucks in revenue service, ORNL analyzed the data and evaluated the data collection equipment. ORNL received ten data files between June 2000 and late January 2001. Procedures were established for transferring the data to ORNL, loading it into appropriate databases, and performing the analyses using a GIS tool.

Trailer-to-tractor communication remains a problem; however, the solution to this problem is certainly forthcoming.

Trailer data can be used to indicate truck roll stability. Instrument drift and temperature dependence apparently can be estimated and compensated for, but a periodic calibration check would give more confidence.

The data collected by the truck-trailer instrumentation can generate a "bad-curve" database. Based on the limited data analyzed so far, it appears that measured lateral acceleration and weight transfer are reasonable and correlated, and that they can be related to road speed and location. That combination of data could be stored in a database for use by other drivers.

The data analysis indicates that GPS data are extremely accurate. Analysis also indicates that the data collected by the truck and the trailer can be used effectively to provide a warning system for drivers. 


\section{REFERENCES}

Bate, John. May 8, 2000. SDL: Stability Data Logger, Version 1.1.20.

Cate, Matthew Alan. August 2000. "Development of a System to Prioritize Sites for the Installation of Automated Truck Rollover Warning Systems in Tennessee," a thesis prepared for the University of Tennessee, Knoxville, Tennessee.

Federal Geographic Data Committee. http://www.ngs.noaa.gov/FGCS/info/sans_SA/.

National Highway Traffic Safety Administration. Various years. "Traffic Safety Facts," http://www.nhtsa.dot.gov/people/ncsa/factshet.html and http://www.nhtsa.dot.gov/people/ncsa/factprev.html\#1996 .

National Highway Traffic Safety Administration. October 1999. Traffic Safety Facts 1998: A Compilation of Motor Vehicle Crash Data from the Fatality Analysis Reporting System and the General Estimates System, http://www.nhtsa.dot.gov/people/ncsa/tsf-1998.pdf .

National Highway Traffic Safety Administration. FARS on-line query system, http://wwwfars.nhtsa.dot.gov/www/query.html .

U.S. Coast Guard, http://www.uscg.mil/hq/g_cp/comrel/factfile/Factcards/DGPS.html .

Winkler, C. B., P. Fancher, R. Ervin. 1999. "Intelligent Systems for Aiding the Truck Driver in Vehicle Control." University of Michigan, Transportation Research Institute, Ann Arbor, Mich. IV Vehicle Navigation Systems and Advanced Controls (SAE-SP-1428).

Warrendale, SAE, 1999, pp. 165-178. Report No. SAE 1999-01-1301. 


\section{APPENDIX A}

SDL:

STABILITY DATA LOGGER 


\section{SDL \\ Stability Data Logger \\ Version 1.1.20 \\ $5 / 08 / 00$ \\ John Bate}

This document describes the overall operation of the SDL program. It is written in VB 6.0. Its main purpose is to accept GPS (Global Positioning System) data, J1708 (truck data bus) data, and Trailer instrumentation data (from stress and strain gauges attached on the trailer).

For DEMO MODE:

1. "Demo Display" is shown on the Startup and Graphs screens.

2. The G forces and weight of the trailer is listed as "uncalibrated"

3. The VORAD Collision Warning is just text.

4. The data shown on the debug display is real.

5. To prevent distracting the driver the system screen saver was set to blank after 1 minute. The system is still operating and data can still be collected.

\section{The Startup Screen}

The first screen seen when starting up the application includes real time display of the $\mathrm{G}$ forces and weight of the truck. 


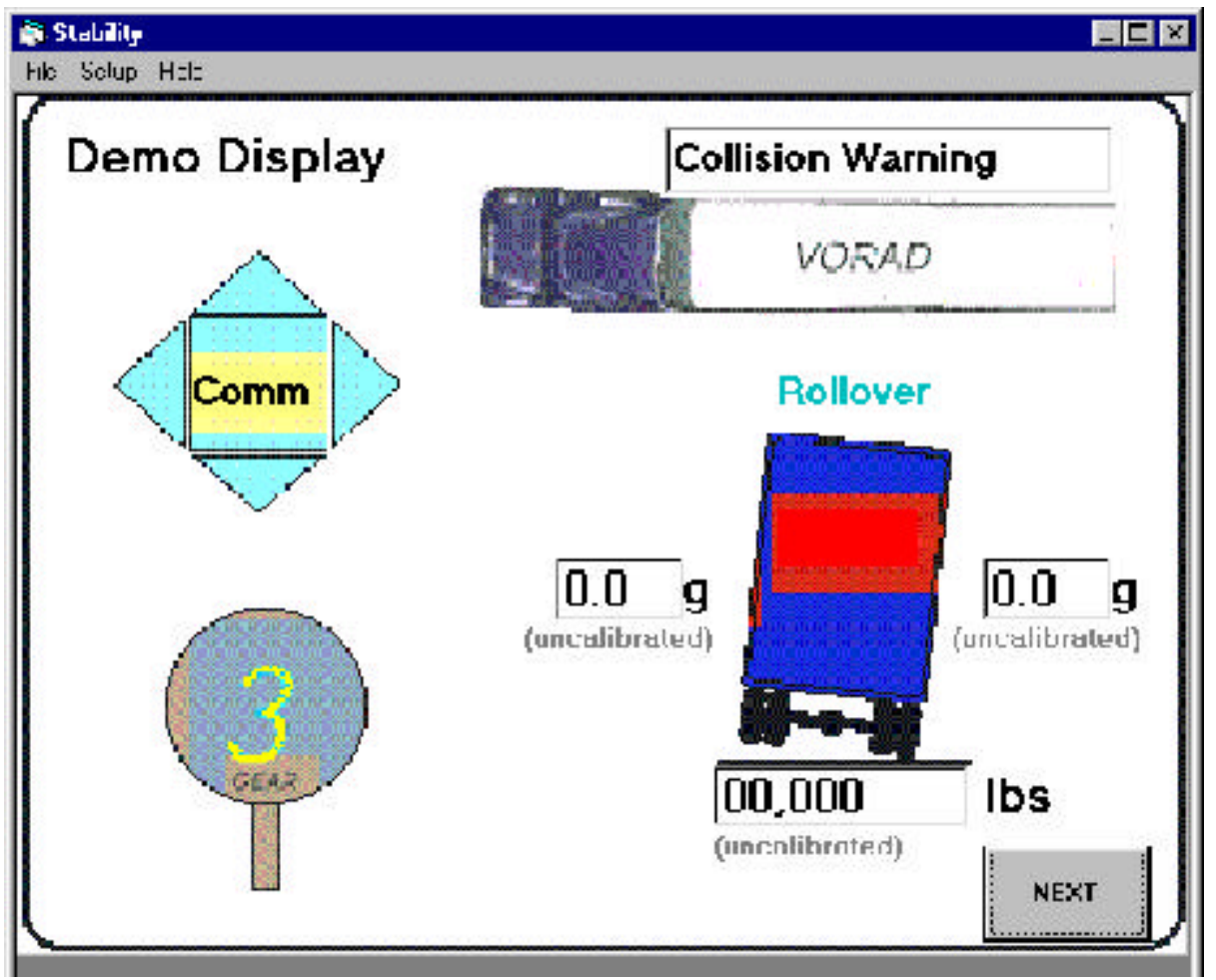

Figure 1. Startup Screen

The "NEXT" button switches to the debug screen.

\section{Monitor Screen}

The next screen is shown in Fig. 2. The "Data Monitor Enables" frame is 8 text boxes used when debugging the data collection hardware. It displays data as seen by the RODL after data filtering has taken place. The three check boxes control the display of that particular data in the text boxes. The checkboxes do not control the logging of the data, only the display. Any data destined for the log file will be displayed here. If all check boxes are unchecked then the display will not update. Typical operation will be to enable one checkbox, view the data, decide on what data is wanted in that group, then set the filters accordingly (in the Setup dialog boxes described later. 


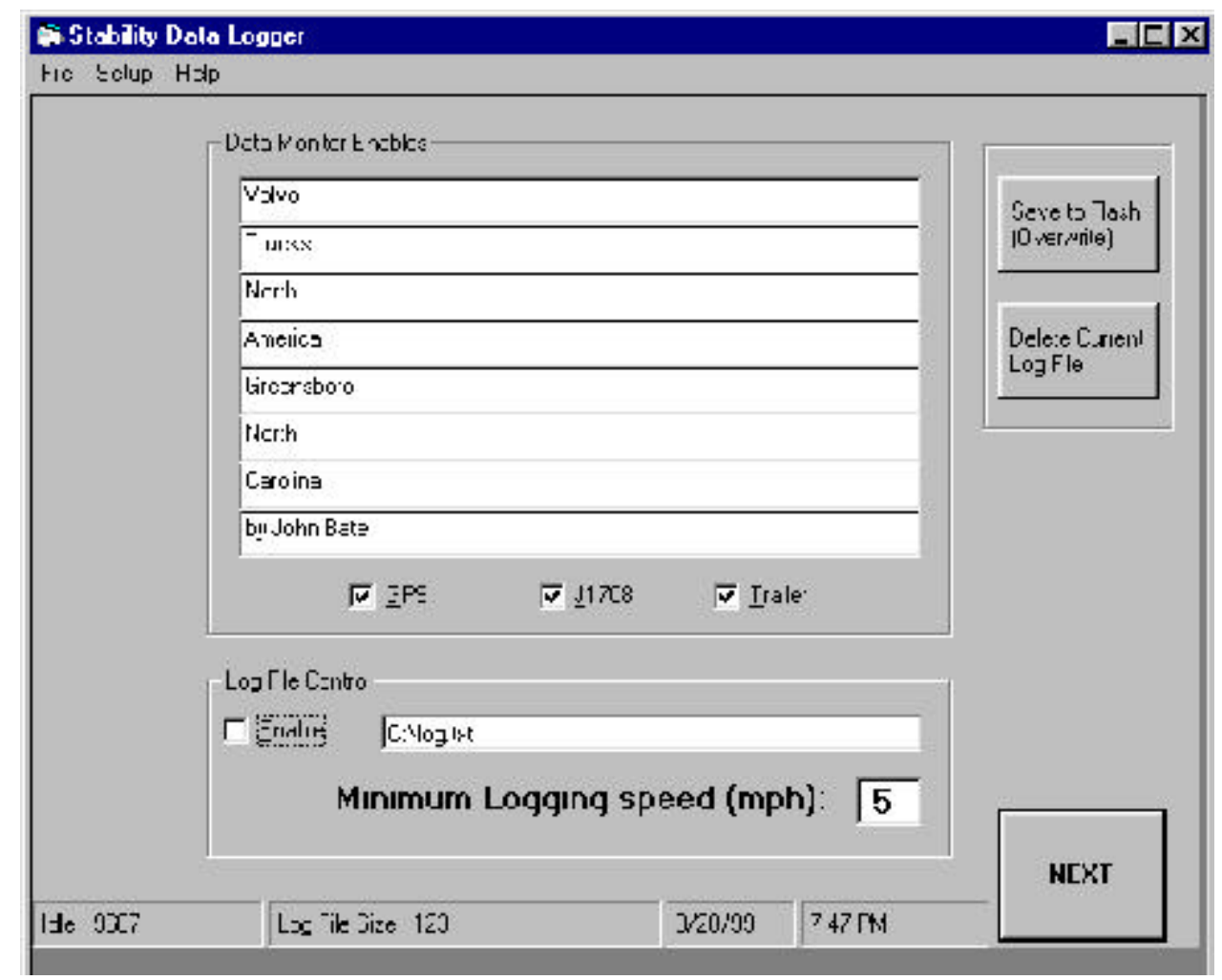

Figure 2. Main Screen

The "Log File Control" frame displays the log file currently in use as well as the enabled status. If the Enable button is checked then the system will log to the file. The log file path cannot be changed when the system is logging.

To edit the log file the Enable button must be unchecked.

The Minimum Logging Speed ( $\mathrm{mph}$ ) indicates at which speed the vehicle must reach before logging will start.

The two buttons "Save to Flash (overwrite)" and "Delete Current Log File" are used when transferring the log file database to another computer. The system must not be logging data (Enable unchecked) for this to work. "Save.." expects a flash PCMCIA disk to be inserted into the second PCMCIA slot in the top of the onboard computer. The log file is copied to "E: Vog.txt" on the flash disk.

"Delete..." deletes the onboard computer's log file. This should be done after the 
file has been copied to the flash disk. This button is enabled only if logging is disabled.

The status bar at the bottom of the main screen is updated once per second. It displays a performance indicator (Idle) and Log File status.

The idle number is an indicator as to how much free idle time the system has. The smaller the number the more processing it is doing and the less idle time it has.

The log file size and status is also displayed. This segment may also display the status of another path: (directory, read-only, illegal file).

The "NEXT" button switches to the Graphs screen (this has been disabled, however the screen still exists)

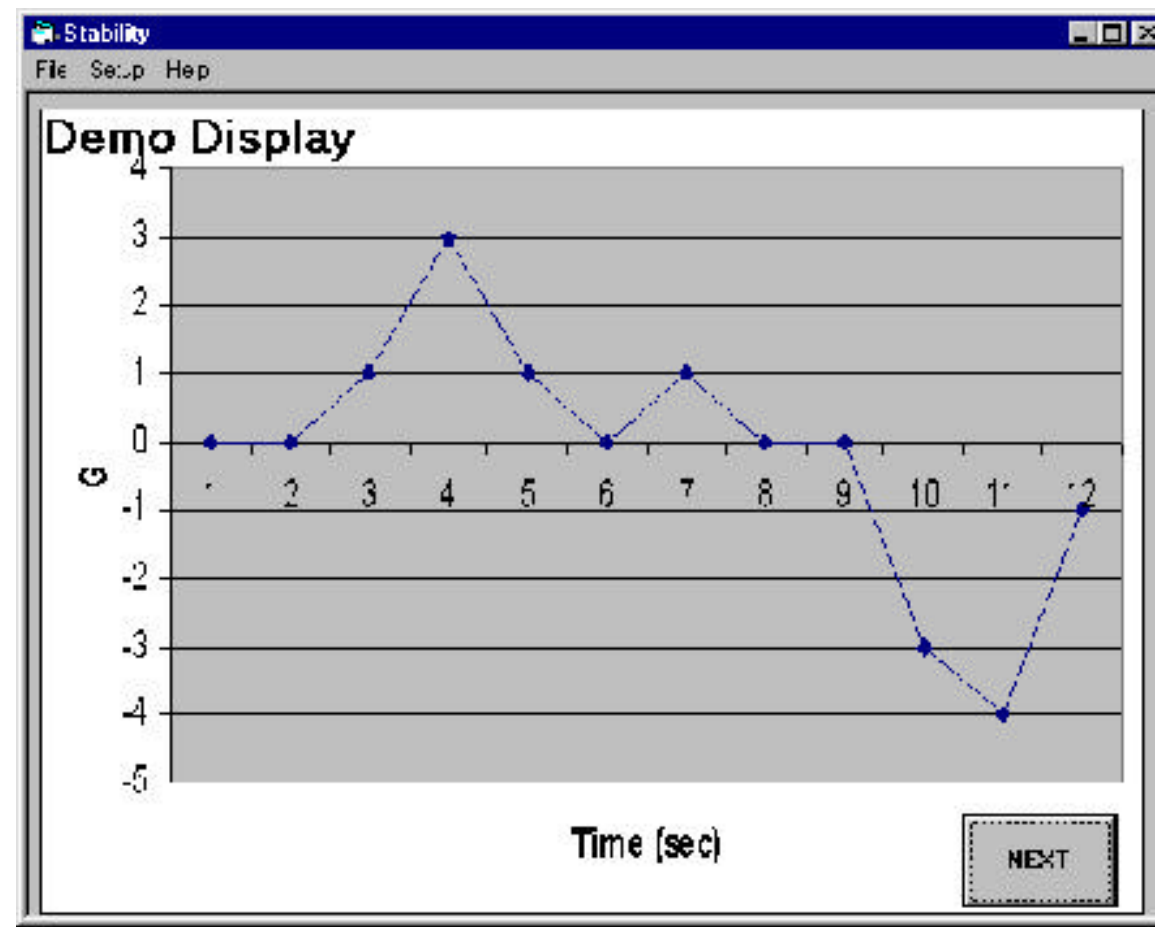

Figure 3. Graphs Screen 


\section{Graphs Screen}

The Graphs screen is for demo purposes only. Data graphs can be included in this application and this is an example (it is not displayed in the current version).

\section{Trip Screen / ID Buttons}

The Trip screen allows the user to record 4 identifiers for the driver, the vehicle, the trailer, and the load.

The Start Trip button causes all identifiers to be stored in the current log file along with a "Start" and time and date message. The Stop Trip stores the word "Stop" and time and date. The system will always log these two buttons but may not log anything else if logging is not enabled. Logging is controlled by the log enable button, not by these buttons.

The "NEXT" button switches to the Startup Screen.

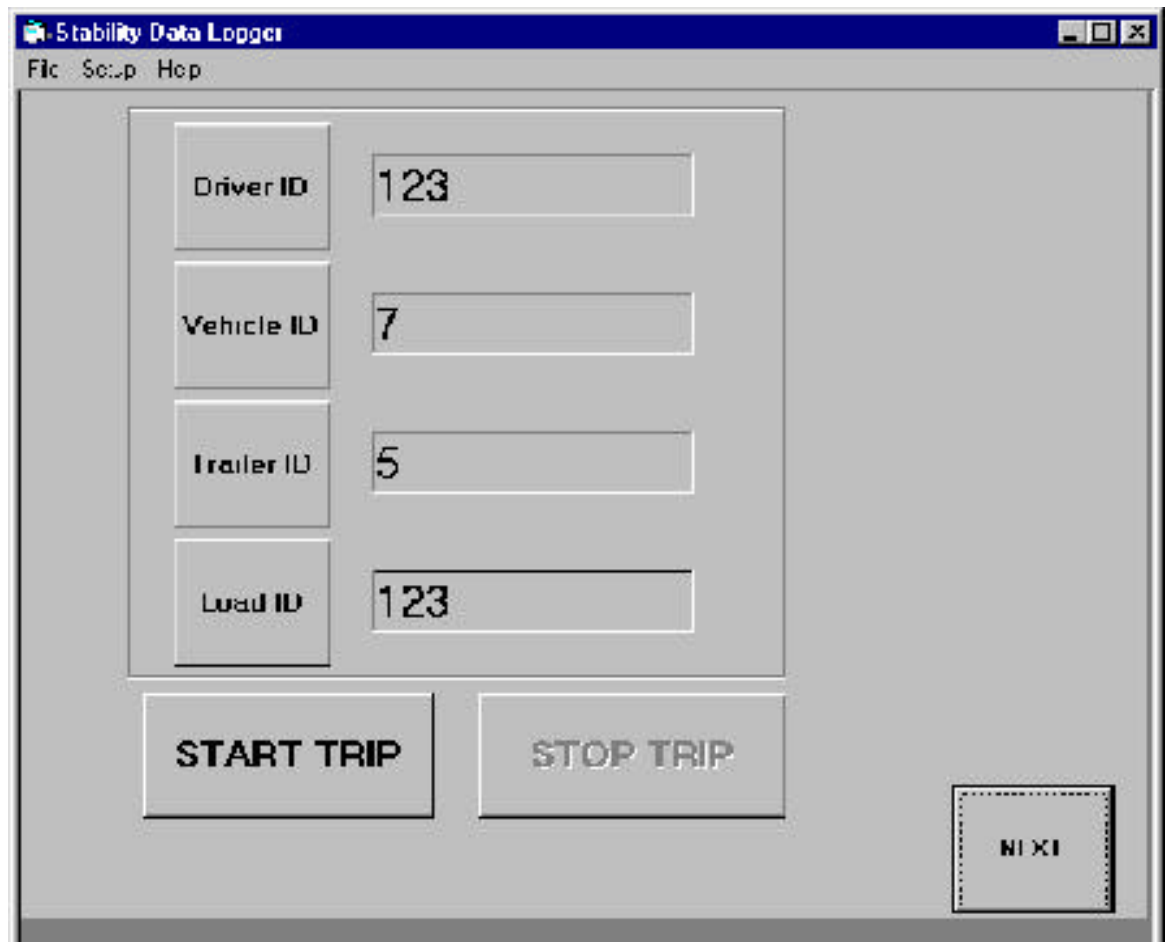

Figure 4. Trip Screen 
If pushed the ID buttons display the number entry panel. Pushing a number will clear out the current number and start a new number. Push Clear to clear the display, push Enter to save the current number. Empty ID fields are allowed.

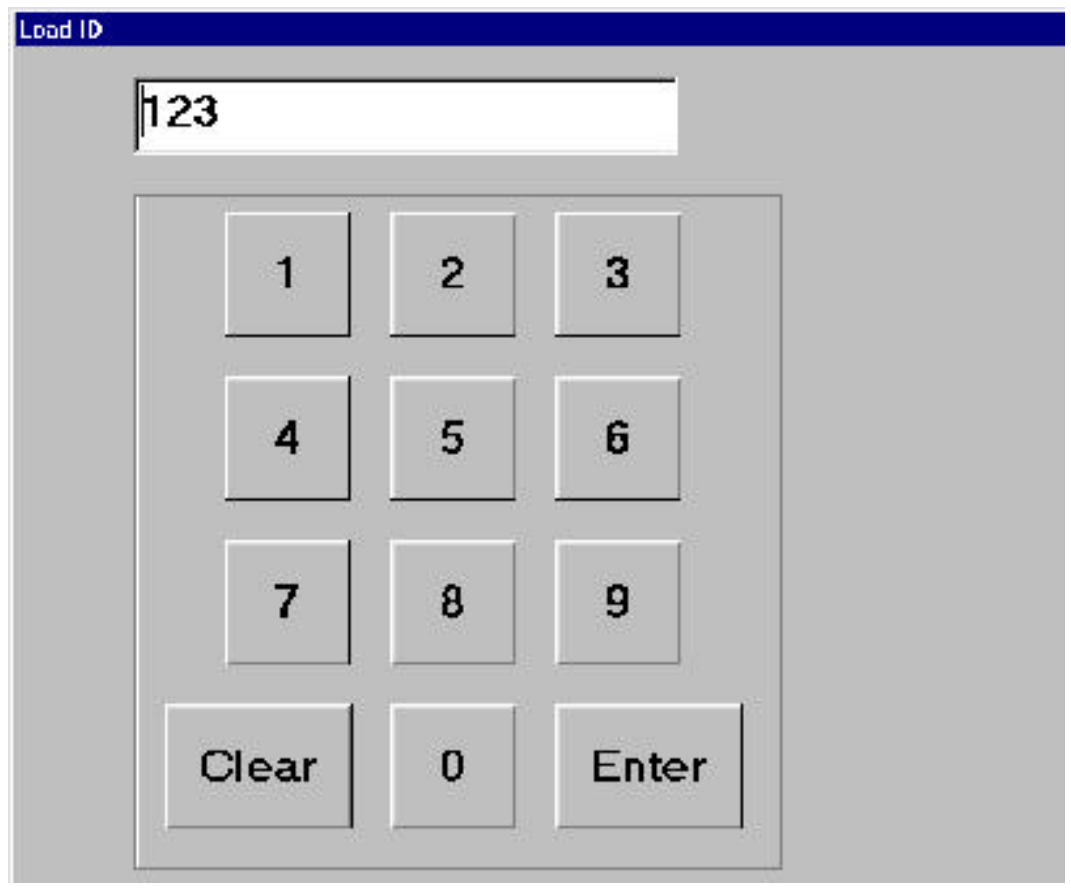

Figure 5. Number Entry Panel

\section{Setup->GPS}

Figure 6 shows the GPS Port Setup dialog box. 


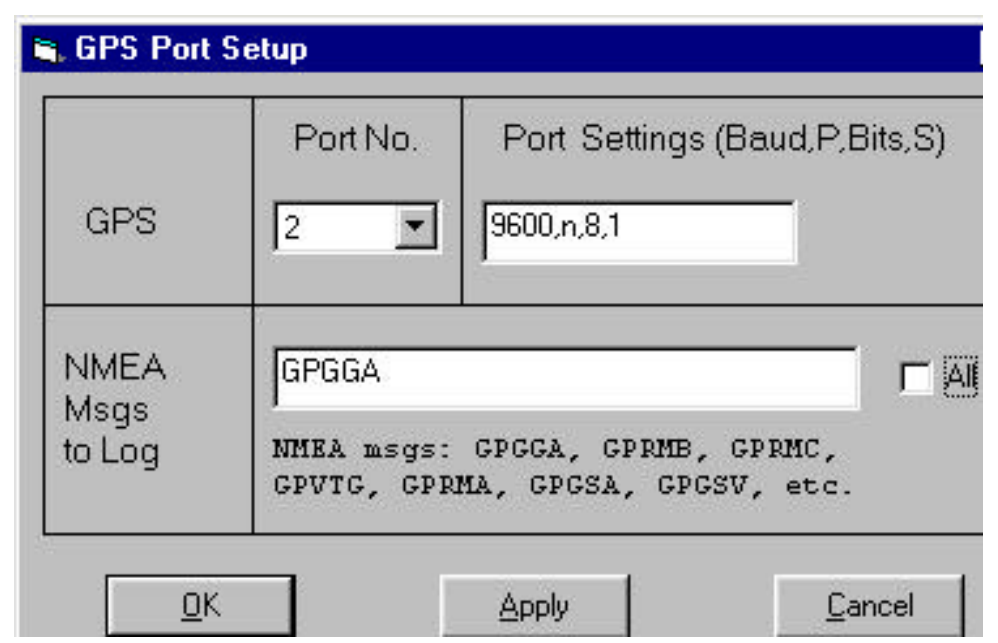

Fig. 6 GPS Port Setup

GPS ports 1-8 are available. Typical GPS devices (NMEA 0183 compatible) are configured with 9600 , No parity, 8 bits, and 1 stop bit.

The "NMEA Msgs to Log" field is strictly text. Enter the NMEA message name (not case sensitive) that you want to allow through the filter. This message will be displayed on the main screen as well as logged (if enabled). Separate multiple names by spaces or commas. The program is looking only for a string match of the incoming NMEA name to anything in the setup filter. Checking the "All" box will cause all messages to be displayed (if enabled) and logged (if enabled)

The GPS device is provided by Trimble Inc. Any NMEA 0183 compatible differential GPS system will work.

\section{Setup->J1708}

Figure 7 shows the J1708 Setup dialog box. 


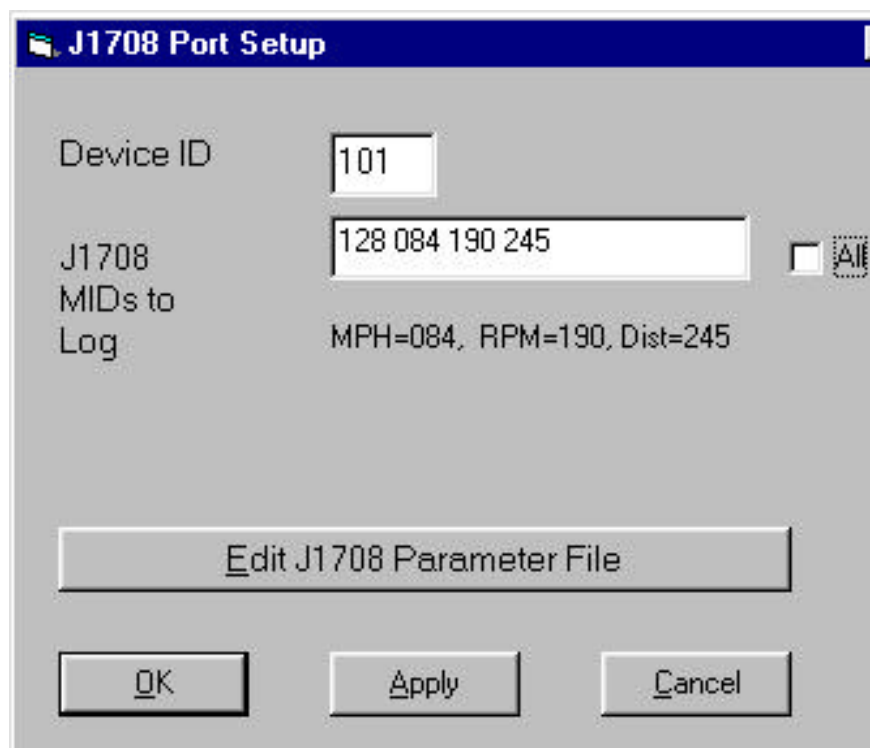

Figure 7. J1708 Setup

Selecting a Device ID causes the system to lookup the port parameters in the proper section of the $\mathrm{J} 1708$ parameter file. This file MUST be set up correctly in order to operate.

The "J1708 MIDs to Log" text box accepts the MIDs and PID. The system can handle up to 10 MIDs, each with 10 PIDs (10 x 10 array). There is not a lot of error checking here so follow the format. Spaces separate MID from PIDS, semicolons separate MIDS. "*" means to accept everything and log it (if enabled).

MID PID PID .....;MID PID;MID *;MID PID

Example:

1442356 67;165 34 45;86 *

This example shows that the user wants to log PIDS 23, 56, and 67 from MID 144, PIDS 34 and 45 from MID 165, and ALL PIDS from MID 86.

Checking the "All" box will cause the system to log ALL PIDS from ALL MIDS that are seen on the $\mathrm{J} 1708$ bus. The filter settings are ignored.

The DPA II J1708 adapter is manufactured by Dearborn Group. They also provide the RP1210 Windows 95/98 compatible DLL. Other adapters will work as long as the proper RP1210 DLL is provided and the source code updated to link 
to the proper RP1210 compatible DLL. The actual RP1210 API calls will remain the same.

\section{Setup Trailer}

Trailer link setup includes setting up the read, message output, and averaging rates as well as selecting which channels to log.

Checking "All" box causes the system to log the data in raw format only. By selecting individual channels the system will log the data in a more natural form if format is known.

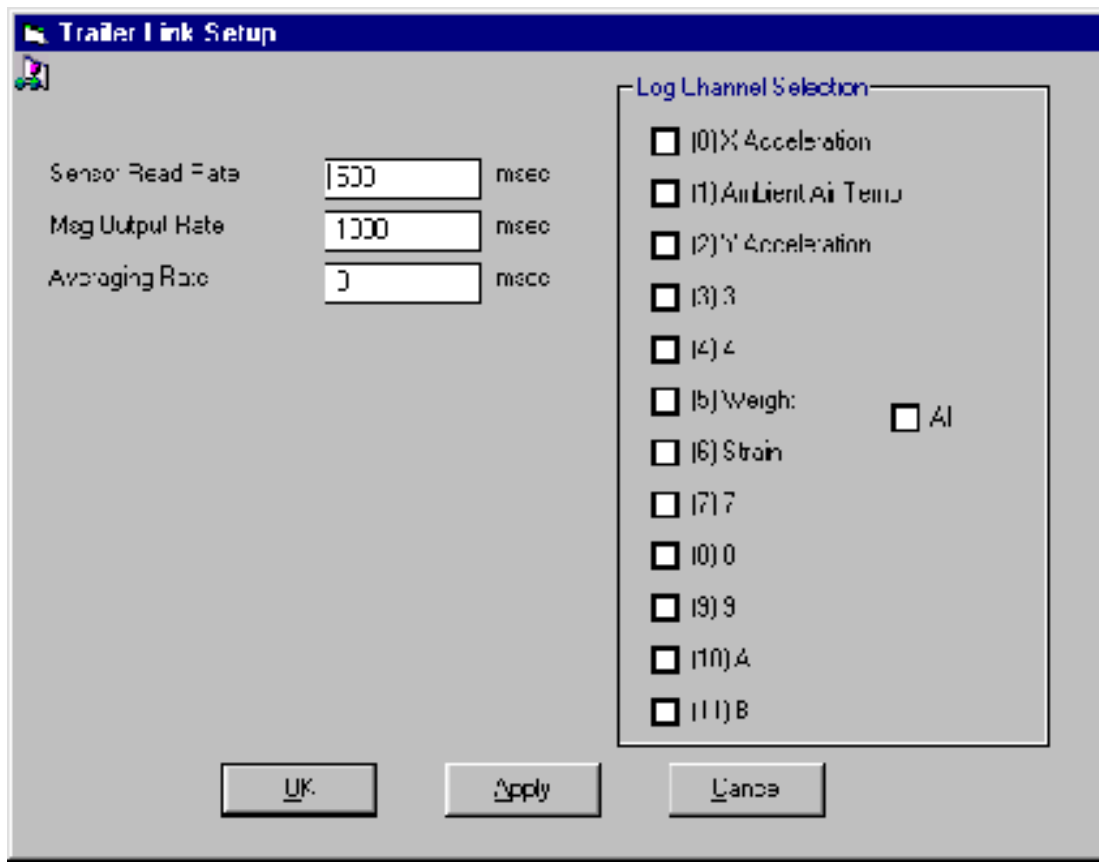

Figure 8. Trailer Setup Screen

\section{Troubleshooting}

There are a few points of possible failure. Figures 9 and 10 display two (of the many) dialog boxes that might show up. 


\section{RP1210_ClientConnect}

142: Hardware not responding

OKK

Figure 9. J1708 connection

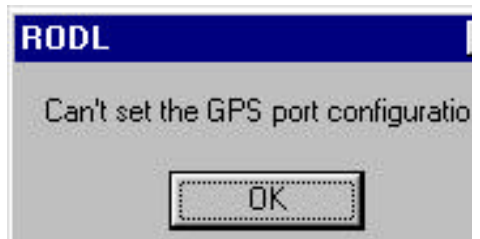

Figure 10. GPS Setup

Figure 9 shows that the J1708 DPA II is not responding. This may be that the adapter is not powered, connected, the Device ID is incorrect, or the parameter file is incorrect.

If the J1708 Data Monitor checkbox is enabled and there is no display check the adapter, device id, and or the parameter file. Also ensure that the J1708 filter is set up correctly.

Figure 10 shows that the GPS port is not available. Ensure that the port is available and that the GPS receiver is attached.

If the GPS Data Monitor checkbox is enabled and there is no display then ensure that the device is powered on, connected, and that the GPS filter is set correctly.
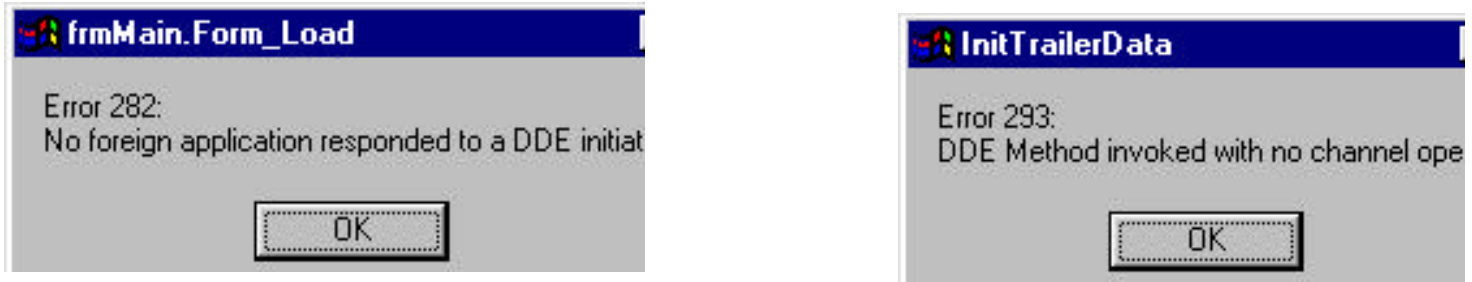

Figure 11. No DDE channels open 
Figure 11 above shows examples when this program was not able to communication with the LMS network server. Possible problems were that the LMS server did not invoke, it crashed, or that this application invoked before the server was ready.

\section{Log File format}

The log file is a ASCII CSV formatted text file. The system will log data whenever the speed of the vehicle is greater than the minimum and logging is enabled.

The log file format consists of a letter (case sensitive) followed by the data, all comma deliminated.

In most cases the system will log incoming data whenever the data has changed.

The $\mathrm{J} 1708$ data bus is continuously broadcasting the current values for a number of vehicle states. To keep the size of the log file to a reasonable size the speed and rpm are only logged as follows:

Speed (S): must change by $2 \mathrm{mph}$

RPM (R): must change by $50 \mathrm{rpm}$

The GPS data will consist of one NMEA message per line. GPS data is logged all the time (if the speed is greater than minimum and logging is enabled). GPS data contains the UTC time used to time sync other log file data.

Following the GPS data will be vehicle speed, engine rpm, and outside temperature if they have changed (if data is not logged then either the $\mathrm{J1708}$ or trailer setup is incorrect, or the data has not changed).

For performance reasons the vehicle speed, engine rpm, and outside temperature are logged and/or displayed only if the GPS data is logged (about once per second).

The trailer data is logged when it changes (if the speed is greater than minimum and logging is enabled). 
The log file data is as follows:

$3,<$ data $>$

$4,<$ data $>$

Raw channel 3 data, currently unassigned or reserved

Raw channel 4 data, currently unassigned or reserved $7,<$ data $>$

Raw channel 7 data, currently unassigned or reserved $8,<$ data $>$ $9,<$ data $>$

Raw channel 8 data, currently unassigned or reserved

Raw channel 9 data, currently unassigned or reserved $A,<$ data $>\{$ TC $\backslash 14 "\}$

Raw channel 10 data, currently unassigned or reserved $B,<$ data $>\{$ TC $\backslash 14$ "

Raw channel 11 data, currently unassigned or reserved

\#,<comment string to end of line $>\{\mathrm{TC} V \mathrm{4} "\}$

Trip start, stop, date - logged only if the Start or Stop trip buttons have been pushed.

I, $<$ driver id $>,<$ vehicle id $>,<$ trailer id $>$, $<$ load id $>\{$ TC $\backslash 4$ " $\}$

Logged when the Start button has been pushed.

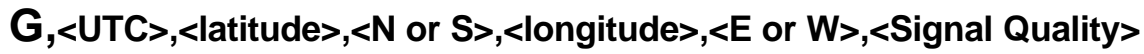

G,142326.000,3604.788390,N,07958.179359,W,1

Logged approximately each second.

This data begins with "G" as the first character followed by UTC

(hhmmss.ss, latitude ${ }^{*} 100, \mathrm{~N}$ or $S$, longitute ${ }^{\star} 100, \mathrm{E}$ or W, GPS quality $(0=$ invalid, $1=$ GPS fix, 2=DGPS fix).

$0,<$ odometer in miles $>\{$ TC $\vee 4 "\}$

$0,45711.3$

Logged about every 10 seconds.

$Q,<$ Strain gauge in volts, $(.02055 \mathrm{mv} /$ micro strain $)>\{\mathrm{TC} \backslash \mathrm{4} "\}$

Q,0.003

Logged about 10/sec (or as set up on Trailer setup screen)

$R,<R P M>\{$ TC $\vee 4 "\}$ 
$\mathrm{R}, 1143$

Logged about $1 / \mathrm{sec}$

$\mathrm{S},<$ Speed in MPH $>\{$ TC $\vee 4 "\}$

S, 65

Logged about $1 / \mathrm{sec}$

$T,<$ all 12 channels of comma separated trailer data $>\{\mathrm{TC} \backslash \mathrm{4}$ " $\}$

$\mathrm{T}, 0.04,-1.56, \ldots$.

Logged when "All” checked on Trailer setup

$\mathrm{C},<$ outside air temp in $\mathrm{C}>\{\mathrm{TC} \backslash \mathrm{4} "\}$

C,25

Logged about $1 / \mathrm{sec}$

$X,<X$ lateral acceleration (right(+)/left(-)) in Gs $>\{$ TC $\backslash / 4$ " $\}$

$\mathrm{X},-0.4$

Logged about 10/sec (or as set up on Trailer setup screen)

$\mathrm{Y},<\mathrm{Y}$ longitudinal acceleration (fore(+)/aft(-)) in Gs $>\{\mathrm{TC} \backslash \mathrm{I}$ " $\}$

$Y, 1.01$

Logged about 10/sec (or as set up on Trailer setup screen)

W, $<$ weight at back axle of trailer in pounds $>\{\mathrm{TC} \backslash \mathrm{V} " \mathrm{\}}$

W,9780

Logged about 10/sec (or as set up on Trailer setup screen)

Installation Instructions

First time loading:

1. Run Programs->Hampshire Touch screen alignment.

2. 7Insert SDL install flash card. Run setup.exe

3. Navigate to Program files\Stability Data Logger, Run 1210.exe and install RP121032.dll

4. Remove SDL flash card.

5. Select rodl.exe, RMB, Send to Desktop, center it on screen, change the name to "Stability Data Logger" 
6. Add RODL.exe to Start->Taskbar Startup, name it "Stability Data Logger" (target: C:IProgram files\Stabilty Data Logger/RODL.exe)

7. Ensure that the Startup menu has the LMS server in it (target:

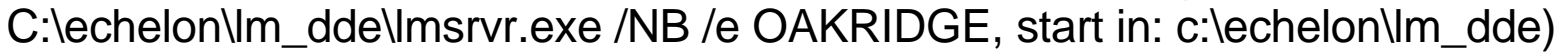

8. Reboot and verify that the Volvo Startup logo, the LMS server, and the Stability Data Logger execute at boot time.

9. Set task bar to Auto Hide

10. [as needed] Set J1708 ID to 101 or 102

11. [as needed] Set GPS Port to 2 or 1, set Baud rate (Raytheon@4800, Trimble@9600, 8,N,1)

12. Exit the data logger

13. Set Screen Saver to "Blank Screen" and Wait time to 1 minutes.

Second time loading:

1. Insert SDL flash card.

2. Copy RODL.exe to c:IProgram files\Stability Data Logger

3. Remove SDL flash card.

\section{Data Download}

To copy the log file off the truck PC:

1. Disable logging (uncheck the log file Enable). The "Save..." and "Delete..." buttons are activated. If the logging screen is not available then push "Next" until you get the logging screen. If you still never see it then first cycle to the Trip screen. Enter the password number 13363932000 as the driver ID. Push "Next".

2. Unscrew two screws and remove the truck's dashboard cover (located just above the ashtray).

3. Insert flash disk storage card to the extra slot on the PC, taking care not to disturb the attached cables.

4. Push the "Save..." button.

5. [Optional] Verify that file was transferred with Windows Explorer

6. Remove flash disk card.

7. Push the "Delete..." button. Verify that the log file size changes.

8. [Re] Enable logging (check the Enable button). Log file size should now be zero.

9. Reinstall cover.

10. Verify correct operation. 


\section{Installation Modification}

02/02/00 Stefan Jansson

This note describes how to modify the SDL installation to allow for two PCMCI adapters being used simultaneously. In the existing installation all interrupts are used by the existing devices and no interrupt is available for the second $\mathrm{PCMCl}$ card. Two modifications have to be performed: The first is in the computer BIOS configuration and the second in WINDOWS device driver settings.

Connect a keyboard to the computer. The plastic cover on the standard connector might have to be trimmed back 1/8" for full engagement.

BIOS modifications:

1. Start or restart the computer.

2. Press "Delete" during boot up to access the BIOS setup menu.

3. Select "Integrated Peripherals".

4. Disable "Onboard Parallel Port".

5. Disable "Built in CPU Audio".

6. Press "ESC" to exit this menu.

7. Select "Save \& Exit Setup"

8. Answer "y" to "Save to CMOS"

WINDOWS modifications:

1. Let WINDOWS start up.

2. Exit the Data Logger Program and go to the Desktop.

3. Select "START", "SETTINGS", "CONTROL PANEL"

4. Start the "SYSTEMS" application.

5. Select the "Device Manager" menu.

6. Select "Ports (COM \& LPT)" from the list.

7. Click on the "+" in the front to see the individual ports.

8. Select the "ECP Printer Port".

9. Click on properties

10. Check "Disable in this hardware profile"

11. Click on "OK"

12. Repeat step 9-11 for "PCI Bridge", under "Other Devices".

13. Repeat step 9-11 for "PCI Multimedia Audio Device, under "Other Devices"

14. Repeat step 9-11 for "Vadem PCI Compatibility PCMCI Controller", under "PCMCI Sockets" 
15. Click on "OK" and exit the "Device Manager".

16. Exit the "Control Panel".

17. Reboot the computer

Note: Some of the devices in 12-14 might not be present. 
APPENDIX B

INTERNet File Transfer Procedure 


\section{Internet File Transfer Procedure}

Initial FTP Client Setup

These instructions assume the use of either version 4 or higher of Microsoft Internet Explorer or Netscape. FTP clients are not restricted to these browsers, but they are suggested because they convenient, free, and readily available.

\section{Find the FTP Site}

Double-click on the Internet browser icon on the desktop (Internet Explorer or Netscape). Type in the following appropriate site name in the Address or Location box ftp://PraxAir@128.219.40.110 ...then press the Enter key. ftp://USXpress@128.219.40.110 ...then press the Enter key.

Type in your password (passwords are case sensitive).

If given a choice, click on your directory (folder) name.

\section{Make an Easy Way to Return to this Site}

Create a desktop shortcut for this location using the following steps:

Click and hold the icon in or in front of the left side of the Address or LOCATION box. Drag this icon to your desktop to create a shortcut for the FTP site. (Leave the FTP site window open.)

Drop (release the button you are holding) the icon on the desktop.

\section{Start Uploading the Data File}

Click on the Start button (on your task bar); click Programs, and then click Windows Explorer. On the left side of the Windows Explorer window, click on the appropriate drive and click and continue clicking on the folder(s) until you reach the folder that contains the file to be uploaded. On the right side of the Windows Explorer window, click, hold down the mouse, and drag the file to be uploaded to the Internet Explorer (the FTP site) window. If a small pop-up window appears follow the directions (usually push the YES button to transfer the file).

\section{Finish Uploading the Data File}

When you see the file appear on the FTP site, click on the word File in the upper left-hand corner of your browser and then click on Close to end your session.

\section{Notify the FTP Manager that a New File is Available}

Send an e-mail to truettlf@ornl.gov and note that a new file was successfully uploaded. Mention the file name and any other information that may make this data file different than any other. For example, "The file 2000_July_15.txt was just successfully uploaded to the FTP site on 128.219.40.110. This file is different from the previous file in that (fill in the blank, e.g., trailer data is missing)."

For routine use of FTP for file transfer, double-click on the FTP site icon on your desktop.

\section{Follow Steps 3-5.}

Start Uploading the Data File

Finish Uploading the Data File

Notify the FTP Manager that a New File is Available 


\section{APPENDIX C}

\section{Visual FoxPro Program Codes}




\section{Visual FoxPro Program Codes}

\section{Program to separate U S X press truck trips}

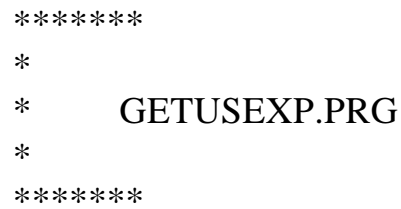

Set talk off

Close all

Clear

If FILE('log.txt') \&\& Does file exist?

gnErrFile $=$ FOPEN $(' \log . t x t ', 12) \quad \& \&$ If so, open read-write

Else

gnErrFile $=$ FCREATE('log.txt') \&\& If not, create it

Endif

If gnErrFile $<0 \quad \& \&$ Check for error opening file

Wait 'Cannot open or create output file' WINDOW NOWAIT

Else $\& \&$ If no error, write to file

* =FWRITE(gnErrFile, 'Error information to be written here')

Endif

Use ItrkroverloriginaldatalUsExpAdd.dbf in 0 alia tt

Sele $\mathrm{tt}$

Zap

$\mathrm{xxno}=0$

xyno $=0$

$\mathrm{xwno}=0$

$\mathrm{xqno}=0$

$\mathrm{xsno}=0$

$\mathrm{xrno}=0$

$\mathrm{xcno}=0$

xjno $=0$

xono $=0$

xino $=0$

xoold $=0$

xcount $=0$

$\mathrm{xl}=0$

ytime $=0$

xgps $=" "$

xlold $=0$

$\mathrm{xo}=-98.00$

yo $=39.0$

$\mathrm{xd}=0$

xdateold $=$ date ()

xdatenew $=$ date ()

xcumdist $=0$

xcumtime $=0$

Dimension gps(9) 
Do whil not feof(gnErrFile)

$\mathrm{xtxt}=$ fgets $($ gnErrFile $)$

$\mathrm{x} 1=\operatorname{substr}(\mathrm{xtxt}, 1$, at $(',$, ,xtxt,1)-1)

Do case

Case $\mathrm{x} 1=$ "X" \&\& lateral Acc

$\mathrm{xxno}=\mathrm{xxno}+1$

repl xv with $x v+$ substr(xtxt, at(',,'xtxt,1)+1,len(xtxt)-at(',',xtxt,1))

Case $\mathrm{x} 1=$ "Y" \&\& Longitudinal Acc

$\mathrm{xyno}=\mathrm{xyno}+1$

repl yv with yv + substr(xtxt, at(',',xtxt,1)+1,len(xtxt)-at(',',xtxt,1))

Case $\mathrm{x} 1=$ "W" \&\& Weight

$\mathrm{xwno}=\mathrm{xwno}+1$

repl wv with wv + substr(xtxt, at(',',xtxt,1)+1,len(xtxt)-at(',',xtxt,1))

Case $\mathrm{x} 1=$ "Q" \&\& Strain

$\mathrm{xqno}=\mathrm{xqno}+1$

repl qv with qv + substr(xtxt, at(',',xtxt,1)+1,len(xtxt)-at(',',xtxt,1))

Case $\mathrm{x} 1=$ "S" \&\& Speed

$\mathrm{xsno}=\mathrm{xsno}+1$

repl sv with sv + substr(xtxt, at(',',xtxt,1)+1,len(xtxt)-at(',,'xtxt,1))

Case $\mathrm{x} 1=$ "R" \&\& RPM

$\mathrm{xrno}=\mathrm{xrno}+1$

repl rv with rv + substr(xtxt, at(',',xtxt,1)+1,len(xtxt)-at(',',xtxt,1))

Case $\mathrm{x} 1=$ "C" \&\& Temperature

$\mathrm{xcno}=\mathrm{xcno}+1$

repl cv with cv + substr(xtxt, at(',',xtxt,1)+1,len(xtxt)-at(',',xtxt,1))

Case $\mathrm{x} 1=$ "J" \&\& No Idea

$\mathrm{xjno}=\mathrm{xjno}+1$

repl jv with jv + substr(xtxt, at(',',xtxt,1)+1,len(xtxt)-at(',',xtxt,1))

Case $\mathrm{x} 1=$ "O" \&\& Odometer

$\mathrm{xono}=\mathrm{xono}+1$

$\mathrm{xdo}=\operatorname{val}(\operatorname{substr}(\mathrm{xtxt}, 3,7))-\mathrm{xoold}$

xoold $=\operatorname{val}(\operatorname{substr}(x t x t, 3,7))$

repl ov with ov + substr(xtxt, at(',,'xtxt,1)+1,len(xtxt)-at(',',xtxt,1))

Case $\mathrm{x} 1=$ "I" \&\& Driver ID

xino $=$ xino +1

repl iv with iv + substr(xtxt, at(',',xtxt,1)+1,len(xtxt)-at(',',xtxt,1))

Case $\mathrm{x} 1=$ "G" \&\& "\$GPRMC"

Repl tt.xno with xxno, tt.yno with xyno, tt.wno with xwno

Repl tt.qno with xqno, tt.sno with xsno, tt.rno with xrno

Repl tt.cno with xcno, tt.jno with xjno, tt.ono with xono, tt.ino with xino

xcount $=$ xcount +1

For $\mathrm{n}=2$ to 8

$\operatorname{gps}(\mathrm{n})=\operatorname{substr}(x t x t$, at(',',xtxt,n-1)+1,at(',',xtxt,n)-at(',',xtxt,n-1)-1)

Endfor

$\operatorname{gps}(\mathrm{n})=\operatorname{substr}(\mathrm{xtxt}$, at(',',xtxt,n-1)+1,len(xtxt)-at(',',xtxt,n-1))

Sele $\mathrm{tt}$

Appe blan

Repl tt.tod with gps(2)

$\mathrm{xn}=-1.0 *(\operatorname{val}(\operatorname{substr}(\operatorname{gps}(5), 1,3))+\operatorname{val}(\operatorname{substr}(\operatorname{gps}(5), 4,7)) / 60)$ 


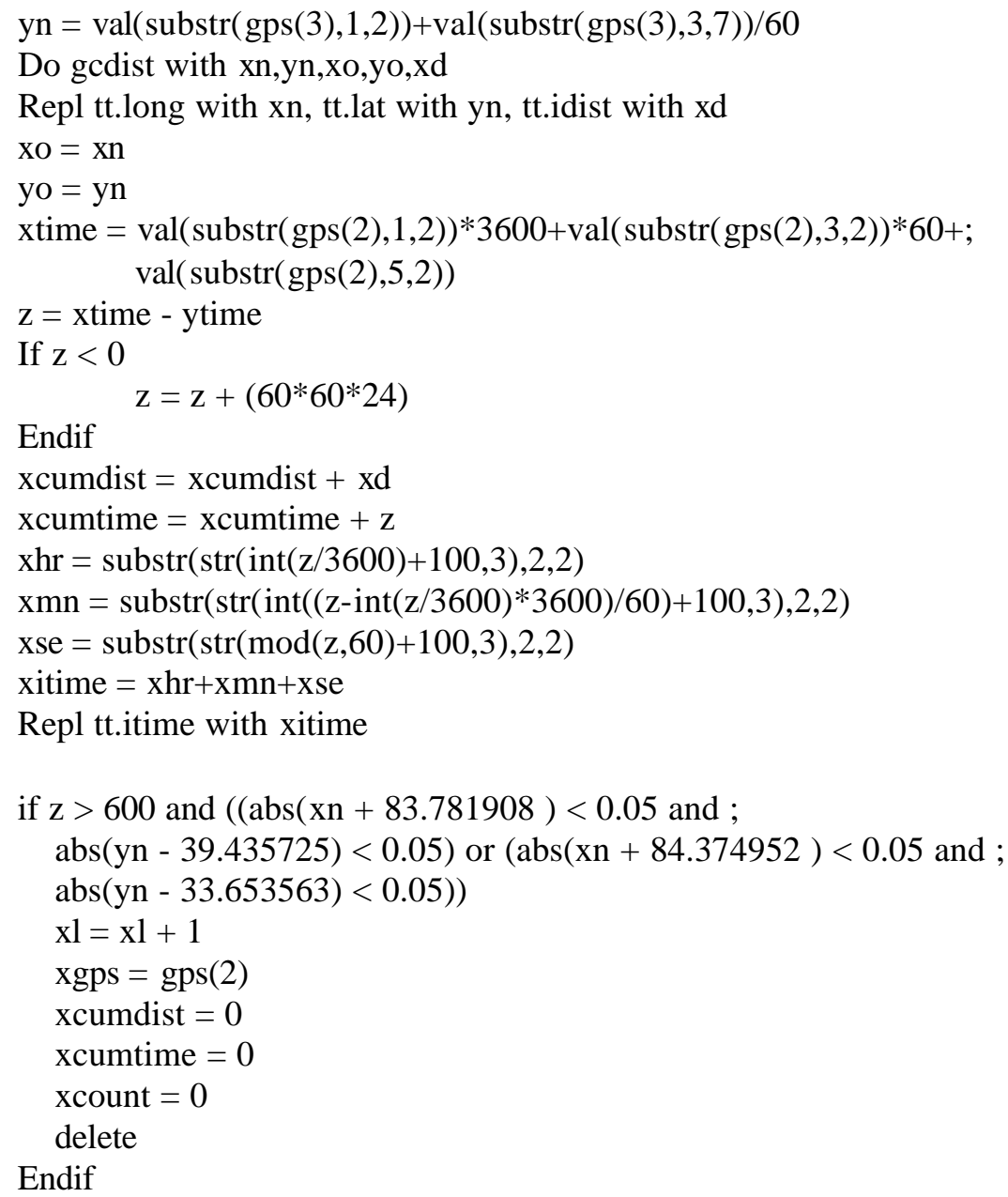

Repl tt.xrec with xcount, tt.cumdist with xcumdist $x h r=\operatorname{substr}(\operatorname{str}(\operatorname{int}(x c u m t i m e / 3600)+100,3), 2,2)$

Otherwise 
Repl tt.xno with xxno, tt.yno with xyno, tt.wno with xwno, tt.qno with xqno Repl tt.sno with xsno, tt.rno with xrno, tt.cno with xcno, tt.jno with xjno

Repl tt.ono with xono, tt.ino with xino

$=$ FCLOSE (gnErrFile) $\& \&$ Close file

Set talk on

Return 


\section{Programs to estimate angles, speed, and accelerations from G PS data}

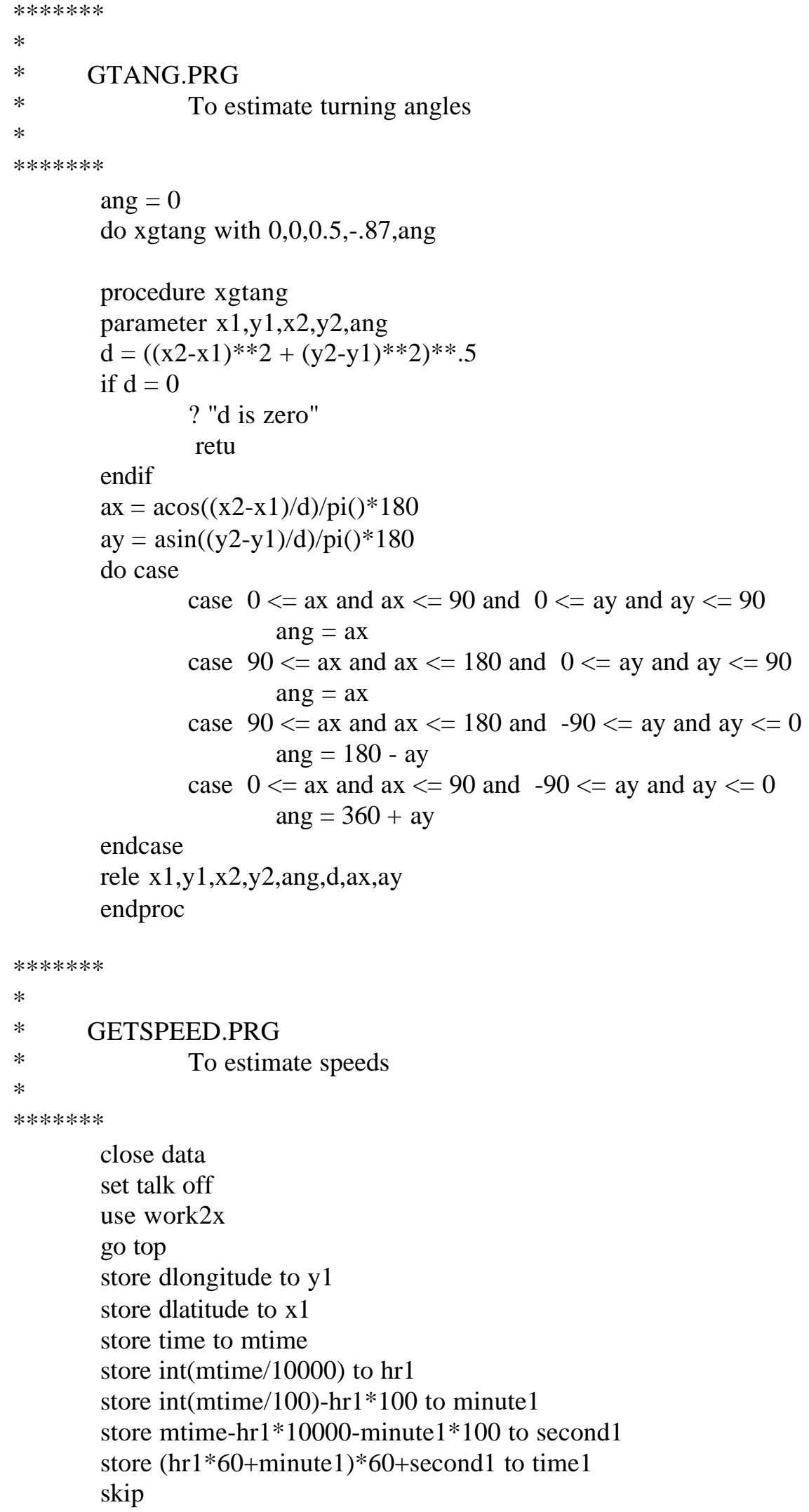




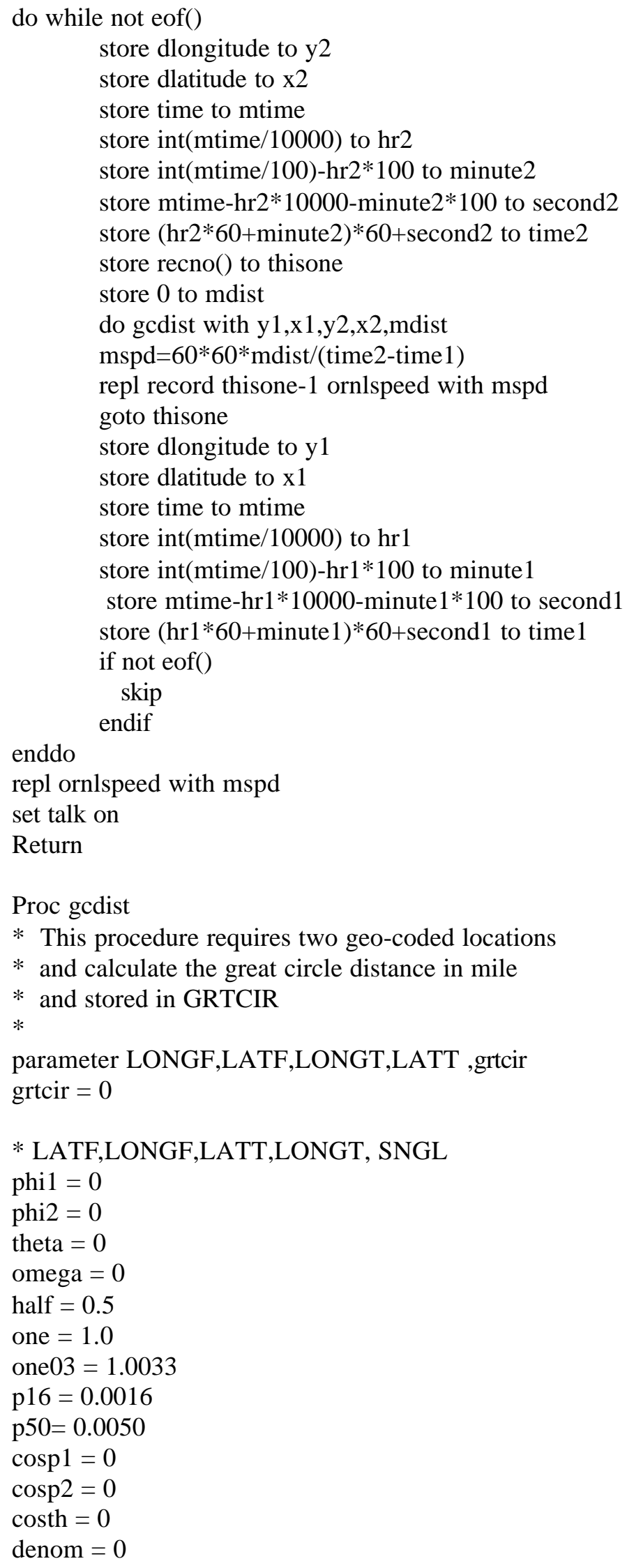

Proc gedist

* This procedure requires two geo-coded locations

* and calculate the great circle distance in mile

* and stored in GRTCIR

$*$

parameter LONGF,LATF,LONGT,LATT ,grtcir grtcir $=0$

* LATF,LONGF,LATT,LONGT, SNGL

phil $=0$

phi $2=0$

theta $=0$

omega $=0$

half $=0.5$

one $=1.0$

one $03=1.0033$

$\mathrm{p} 16=0.0016$

p50 $=0.0050$

$\operatorname{cosp} 1=0$

$\operatorname{cosp} 2=0$

costh $=0$

denom $=0$ 


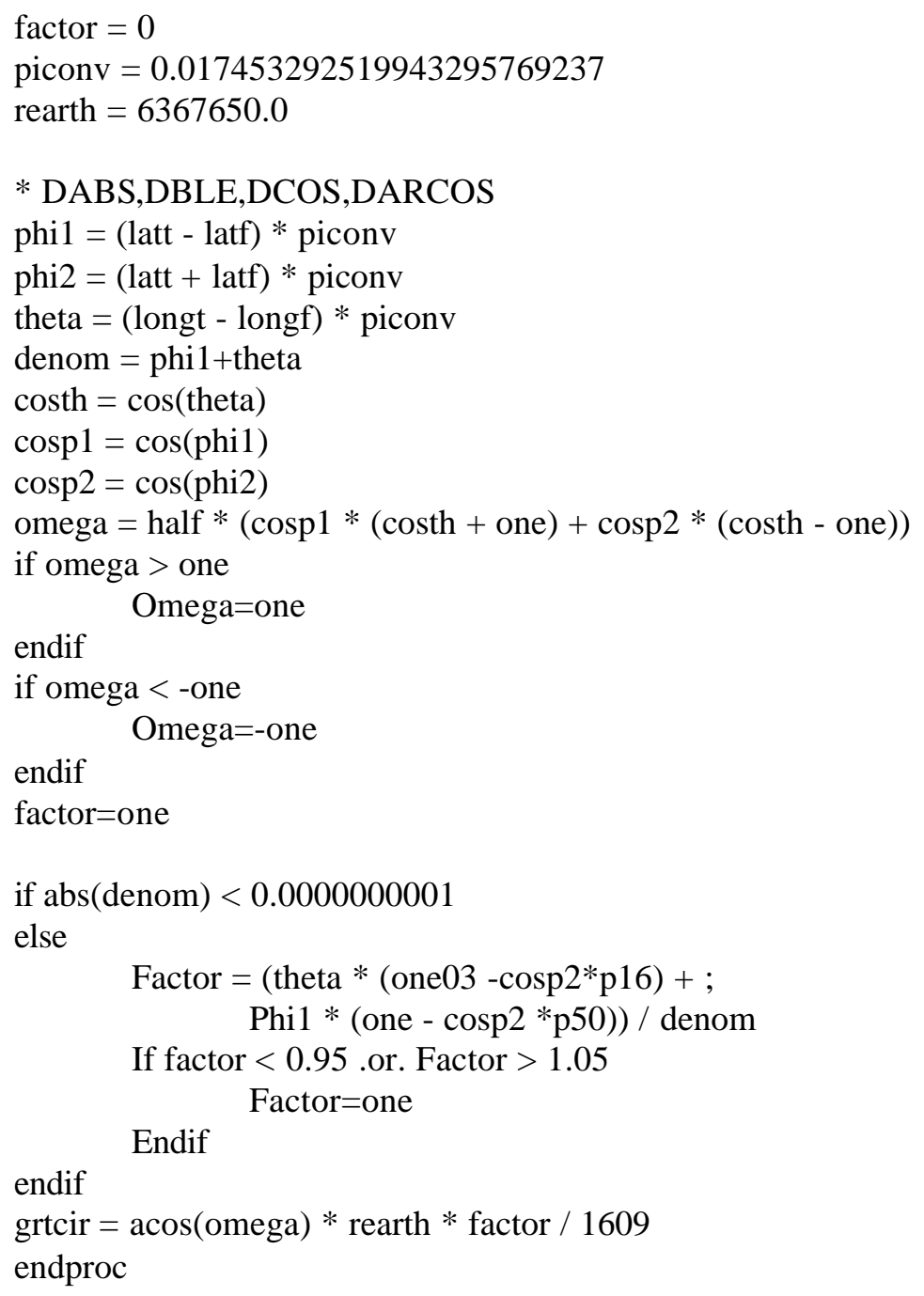

$*$ $* * * * * * *$

para fname

set talk off

set deci to 6

use \&fname

go top

stor ornlspeed/3600 to $\mathrm{s} 1$

skip

do whil not eof()

stor ornlspeed/3600 to s2

stor angle-90 to theta

if angle $<90$ 


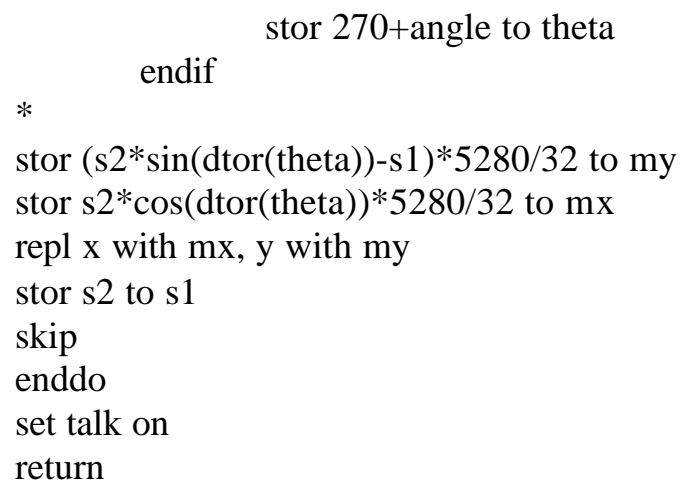


APPENDIX D

\section{Strain Gage Verification}




\section{Strain Gage Verification Test}

Method - Impose reproducible stresses on the trailer suspension and record the measured strain for comparison with other trailers and with records of the measurement for the trailer currently being tested.

Frequency - every six-to-eight weeks or a similar convenient interval.

Equipment required - tractor and (empty) trailer with data acquisition system installed; ramp capable of supporting the weight of the trailer safely, jack capable of lifting rear end of trailer till tandems are off the ground.

Procedure - On a level lot, drive the rig so that the tandem on one side of the trailer rides up onto the ramp and the tandem on the other side remains on (or just off) the pavement. Pause for a few seconds while the trailer wheels are on the top of the ramp. Then drive off the ramp. Repeat for the other side. Collect data during the drive onto the ramp, the pause at the top, and the drive off the ramp (total of a minute or less per side?).

With the jack, lift rear end of trailer till wheels are just off the ground. Measure strain gage readings with wheels just off the ground.

Download the data for transmission to ORNL for analysis.

Explanation - What we're trying to do with the ramps is to make first one side of the trailer suspension and then the other side take essentially all of the trailer weight. That will put a strain first one way and then the opposite - in the suspension torque tube and check out the full-scale readings of the instrumentation. It's useful to keep the tractor and trailer lined up straight, so the tractor suspension has a consistent effect on the measurement.

What we're doing with the jack is making sure the strain in the torque tube is zero, by lifting the wheels so they just hang, and support no weight. That will check out the zero readings of the instrumentation.

If we repeat these measurements under essentially the same conditions at various times during the project, we can estimate how much the instruments might be drifting.

The web address of the ORNL data-download site is

ftp://128.219.40.110/

Files can be transferred to this site by standard drag-and-drop techniques. 


\section{APPENDIX E}

\section{CASe Studies of LATERAL ACCELERATION}

IN SELECTEd CURVES ALONG I-75 


\section{Case Studies of Lateral Acceleration in Selected Curves along I-75}

Analyses of truck data for four specific locations along the corridor traveled by U.S. Xpress trucks were conducted to examine lateral accelerations at four curves along I-75. The figure below is a map that shows where each of these cases is located.

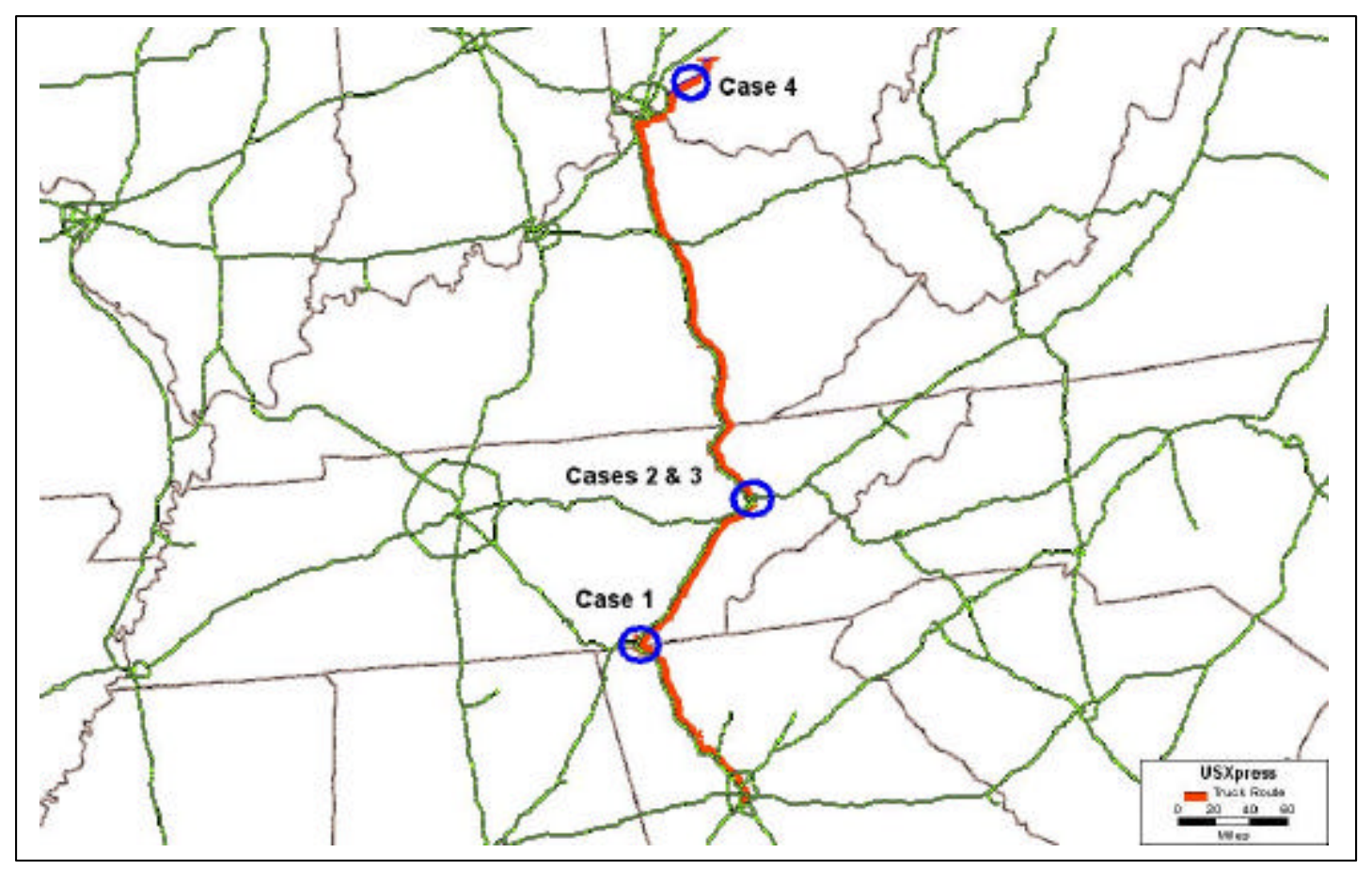

Locations of the four curves discussed in the case studies.

For each of the four cases, two graphs are presented. The first graph in each set shows lateral accelerations measured (in $\mathrm{g}$ ) by the trailer instrument. The second graph of each set is a comparison of the "measured" lateral acceleration (i.e., reading from the instrument mounted on the trailer) and the "estimated" value (from GPS readings of time and location). The calculation assumes a "flat" roadway surface. It also contains "noise" due to stops (long time-gap with small location change) or some other reasons (short time-gap with big location change). Overall, the "measured" value is about half of the "estimated" value which indicates that the roadway design (e.g., elevation of roadway) at the location is doing a proper adjustment to reduce the impact from the turning force to the truck. 


\section{CASE 1. INTERSECTION OF I-24 AND I-75 NEAR CHATTANOOGA, TENNESSEE}

The I-75/I-24 interchange at Chattanooga, Tennessee, was investigated. Typically, I-75 traffic from Georgia would take a turn of about $85 \mathrm{E}$ (1,000 feet turning radius) to the right at this I-75/I-24 junction before continuing to travel northbound. Case 1 - Figure 1 displays a Digital Orthophoto Quadrangles map by U.S. Geological Survey (USGS) at this area. A digital orthophoto is a digital image of an aerial photograph in which displacements caused by the camera and the terrain have been removed. It combines the image characteristics of a photograph with the geometric qualities of a map. The truck trajectory based on the onboard GPS reading is shown as a polyline in this figure. Lateral acceleration measurements collected from a northbound truck trip on I-75 are also shown. These lateral acceleration measurements have been adjusted to correct bias from instrument drift.

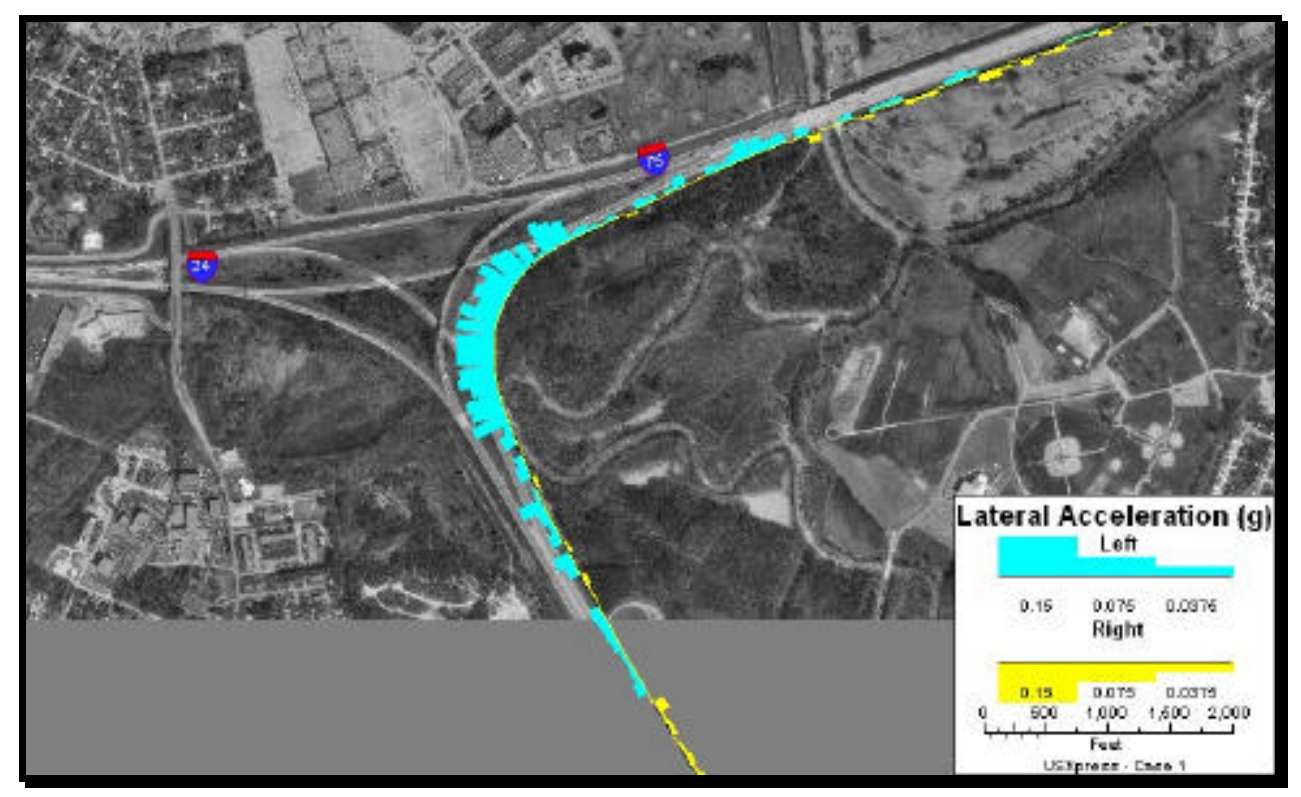

\section{Case 1 - Figure 1. Lateral accelerations measured at the I-24/I-75 junction near Chattanooga, Tennessee.}

These lateral acceleration readings range from $-0.15 \mathrm{~g}$ to $+0.15 \mathrm{~g}$, where $\mathrm{g}$ is the earth gravity acceleration. Lateral acceleration should be near zero when a truck is traveling along a straight line. Its value can be negative or positive depending on the direction of a turn. In this figure, the size of a lateral acceleration measurement is reflected by the width of the line at that location. In order to have a thematic map that is sensitive to positive and negative values, the width of the line is drawn from the center and extended toward either side of the polyline, depending on the sign of the lateral acceleration. For example, a line would be drawn from the center and extended toward the right side of the polyline if the value of a lateral acceleration is positive (shown in yellow). The width of this line 
would be proportional to the magnitude of that lateral acceleration. Note that the color light blue is used to indicate negative values in these maps.

Case 1 - Figure 1 shows that the onboard accelerometer recorded a significant increase in lateral accelerations when the truck negotiated the curve. The truck sustained the highest lateral acceleration $(-0.16 \mathrm{~g})$ when it reached the "crown" of the curve. Further review of speed variations from this truck revealed that the truck was traveling at normal highway speed (around $65 \mathrm{mph}$ ) before reaching the curve. When it arrived at the curve, it decelerated and then reduced its speed to around $53 \mathrm{mph}$ at the "crown" of the curve. The truck accelerated at a slower pace after coming out from the curve and resumed its normal highway speed.

A comparison of estimated and measured lateral accelerations for this location is presented in Case 1 - Figure 2. Lateral accelerations recorded by the accelerometer (i.e., measured) are shown in yellow. The estimated values calculated from the on-board GPS data as described previously are shown in blue. It is apparent that both series contain random variations in the data. Despite such random noises, one can still detect a general trend that estimated lateral accelerations are higher than those recorded by the trailermounted instrument. The difference is greatest when the truck is at the "crown" of the curve. At that point, the estimated lateral acceleration is over $60 \%$ higher than the recorded value.

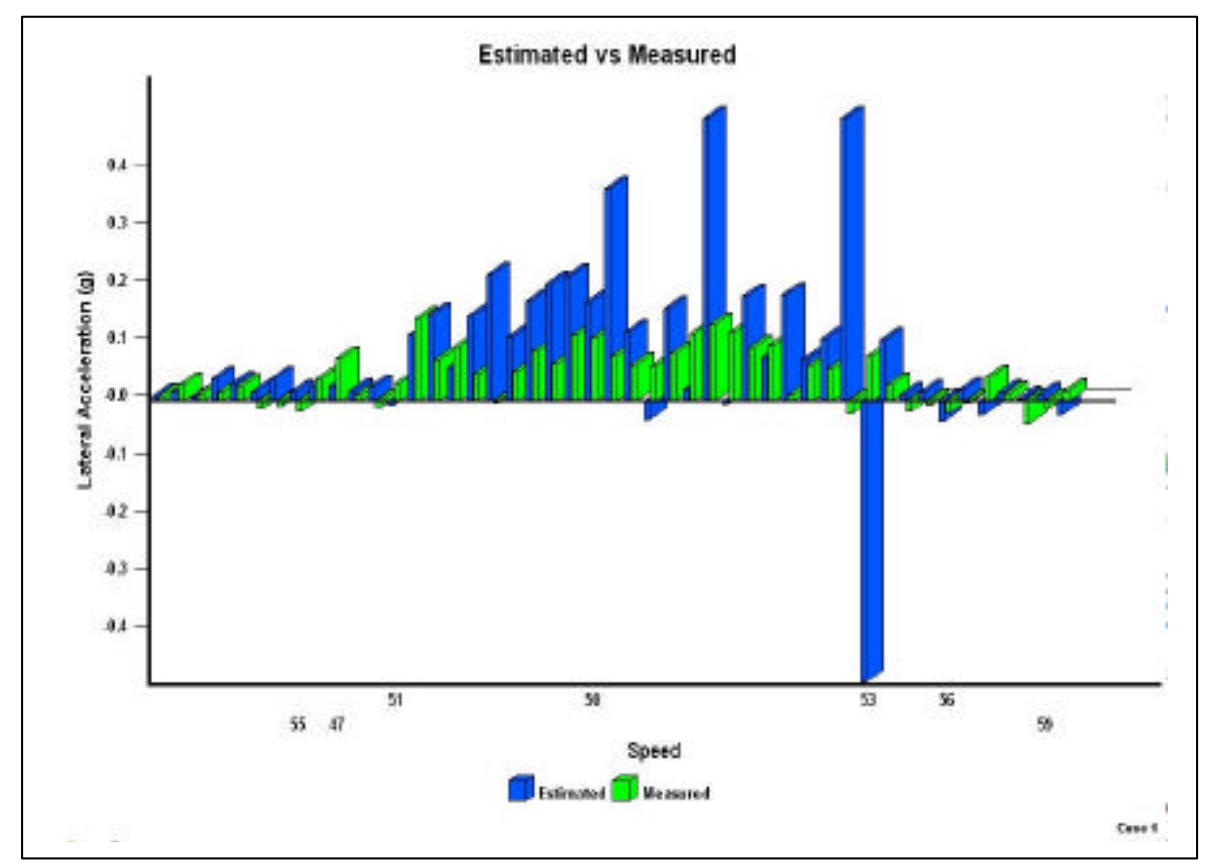

\section{Case 1 - Figure 2. Comparison of measured and estimated lateral accelerations for Case 1 .}


As stated previously, the estimation procedure used in this study assumed the truck was traveling on a flat surface. Therefore, a certain part of the difference between the estimated and the measured lateral acceleration can be viewed as an effect of the pavement geometry. A properly designed highway pavement should have super-elevation to facilitate negotiating the curve. It should be noted that the GPS receiver is mounted on the tractor and the accelerometer is mounted on the rear axle of the trailer. This would also contribute to the difference between the estimated and the measured lateral acceleration.

\section{CASE 2. JUNCTION OF I-640 AND I-75 IN KNOXVILLE, TENNESSEE}

Case 2 - Figure 1 depicts the lateral accelerations recorded by the onboard accelerometer at the I-75/I-640 junction in Knoxville, Tennessee. The radius of this curve is approximately 1,150 feet, which is similar to the curve section at the I-75/I-24 interchange (see Case 1). The truck sustained its highest lateral accelerations (close to $0.1 \mathrm{~g}$ ) when it traveled at the "crown" section of this curve. The lateral accelerations sustained at this curve section are lower than those sustained at the curve of I-75/I-24 interchange.

This figure also shows that the truck sustained a series of positive, negative, and positive lateral accelerations before it actually entered into the "crown" section of this curve. This pattern of lateral accelerations might be caused by lane switching. The truck speed profile for this curve section is generally lower when compared to that around the I-75/I-24 interchange. This is consistent with lower lateral accelerations the truck sustained around this curve section. That is, a slower speed translates into a lower angular velocity and, thus, induces a lower centrifugal force that produces a smaller lateral acceleration.

Case 2 - Figure 2 presents the comparison of estimated and measured lateral accelerations for this curve section. It is apparent that there are quite a few outliers in the lateral accelerations estimated based on the GPS information (in blue). However, as in Case 1, the estimated values are higher than those that are measured. In other words, highway pavement at this curve section also has a super-elevation feature. 


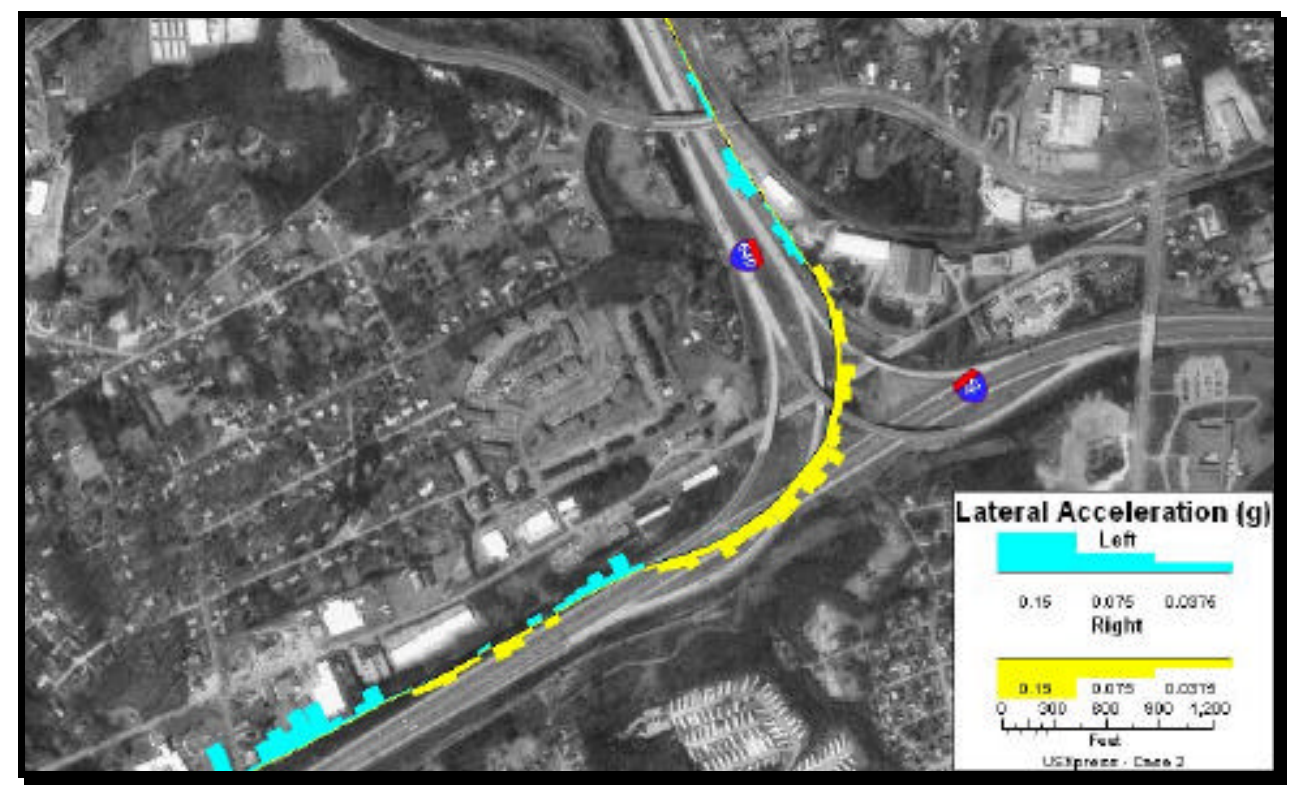

Case 2 - Figure 1. Lateral accelerations measured at the I-640/I-75 junction near Knoxville, Tennessee.

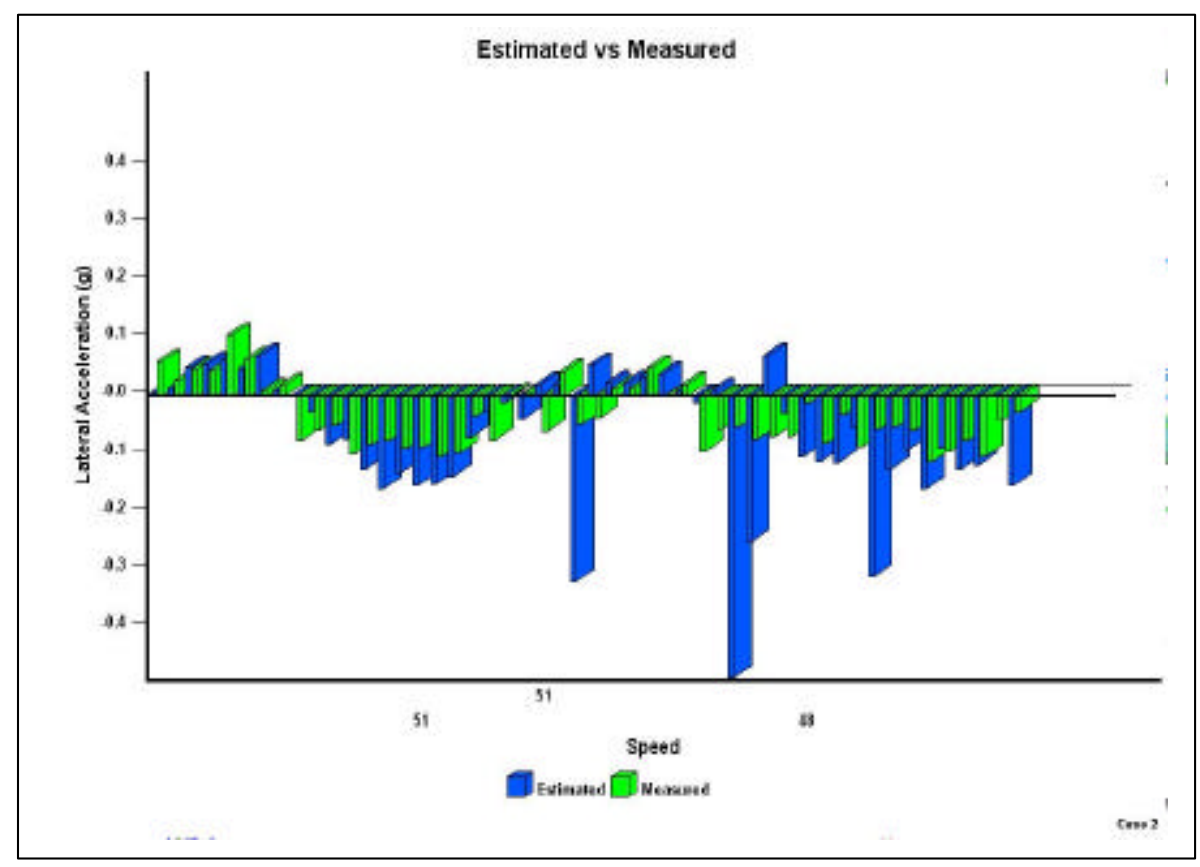

Case 2 - Figure 2. Comparison of measured and estimated lateral accelerations for Case 2. 
CASE 3. JUNCTION OF I-640, I-275, AND I-75 INTERCHANGE IN KNOXVILLE, TENNESSEE

Case 3 - Figure 1 and Case 3 - Figure 2 display the lateral accelerations at the I-640/I275/I-75 interchange, also in Knoxville, Tennessee. The major difference between this curve section and the curves of Cases 1 and 2 is that its turning radius is smaller (only about 725 feet). The highest lateral acceleration recorded by the onboard accelerometer at the "crown" section of this curve is around $0.11 \mathrm{~g}$. However, the truck slowed down to 45 mph to negotiate this smaller curve. The lateral accelerations estimated from the GPS data are much higher than those recorded by the onboard accelerometer.

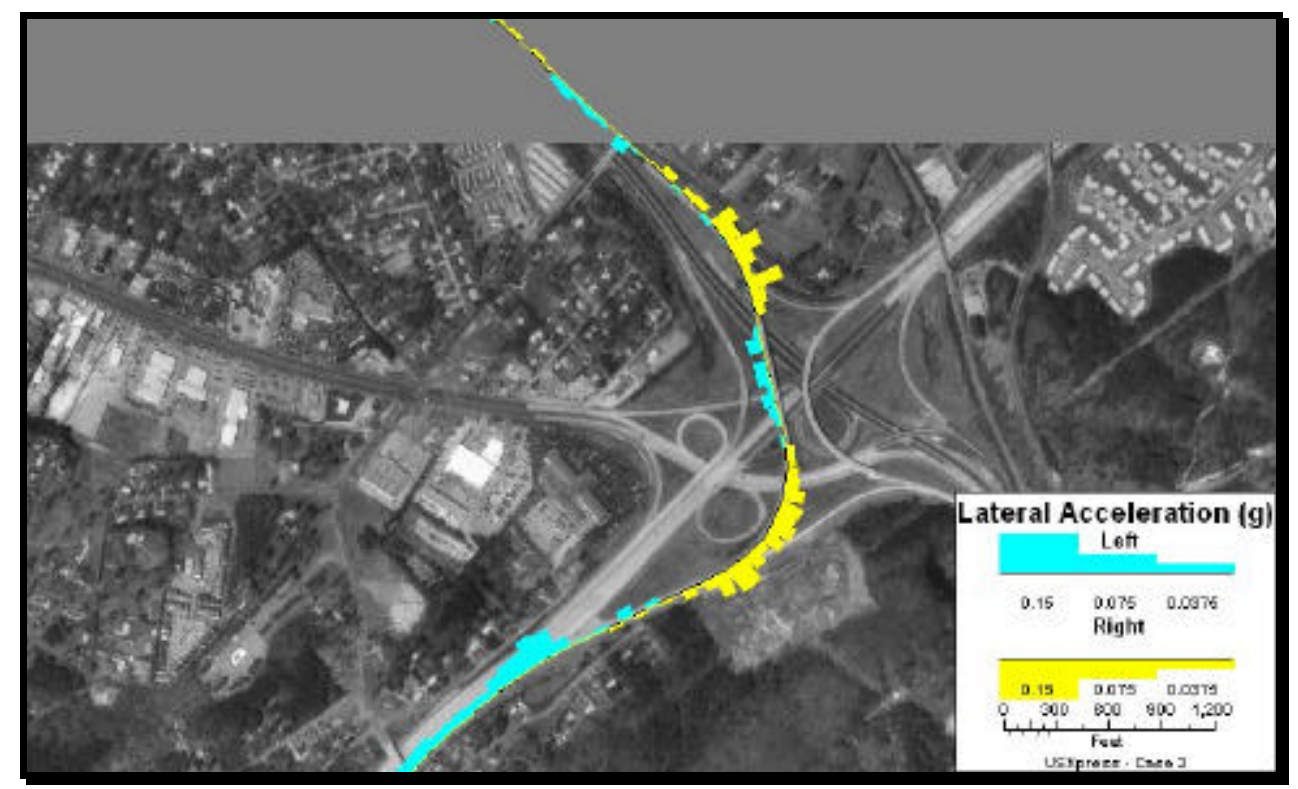

Case 3 - Figure 1. Lateral accelerations measured at the I-640/I-75/I-275 junction near Knoxville, Tennessee. 


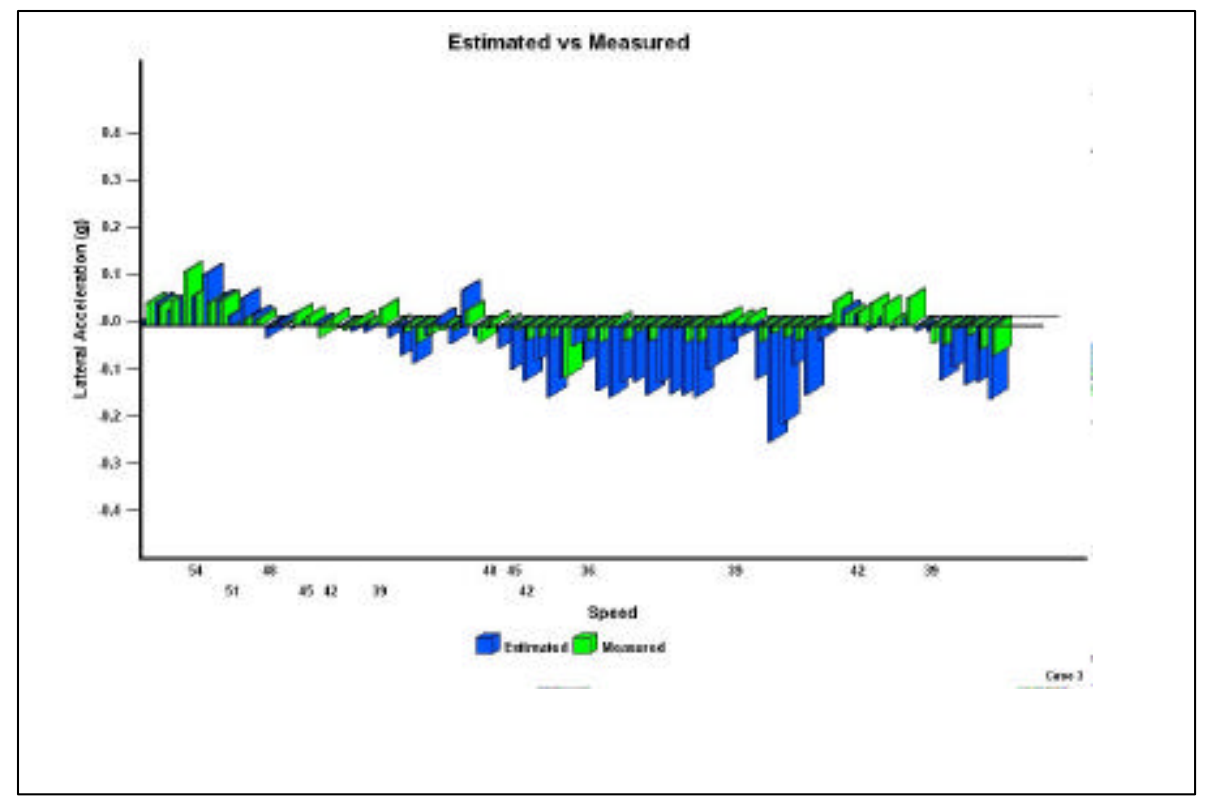

\section{Case 3 - Figure 2. Comparisons of measured and estimated lateral accelerations for Case 3.}

\section{CASE 4. "S" CURVE ON STATE ROUTE 28 NEAR BLANCHESTER, OHIO}

The previous three cases focused on curves at intersections on interstate highways. The following case is an example of truck lateral acceleration on a state highway system. Case 4 - Figure 1 and Case 4 - Figure 2 display lateral accelerations at an "S" curve of State Route 28 just outside Blanchester, Ohio. This case provides a rare opportunity for studying truck lateral accelerations with respect to a "S" curve. The turning radius for these two curve sections are about 315 feet each, which are much smaller than those measured at the previous curves.

Also, the speed profile for this "S" curve is lower. The truck traveled at a speed around $50 \mathrm{mph}$ as it approached the curve. As in Cases 1-3, the truck decelerated rapidly when it was a short distance away from the curve and slowed down to $35 \mathrm{mph}$ when it was in the first "crown" section of the "S" curve. The truck continued to decelerate further and slowed down to $31 \mathrm{mph}$ when negotiating the "crown" section of the second curve. The truck then resumed a speed of about $42 \mathrm{mph}$ after it came out of the "S" curve.

The lateral accelerations recorded by the onboard accelerometer registered readings as high as $0.24 \mathrm{~g}$ when the truck was in the "crown" section of the first curve of the "S." As the truck was slowing down and going to the "crown" section of the second curve of the "S," the lateral acceleration recorded was lower with the highest reading at $0.18 \mathrm{~g}$.

Different from a simple curve section, the truck sustained significant lateral accelerations just before, and also after, the "S" curve. At least at this particular location, two patterns 
were apparent. Super-elevation features were present at both "crown" sections of the "S" curve; however, no super-elevation was present on highway pavements just before and after the "S" curve.

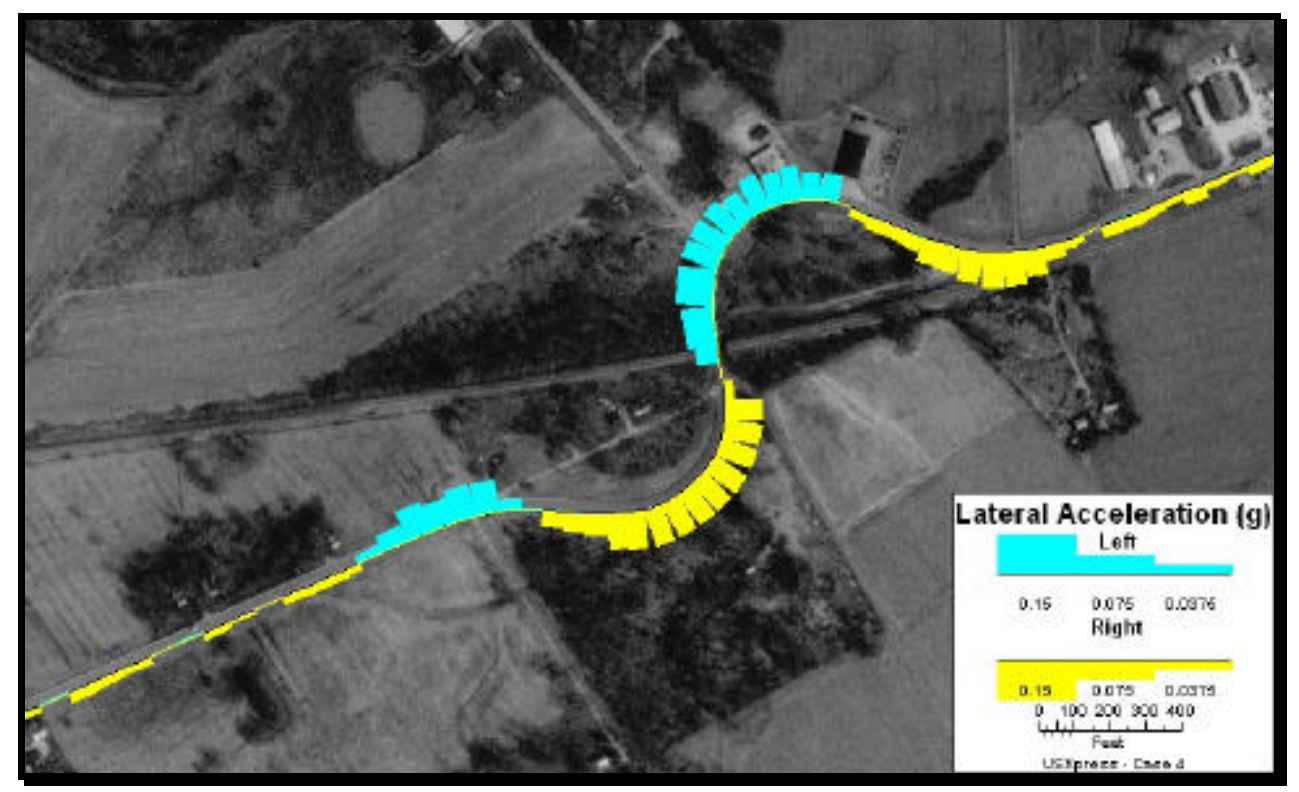

Case 4 - Figure 1. Lateral accelerations measured at an "S"-shaped curve near Blanchester, Ohio.

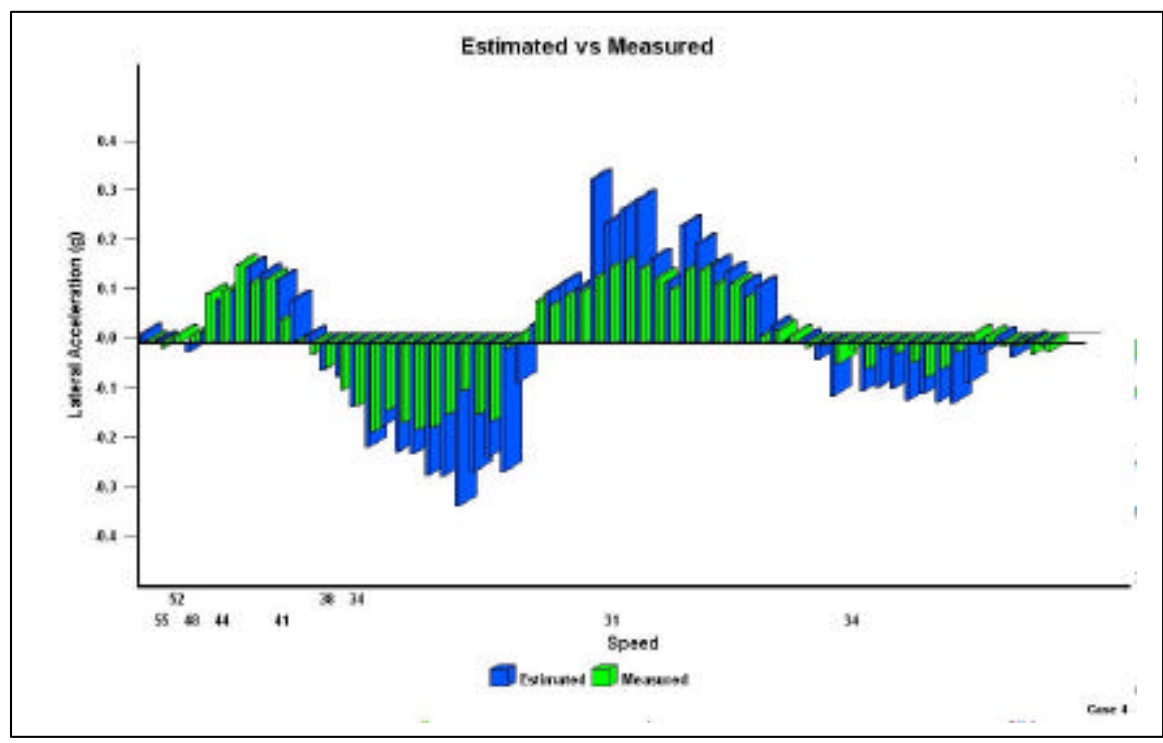

Case 4 - Figure 2. Comparison of measured and estimated lateral accelerations for Case 4. 